NUREG/CR-5304

SAND90-7116

\title{
Radionuclide Behavior in the Environment
}

Redivat by 0 .:

NOV 201991

Prepared by

U. Tveten

Institutt for Energiteknikk

Sandia National Laboratories

Prepared for

U.S. Nuclear Regulatory Commission 


\section{AVAILABILITY NOTICE}

\section{Availability of Reference Materials Cited in NRC Publications}

Most documents cited in NRC publications will be avallable from one of the following sources:

1. The NRC Public Document Room, $2120 \mathrm{~L}$ Street, NW., Lower Level, Washington, DC 20555

2. The Superintendent of Documents, U.S. Government Printing Office, P.O. Box 37082, Washington. DC 20013-7082

3. The National Technical Information Service, Springfield, VA 22161

Although the listing that follows represents the majority of documents cited in INRC publications. It is not intended to be exhaustive.

Referenced documents available for inspection and copying for a fee from the NRC Public Document Room include NRC correspondence and internal NRC memoranda: NRC bulletins, circulars, information notices, Inspection and investigation notices: licensee event reports; vendor reports and correspondence; Commission papers; and applicant and licensee documents and correspondence.

The following documents in the ivUREG serles are avallable for purchase from the GPO Sales Program: formal NRC staff and contractor reports, NRC-sponsored conference proceedings, and NRC booklets and brochures. Also available are regulatory guides, NRC regulations in the Code of Federal Regulations, and Nuclear Regulatory Commission Issuances.

Documents available from the National Technical Information Service include NUREG-series reports and technical reports prepared by other Federal agencies and reports prepared by the Atomic Energy Commission, forerunner agency to the Nuclear Regulatory Commission.

Documents available from public and special technical libraries include all open literature items. such as books, journal articles, and transactions. Federal Register notices. Federal and State legislation, and congressional reports can usually be obtained from these libraries.

Documents such as theses, dissertations, foreign reports and translations, and non-NRC conference proceedings are available for purchase from the srganization sponsoring the publication cited.

Single coples of NRC draft reports are avallable free. to the extent of supply. upon written request to the Office of Administration. Distribution and Mall Services Section. U.S. Nuclear Regulatory Commission. Washington. DC 20555

Copies of industry codes and standards used in a substantive manner in the NRC regulatory process are maintained at the NRC Library, 7920 Norfolk Avenue. Bethesda. Maryland. for use by the public. Codes and standards are usually copyrighted and may be purchased from the originating organization or. If they are American National Standards, from the American National Standards Institute, 1430 Broadway. New York. NY 10018

\section{DISCLAIMER NOTICE}

This report was prepared as an account of work sponsored by an agency of the United States Government. Neither the United States Government nor any agency thereof, or any of their employees, makes any warranty, expressed or implied, or assumes any legal liability of responsibility for a $\because$ third party's use, or the results of such use, of any information, apparatus, product or process disclosed in this report, or represents that its use by such third party would not intringe privately owned righis 


\section{Radionuclide Behavior in the Environment}

Manuscript Completed: September 1990

Date Published: September 1991

Prepared by

U. Tveten

Institutt for Energiteknikk

Postboks 40

$\mathrm{V}-2007$ Kjeller

Norway

Under Contract to:

Sandia National Laboratories

Albuquerque, NM 87185

\section{Prepared for}

Division of Systems Research

Office of Nuclear Regulatory Research

U.S. Nuclear Regulatory Commission

Washington, DC 20555

NRC FIN A1843 
For sale by the U.S. Government Printing Olfice

Superintendent of Documents. Mail Stop: SSOP. Washington. DC 2(1402-9328

ISBN 0-16-035972-4 
The purpose of this report is to document the results of the work performed by the author in connection with the following task, performed for the US Nuclear Regulatory Commission, Office of Nuclear Regulatory Research, Division of Systems Research:

Radionuclide Behavior in the Environment: Review for quality and consistency the available data on measurements of: (i) initial ground contamination of Chernobyl radionuclides in various parts of Norway. (ii) subsequent concentrations of these radionuclides in various environmental media as functions of time. Utilize the data obtained after reasonable quality assurance to verify the existing models, or to make improvements in them, for describing the radionuclide behavior in the environment involving such processes as:

i) Migration into soil

ii) Weathering (in rural and urban areas)

iii) Resuspension

iv) Food-chain contamination by direct initial deposition and subsequent root uptakes

$v$ ) Loss or reconcentration by run-off due to rain and/or melting snow

vi) Others

The task performed within this contract has been to use post-Chernobyl data from Norway to verify or find areas for possible improvement in the chronic exposure pathway models utilized in MACCS. The original definition of the task was somewhat more general, but subsequent discussions with the Nuclear Regulatory Commission showed this to be the intent.

Work has consisted mainly of collecting and evaluating post-Chernobyl information from Norway, or from other countries, when particularly relevant; but has also included experimental work performed specifically for the current task.

In most connections the data available show the models and data in MACCS to be appropriate. A few areas where the data indicate that the MACCS approach is faulty or inadequate are, however, pointed out in the report. These should be examined carefully, and appropriate modifications should eventually be made. 
CONTENTS

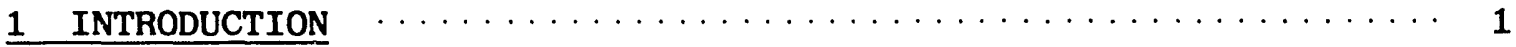

2 CHERNOBYL FALL-OUT LEVELS IN NORWAY $\quad \ldots \ldots \ldots \ldots \ldots \ldots \ldots \ldots \ldots$

3 QUALITY OF INVESTIGATIONS REFERRED TO IN THE PRESENT REPORT $\cdots$

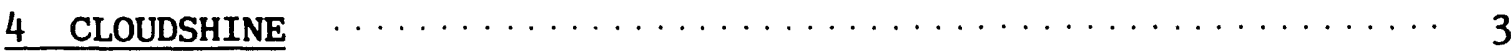

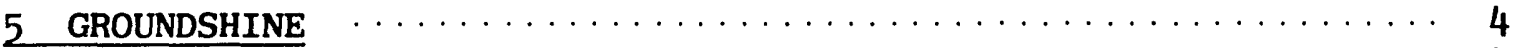

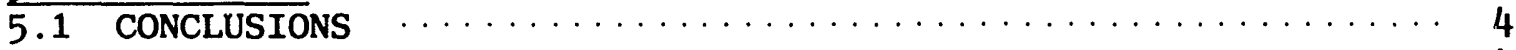

5.2 CONDITIONS UTILIZED IN MACCS $\ldots \ldots \ldots \ldots \ldots \ldots \ldots \ldots \ldots \ldots \ldots$

5.3 PRE- AND POST-CHERNOBYL MEASUREMENTS IN NORWAY $\ldots \ldots \ldots \ldots \ldots .8$

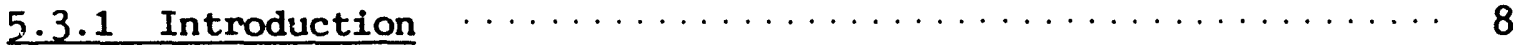

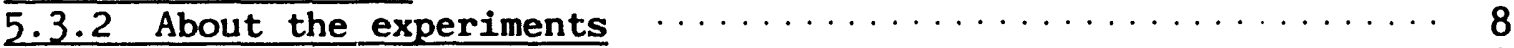

$5.3 .3 \mathrm{Cs}-134$ and $\mathrm{Cs}-137$ on the steel roof $\ldots \ldots \ldots \ldots \ldots \ldots$

$5.3 .4 \mathrm{Cs}-134$ and $\mathrm{Cs}-137$ on the tar-paper roof $\ldots \ldots \ldots \ldots \ldots \ldots 11$

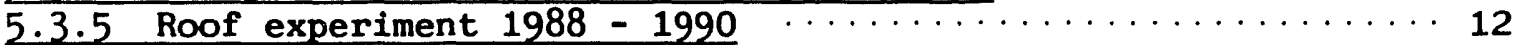

5.3 .6 Weathering in hilly terrain $\ldots \ldots \ldots \ldots \ldots \ldots \ldots \ldots \ldots$

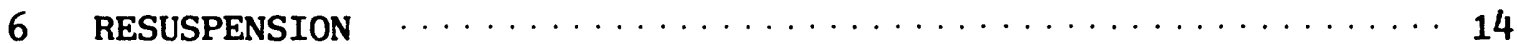

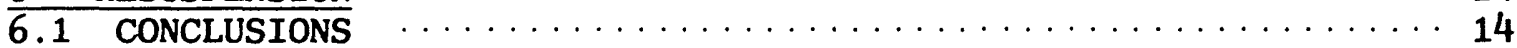

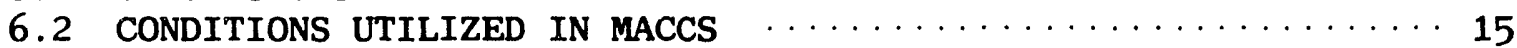

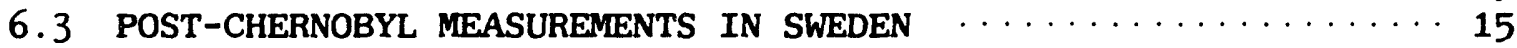

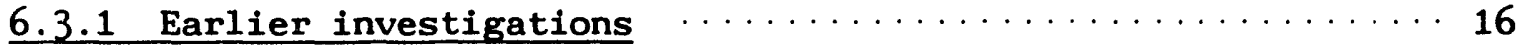

6.3 .2 Pre- and post-Chernoby 1 resuspension $\ldots \ldots \ldots \ldots \ldots \ldots \ldots$

6.3 .3 Air concentration measurements $\ldots \ldots \ldots \ldots \ldots \ldots \ldots \ldots \ldots \ldots \ldots \ldots \ldots$

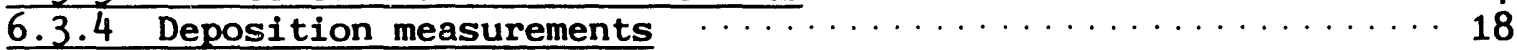

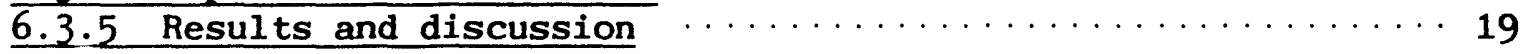

7 TRANSFER FROM SOIL TO PASTURE, PASTURE TO MILK AND TO MEAT $\cdots 23$

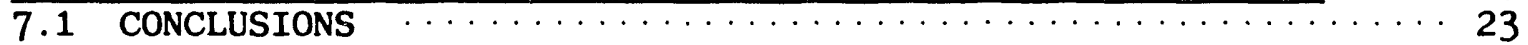

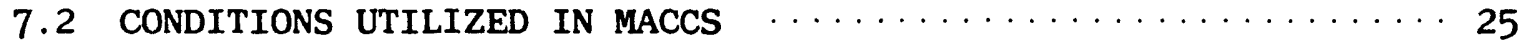

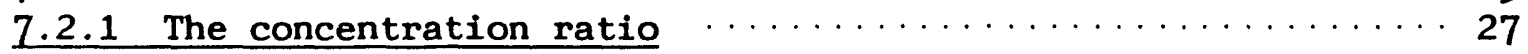

7.2 .2 Transfer from animal food products to man in MACCS $\ldots \ldots 29$

7.2 .3 Connection between MACCS parameter values and measured

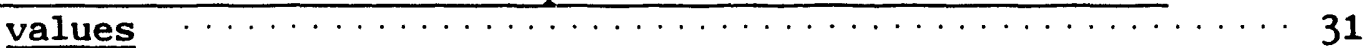

7.3 POST-CHERNOBYL MEASUREMENTS IN NORWAY $\ldots \ldots \ldots \ldots \ldots \ldots \ldots \ldots$

7.3.1 The ratio between cesium levels in soil, grass, beef and milk in semi-natural pastures in Norway $\ldots \ldots \ldots, \ldots 33$

7.3.2 The ratio between cesium levels in soil, grass, beef and milk in plowed pastures in Norway $\ldots \ldots \ldots \ldots \ldots 40$

7.3 .3 Semi-natural us plowed pastures. Soil type. Fertilizer $\cdots 43$

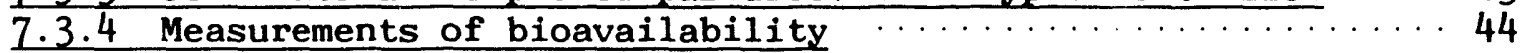




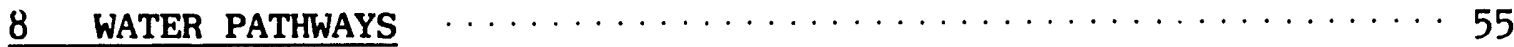

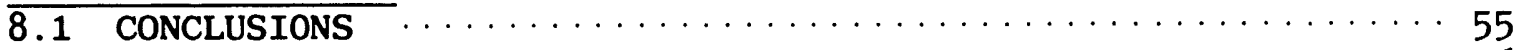

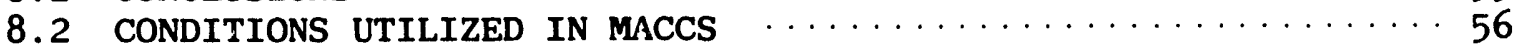

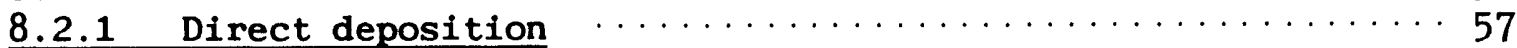

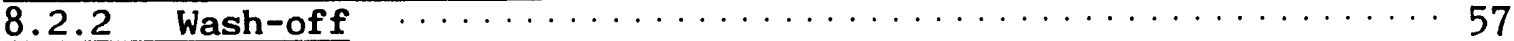

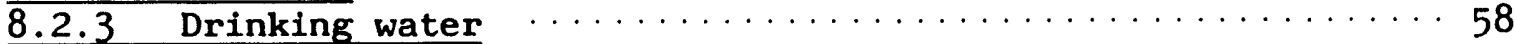

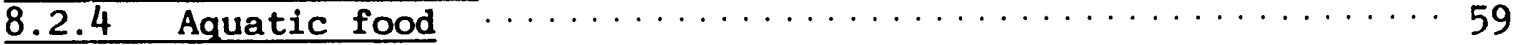

8.2 .5 Connection between MACCS parameter values $\ldots \ldots \ldots \ldots \ldots \ldots \ldots$

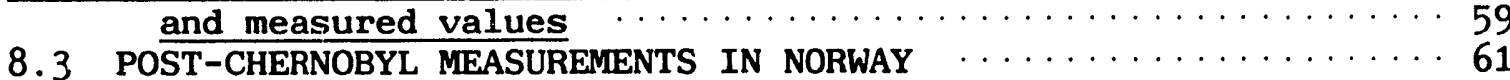

8.3.1 Survey of the radioactivity in game and wild freshwater fish 61

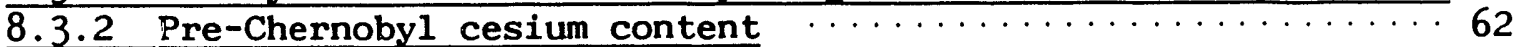

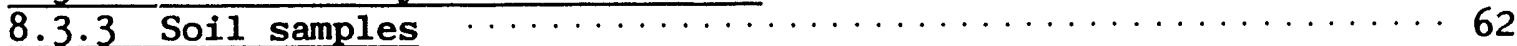

8.3 .4 Ground concentrations and concentrations in trout $\cdots \cdots \cdots 62$

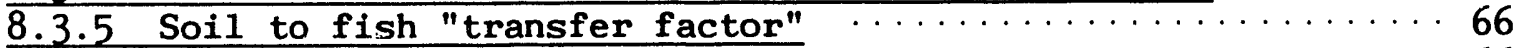

8.3 .6 Concentrations in water in the lakes $\ldots \ldots \ldots \ldots \ldots \ldots 66$

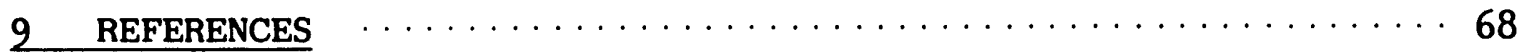


The task performed within this contract has been to use post-Chernobyl data from Norway to verify or find areas for possible improvement in the chronic exposure pathway models utilized in MACCS. The original definition of the task was somewhat more general, but subsequent discussions with the Nuclear Regulatory Commission showed this to be the intent. The task description contained a list of potentially interesting items (not a priority list), as follows:

i) Migration into soil

ii) Weathering (in rural and urban areas)

iii) Resuspension

iv) Food-chain contamination by direct initial deposition and subsequent root uptake

v) Loss or reconcentration by run-off due to rain and/or melting snow

vi) Others

Only a limited amount of sample collections and measurements initiated specifically for this task could be undertaken within the available budget, but permission has been given to cite results of investigations performed at other laboratories in Norway; material that has to a large extent not yet been published.

The present report is closely related to a previously published report (ref. TV90a), also prepared for U.S. Nuclear Regulatory Commission as part of this task, in which the chronic exposure pathway models implemented in the MELCOR Accident Consequence Code System (MACCS) were compared to the chronic exposure pathway models implemented in similar codes developed in countries that are members of the OECD. The earlier report was primarily aimed at analyzing the model structure. The present report attempts primarily to validate the numerical default values of parameters utilized in MACCS.

The following documentation was provided in early summer 1988 as basis for the task:

Ostmeyer, Robert M. and Helton, Jon C.: Exposure Pathways Models for Accidental Radionuclide Releases. Preliminary Draft. January 1988. Available in the NRC Public Document Room.

Chanin, David I., Sprung, Jeremy L. and Ritchie, Lynn T.: MELCOR Accident Consequence Code System (MACCS Version 1.5). User's lidide. (Draft version, last revised 2 June 1988). NUREG/CR-4691. SAND86-1562. Sandia National Laboratories.

Blond, Roger M.: Comments on the Analysis and Results of NUREG-1150. Science Applications International Corporation. 21 December 1987.

Chanin, David I.: Long-Term Mitigating Actions. Changes Implemented May 1988. Sandia National Laboratories. D.C. 26 May 1988, 11:04. 
Computer listings of subroutines STPATH, TRFRCT, WTRTRF, DIRDEP, LNGTPH, LTPROJ, LTMACT, CSTEFF, CSTDCN, LTACUM, STOCHR, OXTPT1, CASGET, OXTPT4, OXTPT5, OXTPT6, OXTPT7, OXTPT8, OXTPT9, DOSGET, OXTPT10, ECCGET, OXTPT11, OXTPT12 and GETIMP from the MACCS computer program. Sandia National Laboratories, 10 June 1988, 15:18.

CHRON user input file. Sandia National Laboratories. 10 June 1988, $10: 19$.

In November 1988 the following documentation was made available:

Chanin, David I., Sprung, Jeremy L, and Ritchie, Lynn T.: MELCOR Accident Consequence Code System (MACCS Version 1.5). User's Guide. (Prepublication review version of 21 September 1988). Sandia National Laboratories.

Rollstin, Judy: Terrestrial Food Pathways Parameters. (Informal communication). Sandia National Laboratories. August and September 1988.

The information contained in the documentation received in November 1988 is based upon a review of the information in the earlier documentation, and when there is conflict, the most recent documentation is valid. Information from the present task formed part of this review material.

June 1, 1989 additional documentation was received:

Chanin, David I., Sprung, Jeremy L., Ritchie, Lynn T. and Jow, HongNian: MELCOR Accident Consequence Code System (MACCS Version 1.5). Volume 1: User's Guide. (Final Draft May 11, 1989). NUREG/CR-4691 (SAND86-1562). Sandia National Laboratories.

MACCS Code Listing dated May 16, 1989. (Listing of input data (dated March 7, 1989) was received separately May 15, 1989).

Summary of the method used to calculate the maximum allowable ground concentrations PSCMLK, PSCOTH, GCMAXR. An informal draft dated May 18, 1989.

It should be pointed out that the final version of the Users Guide for the MACCS code (NUREG/CR-4691) was received after actual work on the present task was completed. The contents in the chapters entitled "Conditions utilized in MACCS" in the present report has not been thoroughly checked against this latest version. There does not seem to be any significant differences relative to earlier information conveyed, however.

\section{CHERNOBYL FALL-OUT LETELS IN NORWAY}

In 1986 the Norwegian National Institute of Radiation Hygiene conducted a country-wide survey in order to determine the Cs-134 and Cs-137 levels all over the country after Chernobyl (ref. BA86). 
From each of the 450 municipalities in Norway were collected eight soil samples, from four different locations. The levels determined (sum of $\mathrm{Cs}-134$ and $\mathrm{Cs}-137$ ) are shown in the figure on the following page. Other nuclides were also measured, but these results are not reported in the present report.

From the survey it was estimated that the total fall-out of Cs-134 and Cs-137 from the Chernobyl accident on Norwegian territory was respectively $1,200 \mathrm{TBq}$ and $2,300 \mathrm{TBq}$. This is approximately $6 \%$ of the cesium activity released from the reactor.

\section{QUALITY OF INVESTIGATIONS REFERRED TO IN THE PRESENT REPORT}

Shortly after the Chernobyl accident it was decided to create a Nordic Chernobyl Data Base (ref. TV90b). As teh amount of measurement data in the Nordic countries after Chernobyl was very large and with evidently large variations in quality, it was in the beginning of 1987 decided to perform an intercalibration exercise between the laboratories that were planning to supply information to the Data Base.

The exercise consisted of measurement of the following samples:

- Dried milk

- Lichen collected in Northern Sweden

- Seaweed collected near the Ringhals nuclear power plant in Sweden

- Water, synthetic with shortlived nuclides added

- Background sample; clay collected at $2 \mathrm{~m}$ depth in Denmark

- Surface soil from area in Sweden with high Chernobyl fall-out

So far 3 laboratories from Denmark, 3 from Finland, 4 from Norway and 11 from Sweden have completed the intercalibration exercise. The main conclusions from the exercise were that all cesium measurements were acceptable, all background measurements were acceptable, the laboratories that participated in the full range of the exercise also were in best mutual agreement.

The laboratories that have performed the measurements referred to in this report were among the ones that performed most satisfactorily in the exercise.

\section{CLOUDSHINE}

No known post-Chernobyl measurements can be used to validate the cloudshine calculations. Although air concentrations were measured almost everywhere, there are no corresponding measurements of indoor exposure.

After Chernobyl it was hoped that some experiments carried out by the Norwegian National Institute for Radiation Hygiene provided just this opportunity. Devices for measuring radon in houses had been distribu- 
ted to a large number of households shortly before Chernobyl, and it was hoped that it would be possible to separate the radon exposure, exposure from Chernobyl fall-out on ground and the surfaces of the house, and radiation from the cloud. This, however, has not been achieved. The information available was not sufficient.

It seems that the best way to validate the MACCS cloudshine model is still to compare it to more advanced Monte Carlo models.

\section{GROUNDSHINE}

\subsection{CONCLUSIONS}

The Norwegian experiments, including some performed specifically for this task, address one specific aspect related to groundshine: The rate at which it can be expected to decrease.

The conclusion is that the rates both for short-term and long-term weathering used in MACCS, when colipared to the results of pre- and post-Chernobyl experiments, are conservative.

The conditions used in MACCS are based upon experiments representing a person exposed outdoors in a rural area, but they are actually applied to al1 population groups. The largest part of the population, whether they live in urban or rural areas, spend most of the time indoors. Indoor groundshine exposure in one-family houses is usually dominated by radiation from the radioactive materials deposited upon the roof, because roofs are built from lighter materials than the walls. This makes the Norwegian experiments particularly relevant.

The Norwegian experiments are evidently not directly valid for areas with high-rise buildings, since the dose contribution from the roofs will then no longer dominate the groundshine dose. But they may nevertheless give an indication of the long-term weathering characteristics of paved surfaces (streets etc.), since it is reasonable to believe that these characteristics may be somewhat similar to the tar-paper roofs in the Norwegian experiments.

Concerning the vertical distribution of cesium in soil, there are at least two sets of measurements available at present from Norway; of which one set is reported in chapter 5.3.4.2. The other set, performed at the National Institute of Radiation Hygiene, is not included here. The results of both sets are as expected. Almost all cesium is in the upper few centimeters of soil even after a couple of years.

\subsection{CONDITIONS UTILIZED IN MACCS}

In MACCS it is not differentiated between urban and rural areas. At present all probabilistic risk assessment programs use basically the same approach to this exposure pathway. In this approach it is always assumed that the deposited readioactive materials are evenly distribu- 


\section{RADIOACTIVE FALLOUT PATTERN IN NORWAY}

LEVELS OF CESIUM-134 AND CESIUM-137 IN SCIL

DUE TO THE CHERNOBYL ACCIDENT

DATA SOURCE:

NATIONAL INSTITUTE OF RADIATION HYGIENE PRODUCED BY:

THE NORWEGIAN MAPPING AUTHORITY

Málestokk 1:5000000

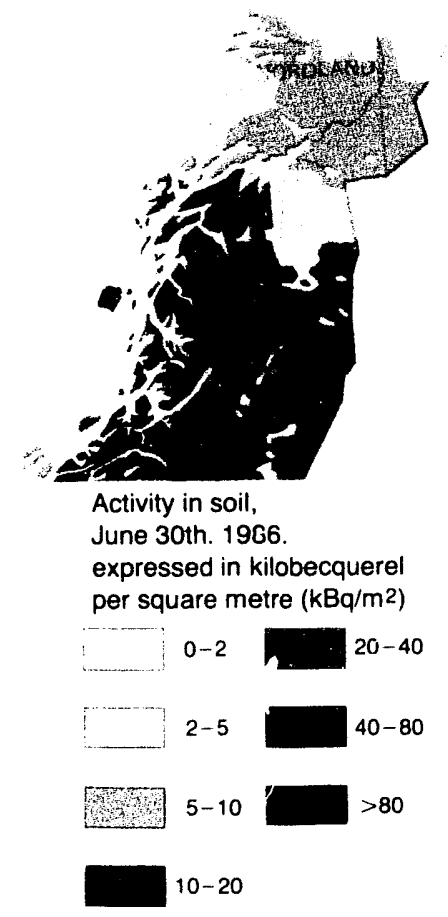

The map is based on analyses ol pooled samples from 450 municipalities. Each pooled sample consisted of individual samples

from four different locations in each municipality. Previous cesium 137 fallout activities have been subtracted.

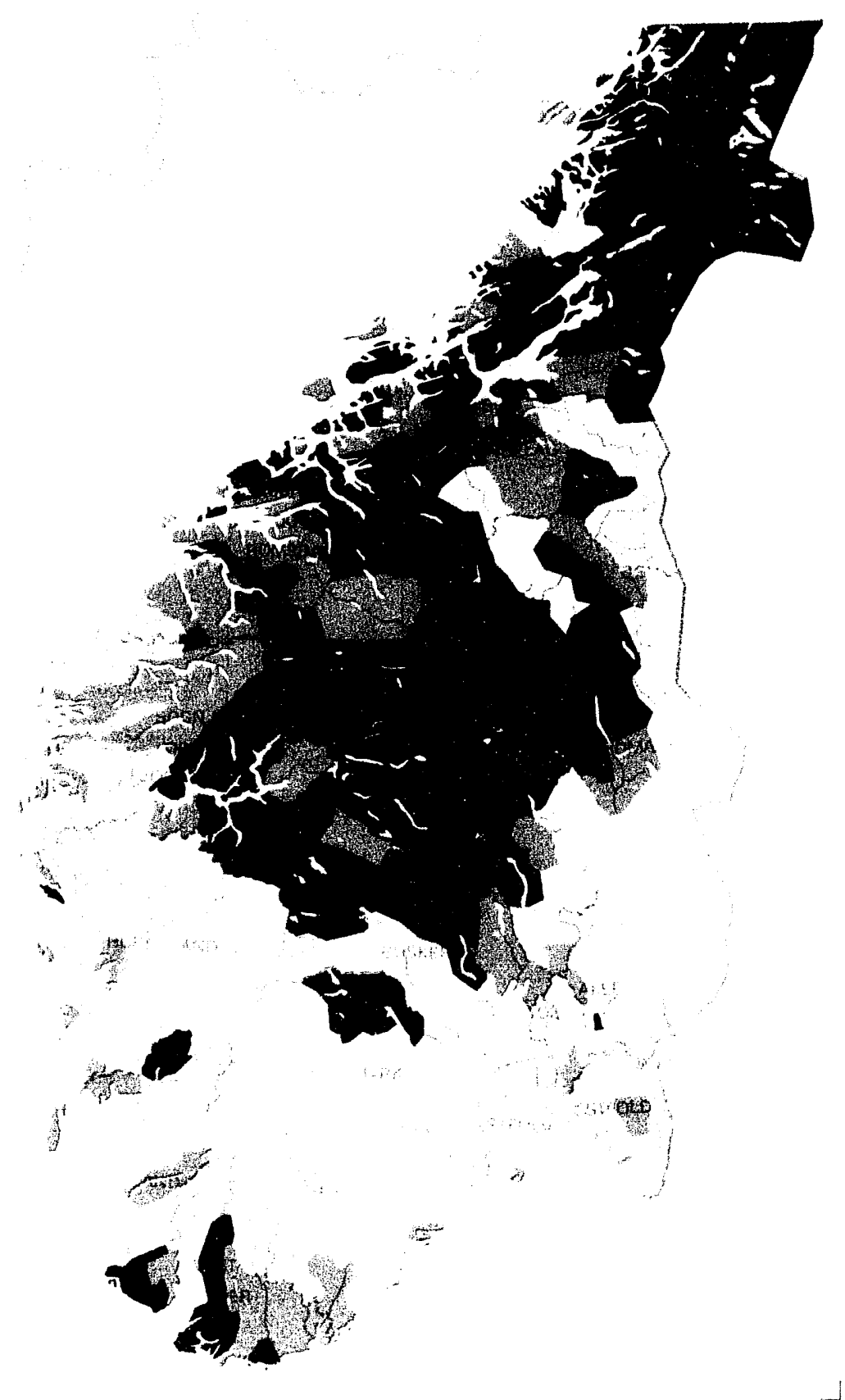

PRINTED IN THE NORWEGIAN MAPPING AUTHORITY 11-88 Reproduced in accordance with Permission No. 284/91, The Norwegian Mapping Authority. 
ted upon an infinite smooth, flat surface, representing the ground. Exposure to an individual is calculated using standard expressions, routinely used in radiation shielding. The ground concentration all over this surface is assumed to be the same as in the position of the individual.

Subsequently shielding factors are applied, partly to account for the fact that the surface in reality is not smooth, and partly to take the shielding effect of houses into account.

Groundshine is reduced with time, and not only because of radioactive decay. Percolation of the radioactive materials into ground will give additional shielding, although this movement is very slow. In connection with groundshine it is the radiation field above ground that is important, and binding to the soil will not reduce this field. The "classical" reference describing this reduction is:

Gale, H.J., Humphreys, D.L.O. and Fisher, E.M.R.: Weathering of Cesium-137 in Soil. Nature, 201, pp 257 - 261. 1964.

The long-term groundshine dose commitment in the position $(x, y)$ in the spatial grid, and from a specific nuclide, is in MACCS calculated from an expression of the form:

$\operatorname{DLTG}(x, y)=S F * \int_{t_{b}}^{t_{e}} \operatorname{GDF} * \operatorname{GCL}(x, y, t) * d t$

where

$\operatorname{GCL}(x, y, t)=\operatorname{GC}_{0}(x, y) *\left(A_{1} * \exp \left(-\lambda_{1} t\right)+A_{2} * \exp \left(-\lambda_{2} t\right)\right) * \exp \left(-\lambda_{R} t\right)$

$\operatorname{DLTG}(x, y)$ is an abbreviation for Dose Long-Term Groundshine (Sv)

SF shielding factor (dimensionless)

GDF groundshine dose-rate factor $(\mathrm{Sv} / \mathrm{sec}) /\left(\mathrm{Bq} / \mathrm{m}^{2}\right)$

$\mathrm{GC}_{\mathrm{O}}(\mathrm{x}, \mathrm{y})$ initial radionuclide concentration at position $(\mathrm{x}, \mathrm{y})\left(\mathrm{Bq} / \mathrm{m}^{2}\right)$

$t_{b}$ and $t_{e}$ times for beginning and end of groundshine exposure

$A_{1}$ and $A_{2}$ fraction of deposit that is weathered quickly and slowly, respectively (dimensionless). Sum of these should be one.

$\lambda_{1}$ and $\lambda_{2}$ short-term and long-term weathering rates (per time unit)

$\lambda_{R} \quad$ rate of radiological decay (per time unit)

The groundshine dose-rate factor is the dose-rate 1 meter above an infinite smooth plane contaminated with $1 \mathrm{~Bq}$ per square meter. This simplification can be used, since under most relevant conditions the size 
of the radioactive plume causing the contamination is large compared to the maan-free-path of gamma radiation in air.

The values used in the MACCS sample problem to calculate weathering are:

$$
A_{1}=0.65 \quad A_{2}=0.35
$$

Instead of the lambda-values are given the corresponding half-lives:

Thalf $f_{1}=219$ days $\quad$ Thalf $_{2}=32850$ days

The shielding factor used is: $\quad S F=0.33$

\subsection{PRE- AND POST-CHERNOBYL MEASUREMENTS IN NORWAY}

\subsubsection{Introduction}

Experiments on long-term wash-off from roof materials have been performed as part of the Nordic Safety Program. The same technique and equipment has been used to measure long-term wash-off of pre- and post-Chernobyl cesium. The pre-Chernobyl cesium was artificially administered.

A set of measurements of soil samples, performed in order to collect information on short-term weathering of cesium in hilly terrain, has been performed as part of this task for the Nuclear Regulatory Commission. These measurements are described in chapter 5.3.6.

\subsubsection{About the experiments}

At the grounds of the Institutt for Energiteknikk in Norway some "roofs" (mounted on simple wooden frames) were erected in 1982 for experiments on weathering of cesium. Cs-134 as chloride in solution was used in the experiments.

Two types of roof materials were investigated; tar-paper as roof material and a type of silicone-painted steel plate, made to imitate glazed tiles. One of the tar-paper roofs was only used as a reference roof in the pre-Chernobyl experiments, and the only activity on this roof is what came with the Chernobyl fall-out. The steel plate roofs were used in the pre-Charnobyl experiments, and has Cs -134 both from Chernobyl and from the pre-Chernobyl experiment.

\section{$5.3 .3 \mathrm{Cs}-134$ and $\mathrm{Cs}-137$ on the steel roof}

The amount of $\mathrm{Cs}-134$ put 'pon the roof in 1982 was $1.5 \mu$ Curie (on the whole roof area of $2.88 \mathrm{~m}^{2}$ ). This is equivalent to $55.5 \mathrm{kBq}$. It was 
applied to the roof on the 29 October 1982. The wash-off from the roof was determined by collecting all run-off water from the roof. When measurements were terminated, the 13 November 1982, the concentration of $\mathrm{Cs}-134$ in the run-off water was insignificant. At this time only $22 \%$ of the Cs -134 applied remained on the roof (corrected for radioactive decay, meaning that this value basically is valid for any cesium nuclide, after it has been multiplied by the appropriate radioactive decay reduction factor.) This wash-off corresponds to a half-life of 6.9 days, but the experiment also showed that the rate was very uneven, and much slower at the end of the experimont than immediately after application.

A sample of $(50 \times 34) \mathrm{cm}^{2}$ was cut from the steel roof the 6 June 1988, and subsequently measured. Decay-corrected back to the time of Chernobyl the activity on the roof was found to be $25.5 \mathrm{Bg} / \mathrm{m}^{2}$ of $\mathrm{Cs}-134$ and $9.59 \mathrm{~Bq} / \mathrm{m}^{2}$ of $\mathrm{Cs}-137$.

For comparison, it is interesting to determine how much of the Cs-134 from 1982 would remain on the roof in June 1988, if it is also assumed that no further wash-off had taken place after termination of the experiment in November 1982. Radioactive decay from late October 1982 to early June 1988 ( 5 years, 7 months and 7 days) must be taken into account. The half-life of $\mathrm{Cs}-134$ is 750 days. The fraction of the Cs-134 from 1982 remaining would be:

$$
\exp (-0.693 \cdot(5.52 \cdot 365) / 750)=0.155
$$

The amount remaining at the roof 6 June 1988 (assuming no wash-off after November 1982) would accordingly be $8.6 \mathrm{kBq}$ on the whole roof, equivalent to $3.0 \mathrm{kBg} / \mathrm{m}^{2}$.

Comparing tnis to the measurement of 6 June 1988, it is evident that wash-off from the roof actually has; continued after completion of the pre-Chernobyl experiment, and has been quite pronounced.

(In the remainder of this chapter all cited values for cesium activity have been decay-corrected back to the time of Chernobyl, unless otherwise stated).

The Chernobyl fall-out on the roofs was not measured at the time, simply because there were so many other tasks that were more important. But in connection with the present investigation, conducted for the Nuclear Regulatory Commission, soil samples were collected from a field not far from the roofs (about 50 - 100 meters). The area close to the roofs was avoided, since there might be a small possibility of Cs-134 contamination there from the pre-Chernobyl experiments. Another experiment within this same task for the Nuclear Regulatory Commission showed that the reduction of the Chernobyl fall-out in soil will almost entirely be due to radioactive decay. Horizontal migration seems to be very slow, even where the terrain is relatively steep.

Two cylindrical soil samples of diameter $8 \mathrm{~cm}$ and depth about $8 \mathrm{~cm}$ were measured. The height of the soil column is not important, as almost all the cesium is still in the litter layer. The results from 
the two samples differ by about $30 \%$ for $\mathrm{Cs}-134$ and $10 \%$ for $\mathrm{Cs}-137$, but on the average the ground activities are $1.43 \mathrm{kBq} / \mathrm{m}^{2}$ for $\mathrm{Cs}-134$ and $2.51 \mathrm{kBg} / \mathrm{m}^{2}$ for $\mathrm{Cs}-137$.

These values can be compared to results from a country-wide survey conducted by the National Institute for Radiation Hygiene during the Summer of 1986 (ref. BA86). Four soil samples from each municipality in Norway were collected (altogether about 1800 samples). The municipality called Skedsmo, in which the Institutt for Energiteknikk is located, was also included in the survey. The surface activities in Skedsmo were found to be $1.62 \mathrm{kBq} / \mathrm{m}^{2}$ of $\mathrm{Cs}-134$ and $3.76 \mathrm{kBq} / \mathrm{m}^{2}$ of Cs-137, which agrees quite well with the values in the previous paragraph.

It may be assumed that Chernobyl fall-out on the roofs was equal to fall-out on the ground, except from a correction factor for slope of the roofs. The metal roof is typical of a one-family house, and the slope is $23^{\circ}$. Accordingly the ground activities determined from our soil samples are equivalent to $1.32 \mathrm{kBg} / \mathrm{m}^{2}$ for $\mathrm{Cs}-134$ and $2.31 \mathrm{kBg} / \mathrm{m}^{2}$ for $\mathrm{Cs}-137$ per $\mathrm{m}^{2}$ of roof area on the steel roof.

From the information above it is possible to calculate weathering half-lives for the roof. It is customary to assume an expression for weathering containing two exponential terms; one describing fast and one slow weathering. In the present case the activity is known only at two points in time, and the half-lives determined represent the whole time interval involved.

All Cs-137 on the roof is Chernobyl fall-out, while some of the Cs-134 activity might be left-overs from the pre-Chernobyl experiment. The weathering half-life of the steel roof is accordingly determined from the Cs-137 measurements. The original Chernobyl fall-out is $2.31 \mathrm{kBg}$ and the remaining activity $6 \mathrm{June} 1988$ was $9.59 \mathrm{Bg}$, both per $\mathrm{m}^{2}$ metal roof. This gives a half-life of 27.2 days.

It is natural to assume that the two cesium nuclides have the same weathering half-life, and using the half-life above it is possible to determine the amount of Cs-134 activity of Chernobyl origin (based upon the soil measurement with correction for the slope of the roof) remaining on the roof at the $6 \mathrm{June} 1988: 4.15 \mathrm{Bg} / \mathrm{m}^{2}$. Total Cs-134 activity measured at 6 June 1988 was $25.5 \mathrm{~Bq} / \mathrm{m}^{2}$, and accordingly most of this Cs-134 activity $\left(21.3 \mathrm{Bg} / \mathrm{m}^{2}\right)$ was left over from the pre-Chernobyl experiment.

The activity level at 6 June 1988 of $21.3 \mathrm{~Bq} / \mathrm{m}^{2}$ of Cs-134 from the previous experiment, together with the $5.9 \mathrm{kBq} / \mathrm{m}^{2}$ remaining on the roof at the time when the pre-Chernobyl experiment was terminated on the 13 November 1982, can be used to determine the weathering halflife over this time period, which is found to be 250 days. If the half-life is calculated for the whole time period since initiation of the pre-Chernobyl experiment on the 29 October 1982, the result is 208 days. 
All of these results indicate that there are several fast and slow weathering components. The weathering half-life over a period of a couple of years seems to be at around 100 days, while over a period of five to six years, it is around 200 - 250 days. During the first weeks after deposition, however, the half-life is very much smaller, at less than 10 days. And the first few days after deposition there is not much sense in referring to a half-1ife, as the wash-off will depend primarily upon just when it rains. All this refers to the steel roof.

With the few points in time available from these observations, these conclusions have to be applied with caution. Nevertheless, the important observation from these measurements is that wash-off continues over long time periods. Present assumptions utilized in accident consequence assessments are limited to at best taking into account a certain amount of initial wash-off. Wash-off over periods of the order of years is completely ignored. It must, however, also be remembered that wash-off is not the same as disappearance. Potential exposure from the redistributed radioactivity must also be taken into consideration.

\subsubsection{Cs-134 and $\mathrm{Cs}-137$ on the tar-paper roof}

The tarpaper roof, which is typical of an apartment building, has a slope of $5^{\circ}$. This slope is so small that there will be almost no difference between activity per $\mathrm{m}^{2}$ ground and per $\mathrm{m}^{2}$ roof, but if one wishes to be exact, the ground activities determined from the soil measurements are equivalent to $1.42 \mathrm{kBg} / \mathrm{m}^{2}$ for $\mathrm{Cs}-134$ and $2.50 \mathrm{kBg} / \mathrm{m}^{2}$ for $\mathrm{Cs}-137$ per $\mathrm{m}^{2}$ of roof area on the tar-paper roof of Chernoby 1 fall-out.

The tar-paper was taken off the roof 6 June 1988. A sample of (154 $x$ $8.5) \mathrm{cm}^{2}$ was measured, and it was found that the activity on the roof was $307 \mathrm{~Bq} / \mathrm{m}^{2}$ of $\mathrm{Cs}-134$ and $247 \mathrm{Bg} / \mathrm{m}^{2}$ of $\mathrm{Cs}-137$. On this tar-paper roof the only activity is from Chernobyl fall-out. The ratio between Cs -134 and $\mathrm{Cs}-137$ is 0.56 , which is a little higher than the ratio determined from the air filter measurement at the Institute over the sampling period 28 - 29 April 1988, from 1o:00 to 16:00 local time. The air filter ratio is 0.49 .

The half-1ife can be determined from both the Cs-134 and the Cs-137 measurements from the 6 June 1988, compared to the soil sample measurements. The hallf-lives determined are 348 days and 351 days based upon the $\mathrm{Cs}-134$ and $\mathrm{Cs}-137$ data respectively.

Evidently wash-off from the tar-paper is, as expected, much slower than from the metal roof. However, also in this case the results show that wash-off continues over the years, contrary to what is usually assumed. More short-term experiments performed at the Institute in an earlier project period indicated that there was wash-off of about $40 \%$ of $\mathrm{Cs}-134$ activity over a period of about eight months. This corresponds to a half-life of 297 days. Just as for the steel roof wash-off is fastest immediately after deposition, when $3 \%$ was washed off over the first two days and $10 \%$ over the first 10 days. 


\section{3 .5 Roof experiment $1988-1990$}

In 1988 it was observed that the wooden frames of the experimental roofs were decaying, and they were removed. It was at this occassion it was decided to save a few samples for analysis of remains of the Chernobyl fall-out (as described. in chapters 5.3.3 and 5.3.4). But one of the tar-paper roofs is still intact, and has been used for an additional medium- and long-term Cs-134 experiment, as part of the present task. In the following is a description of this experiment:

17 October 1988 20 October 1988

24 October 1988 26 October 1988

27 October 1988

28 October 1988

9 November 1988

24 November 1988

22 December 1988

4 January 1989
New tar-paper put on the roof.

Contaminated with $20 \mathrm{ml}$ of the solution used in the pre-Chernobyl experiment, which 1 November 1982 contained $1 \mu \mathrm{Ci} / \mathrm{ml}$. The solution was added to $50 \mathrm{ml}$ water and applied to the roof in stripes about $10-15 \mathrm{~cm}$ apart. Taking radioactive decay into consideration the total activity applied to the roof was about $2.5 \mu \mathrm{Ci}$, but this value is not important, since all measurements are taken relative to the solution. The solution dried up completely on the roof during the contamination procedure.

First run-off water sample collected, 2.15 liter. About $10 \mathrm{~cm}$ wet snow coming down from ca 16:00 and throughout the evening.

Rain showers. Ca. $3 \mathrm{~cm}$ snow left on the roof in the morning.

Rain showers morning and forenoon. All snow on the roof had now melted. Snow and wet snow continued to come down throughout the afternoon. 61 liter run-off water collected.

Collected 17.5 liter run-off water. Frost during the nights in this collection period. Collected 43 liter run-off water. Frost during the nights in this collection period.

Collected 71 liter run-off water. Frost during the nights in this collection period.

Collected 79 liter run-off water. Frost during the nights in this collection period.

The observed wash-off during this period is summarized in Table 5.1.

The experiment has, however, continued after this time, but in a different (and less expensive) manner. Instead of collecting run-off water from the roofs, narrow strips of the roof material are cut off. The strips are $8 \mathrm{~cm}$ wide and $144 \mathrm{crn}$ long, along the slope of the roof. Every four to six months a strip is cut off and measured. The experiment will continue as long as there is roof material left to sample. For now, at least, the edges of the roof are avoided.

When the roof was cortaminated 20 October 1988, this was done by spraying onto the roof $20 \mathrm{ml}$ of a Cs-134 solution left over from the experiments conducted in 1982. The 1 November 1982 the solution was said to contain $1 \mu \mathrm{Ci} / \mathrm{ml}$; equivalent to $37 \mathrm{kBq} / \mathrm{ml}$. 


\begin{tabular}{|c|c|c|c|}
\hline & $\begin{array}{l}\text { Sample } \\
\text { date }\end{array}$ & $\begin{array}{l}\text { Run-of water } \\
\text { volume (liter) }\end{array}$ & $\begin{array}{l}\% \text { of contaminant } \\
\text { contained in run-off water }\end{array}$ \\
\hline \multirow[t]{2}{*}{$\begin{array}{r}24 \\
28 \\
9 \\
24 \\
22 \\
4\end{array}$} & $\begin{array}{ll}\text { Oct. } 1988 \\
\text { Oct. } 1988 \\
\text { Nov. } 1988 \\
\text { Nov. } 1988 \\
\text { Dec. } 1988 \\
\text { Jan. } 1989\end{array}$ & $\begin{array}{l}2.15 \\
61 \\
17 \cdot 5 \\
43 \\
71 \\
79\end{array}$ & $\begin{array}{l}0.174 \\
2.35 \\
0.818 \\
1.34 \\
1.63 \\
1.76\end{array}$ \\
\hline & Sum & 274 & 8.1 \\
\hline
\end{tabular}

Table 5.1 Wash-off in roof experiment.

In the remainder of this chapter all activity values will be decaycorrected to 20 0ctober 1988. At that date the $20 \mathrm{ml}$ of contaminant solution would contain $102.3 \mathrm{kBq}$ of $\mathrm{Cs}-134$ if only radioactive decay is taken into account.

Based upon the assumption that radioactive decay has been the only factor that has changed the concentration of $\mathrm{Cs}-134$ in the contaminant solution, the Cs-134 concentration on the roof (roof area $2.88 \mathrm{~m}^{2}$ ) at the start, of this experiment would be $35.5 \mathrm{kBq} / \mathrm{m}^{2}$.

It is, however, difficult to tell whether a certain increase in concentration due to evaporation of the solution has occurred in addition to radioactive decay. Accordingly although the measurements of the individual strips can be intercompared, comparison to the calculated value of $\mathrm{Cs}-134$ contamination of the roof at the start of the experiment must be done with caution.

Here are the results from the strips measured up till now:

28 February 1989

31 August 1989

12 December 1989

1 June 1990

$$
\begin{array}{cc}
7.47 & \mathrm{kBq} / \mathrm{m}^{2} \\
10.8 & \mathrm{kBq} / \mathrm{m}^{2} \\
9.00 \mathrm{kBq} / \mathrm{m}^{2} \\
8.53 \mathrm{kBq} / \mathrm{m}^{2}
\end{array}
$$

The first observation to make is that these values are very low compared to the calculated value for activity on the roof at start of the experiment. The second observation is that distribution over the roof must be somewhat uneven. The third observation is that, also judging from the other experiments, at such a short time interval significant reduction in $\mathrm{Cs}-134$ concentration due to wash-off could hardly be expected to have occurred on a tar-paper roof.

\subsubsection{Weathering in hilly terrain.}

The Chernobyl fal1-out in Norway is very unevenly distributed, even on 
a very small scale. Soil samples collected a few meters apart may have cesium contents differing by a factor of ten or more. In some cases this seems to have some connection with terrain features, so that the concentrations in low parts of the area (e.g. ditches) are higher. Most of the observations of this type have, however, been made in the mountain areas, where there was a partial snow cover at the time of deposition.

In order to see if similar terrain effects are present in an area free of snow at the time of deposition, some soil samples have been collected at grounds of the Institute, as part of the present task. The samples were collected in a relatively steep slope. On top there is a flat space about five meters wide, then the slope (about twenty meters measured along the slope), and it ends in a ditch along a road, running across the bottom of the slope. If the Chernobyl cesium was mobile at the time of deposition, we would expect the ground concentration in the slope to be lower than the ground concentration in the flat area on top of the slope, and the concentration in the ditch to be higher. Chernobyl deposition in this are was wet deposition, precipitated with modest amounts of rain.

Soil samples have been collected in the flat area, the middle of the slope and in the ditch. The ground concentration is about $2000 \mathrm{~Bq} / \mathrm{m}^{2}$ of $\mathrm{Cs}-137$, decay-corrected back to 28 April 1986, and the differences between the three types of area are insignificant, indicating that in the clay-rich type of soil in this area, where the Institute is located, the activity was retained where it was deposited. The Cs-134 concentration is about one half of the Cs-137 concentration, also decaycorrected. Further investigated had been planned, but these plans were cancelled, since the results from this one set of measurements left little doubt as to what the conclusion would be.

\section{RESUSPENSION}

\subsection{CONCLUSIONS}

The resuspension factors measured by the Swedish Defence Research Establishment are considerably lower than those used in MACCS. These measurements are relevant in connection with inhalation doses. They are, however not relevant in connection with resuspension onto plants and the implications of this upon exposure via the nutrition pathways. Nor are they relevant in connection with the problem of redistribution of deposited materials and the implications of this probiem (e.g. reduction of the effect of decontamination by later re-contamination with resuspended materials).

Since the purpose of MACCS calculations is primarily to calculate time-integrated population doses rather than individual doses, the rate at which the materials become unavailable for resuspension is 
almost as important as the resuspension factors. This rate, as determined from the Swedish experiments is faster than the one used in MACCS, but the observations span only a period of three years, and are accordingly quite uncertain.

\subsection{CONDITIONS UTILIZED IN MACCS}

The resuspension factor is defined as the ratio between the airborne resuspended radionuclide concentration $\left(\mathrm{Bq} / \mathrm{m}^{3}\right)$ and the surface radionuclide concentration $\left(\mathrm{Bq} / \mathrm{m}^{2}\right)$. The concentration of resuspended radionuclides in air must evidently be a function of the height above ground, and in connection with inhalation the interesting height will be some $170 \mathrm{~cm}$ for adults, and considerably iess, of course, for children. This reference height is not, as far as I can see, mentioned anywhere in the MACCS documentation, and it must just be assumed that it is referred to a sensible height.

The resuspension factor is given as a function of time, since there is evidently an aging effect, caused by weathering and other processes. In MACCS the resuspension factor is defined by the following expression, which consists of a short-term (days), intermediate-term (weeks to months) and long-term (years) component.

$R F(t)=10^{-3} \exp (-250 t)+10^{-5} \exp (-0.68 t)+10^{-9} \exp (-0.007 t)$

The half-lives of these components are 1 day, 1 month (according to the Users Guide, but 1 year according to report NUREG/CR-4184) and 100 years respectively. $t$ in the equation is measured in years.

In the Users Guide the term in front of the short-term component is $10^{-4}$ instead of $10^{-3}$. This change and the change in intermediate-term half-1ife appear to have been made April 1988.

\subsection{POST-CHERNOBYL MEASUREMENTS IN SWEDEN}

When exposure of a population via different exposure pathways has been compared in earlier accident consequence assessments (like the American Reactor Safety Study (ref. WA75)), the main exposure of the population was usually found to be due to external radiation from the ground and intake of radionuclides with the food, while resuspension was a pathway of little importance compared to the others.

The data upon which these evaluations of the resuspension pathway were based were from weapons test sites in the Nevada desert area. Resuspension under other conditions may be rather different. In particular the suitability of these data for calculation of resuspension in urban areas could be doubted. In urban areas one can imagine that there may be considerable resuspension even at low wind speeds, as an effect of the traffic. Cars may resuspend activity both as a result of the air 
turbulence caused, and as a result of the wear on the road surface caused by the wheels.

A project on resuspension was proposed from the beginning of the program period. Possible approaches were discussed with the Norwegian Air Research Institute and with Risø National Laboratory. One proposed approach involved the use of gold as tracer, due to the extremely low ambient air concentrations, and because extremely small amounts can easily be measured by activation analysis. Both financial and manpower resources, however, were insufficient at that time, and no institution was sufficiently interested to take on responsibility for performing this project.

After Chernobyl. the situation was completely different. The suitable tracer was now present, and the National Defence Research Establishment, Sweden has performed the project on resuspension, using their air filter stations. The results of these investigations are reported in (ref. BJ87 and BJ88).

\subsubsection{Earlier investigations}

In addition to the investigations of nuclear weapons fall-out in desert areas, already mentioned, some interesting investigations have been carried out. A survey of these investigations was prepared as part of the previous Nordic Safety Program, and a brief summary is given below.

In the American Reactor Safety Study a time-varying resuspension factor was used. The time dependence reflected downward migration of cesium in soil or other processes with similar effect upon the availability of cesium for resuspension. The resuspension factor varied from $10^{-5} \mathrm{~m}^{-1}$ for freshly deposited material to $10^{-9} \mathrm{~m}^{-1}$. It is said in the Safety Study that these values probably are too low for urban areas, but alternative values are not given.

The resuspension factor is defined as the ratio between air concentration and ground concentration. What is easily forgotten in this connection is that the air concentration is not a welldefined quantity. It will obviously vary both with the height above ground and with the weather conditions. The interesting height above ground is about 150 to $170 \mathrm{~cm}$, where breathing usually takes place.

It is reasonable to expect resuspension to be more pronounced under dry than under wet weather conditions. The effect of the wind speed, however, is more difficult to foresee. Higher wind speeds will lift more material from the ground, but will at the same time give increased dillution. Altogether, hiwever, it seems that higher wind speeds give higher concentrations of resuspended material. The size of the area from which resuspension takes place is also important, if ground concentrations are non-uniform. The local/regional character of resuspension has been addressed in the present project. 
One of the earlier investigations is of particular relevance in connection with traffic and resuspension (ref. SE76). In the experiment described there, a powder is distributed on a surface, and cars drive across it. Among the results, it is found that for the fast driving the fraction of material resuspended per vehicle pass is about $10^{-2}$. However, this piece of information is too unqualified to be compared with resuspension in a strict manner. If one does not know the concentration in air, the resuspension factor can not be determined. In order to "translate" this fraction of resuspended material, one needs information on how long the material will stay resuspended; and not least, one needs information on the vertical concentration distribution. If we assume that the resuspended materials will stay in suspension somewhat longer than the time interval between twn car passes, and that the resuspended material is evenly distributed in a two meter thick layer of air (somewhat higher than a car), the corresponding value for the resuspension factor will be ca. $10^{-2} \mathrm{~m}^{-1}$. This is a very large resuspension factor, and is in fact so large that it indicates that car driving would be quite an efficient method of decontamination. It must be concluded that these experimental conditions are not representative of a fall-out situation.

\subsubsection{Pre- and post-Chernobyl resuspension}

During the mid-80 5 the amount of weapons fall-out Cs -137 penetrating to ground level from the stratosphere had at that time become sufficiently small, so that it became possible in Sweden to observe resuspension of deposited cesium. After the Chernobyl accident the ground level air concentration of radioactive Cs-137 is entirely dominated by resuspended radionuclides (except for the first few months postChernobyl).

\subsubsection{Air concentration measurements}

Air samples are collected all over Sweden, as shown by Figure 6.1. The sampling stations marked with - belong to the surveillance network of high volume $\left(1100 \mathrm{~m}^{3} / \mathrm{h}\right)$ air sampling devices designed for verification of nuclear test bans. The stations in the Găvle area, marked $\square$, are mobile air sampling devices specially made for this study. These mobile stations have a capacity of filtrating about $330 \mathrm{~m}^{3} / \mathrm{h}$ of air through a $0.58 \cdot 0.58 \mathrm{~m}^{2}$ glass fiber filter. Filters are changed two or three times a week at all stations, and measured weekly on Ge-detectors, giving a detection limit for both Cs-134 and Cs-137 of less than 0.1 and $0.5 \mu \mathrm{Bq} / \mathrm{m}^{3}$ for the stationary and the mobile air sampling stations, respectively. This means that the air concentration of both the cesium isotopes has been above the detection limit for all the sampling stations at all times.

At the permanent air sampling stations, which belong to the surveil1ance system, air concentrations have been measured continuously since 
long before the Chernobyl accident. The Visby station is the only permanent station mounted post-Chernobyl.

In Găvle the mobile air sampling stations were put in place in May 1987, particularly in order to study differences in resuspension due to the local environment, and especially in urban areas. There were stations in city, forest, grass and farming areas.

\subsubsection{Deposition measu rements}

Two types of measurements have been performed in order to establish characteristics of the deposited activity: gamma-ray spectrometric measurements and soil sample analysis. In connection with resuspension knowledge of the total deposited amount is not sufficient, as part of

Figure 6.1 Air sampling stations in Sweden.

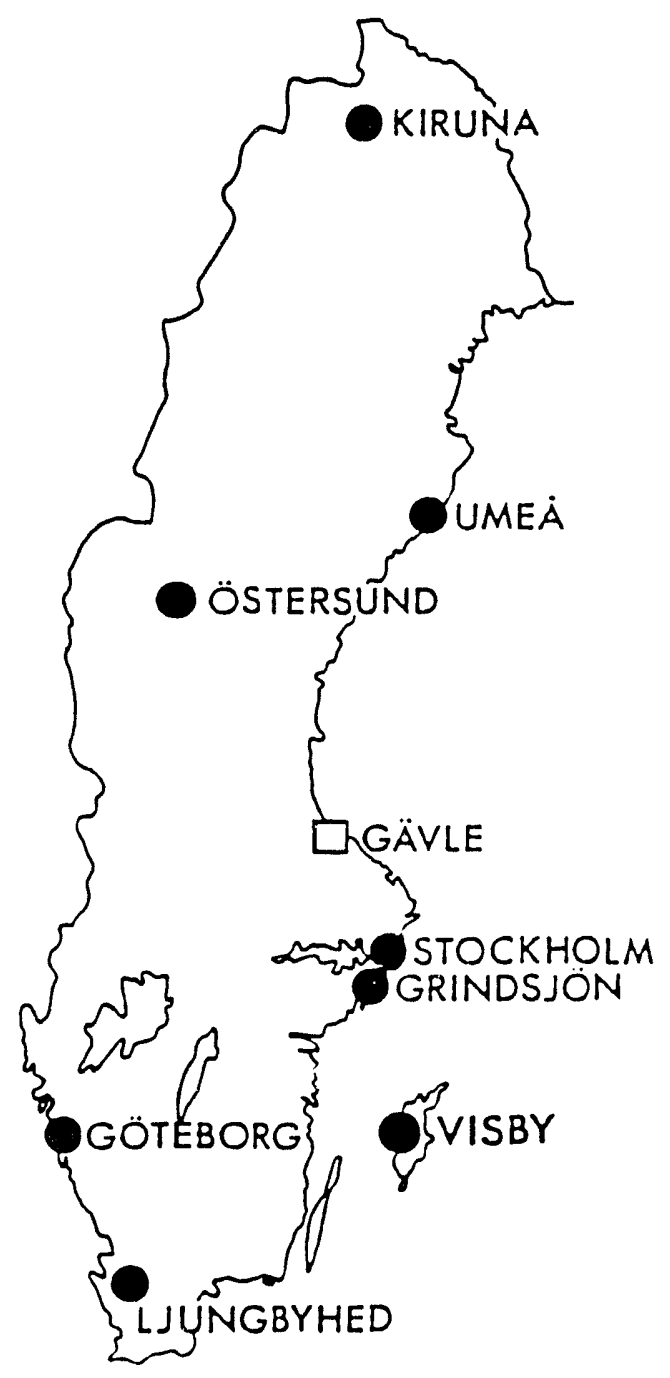


this will not be available for resuspension, mainly for the reason that it is no longer on the surface. From the two types of measurements performed it is possible to determine the relaxation length. This is a quantity in common use in shielding terminology, and it describes the amount of material between a radiation source and a detector. In this study it is found that it is also useful for describing the fraction of radioactive material available for resuspension.

\section{$\underline{6.3 .5}$ Results and discussion}

During the first weeks or months after the Chernobyl accident considerable amounts of fission products were floating around in the atmosphere. It is therefore difficult to separate between the contributions due to resuspension and fresh radioactivity, not yet delosited, during May and June 1986. The first two months post Chernobyl, have therefore been excluded.

It is found that the activity concentrations of Cs-137 and Cs-134 follow each other. As Cs-134 is detectable at all sampling stations during the whole period, and as Cs-134 was not present pre-Chernoby1, only Cs-134 is studied. All resuspension factors and conclusions, however, also apply to Cs-137.

The air concentration of $\mathrm{Be}-7$ has been measured at all 12 sites where air sampling has been performed continuously for at least 1.5 years. Figure 6.2 shows the results for three stations, and as can be seen, both the air concentration and the seasonal variation of the cosmogenically produced $\mathrm{Be}-7$, is very similar for all sites. Even when sites Stockholm and Găvle ( $>100 \mathrm{~km}$ apart) are compared only small differences can be seen. This is typical for a globally distributed radionuclide. The important point, however, is that $\mathrm{Be}-7$ can be used as a normalizing factor for air samples from different stations.

The air concentrations of $\mathrm{Cs}-134$ measured are rather well correlated to the deposition after the Chernobyl accident in the area surrounding each air sampling station. Seasonal variations occur somewhat like for $\mathrm{Be}-7$, but due to different reasons. The seasonal variation for $\mathrm{Be}-7$, with one peak in spring and a smaller one in autumn, comes from the change of the tropopause, while the variation for Cs-134 is due to weather conditions, and the lack of binding vegetation during autumn, winter and spring. Stations that were extremely similar for Be-7, as Stockholm and all the sites in the Gävle area, are not at all similar regarding the cesium nuclides (Figure 6.3 ).

Transportation of resuspended materials over longer distances $(>100$ $\mathrm{km}$ ) can be regarded as small, except during extreme circumstances with high wind speeds. Only occasionally, at times with strong wind from the North, has the air concentration in Stockholm been significantly increased due to resuspension from the high deposition areas starting 50-60 km North of Stockholm. Some indications of much longer transport of resuspended radionuclides have been found. At some occasions the 


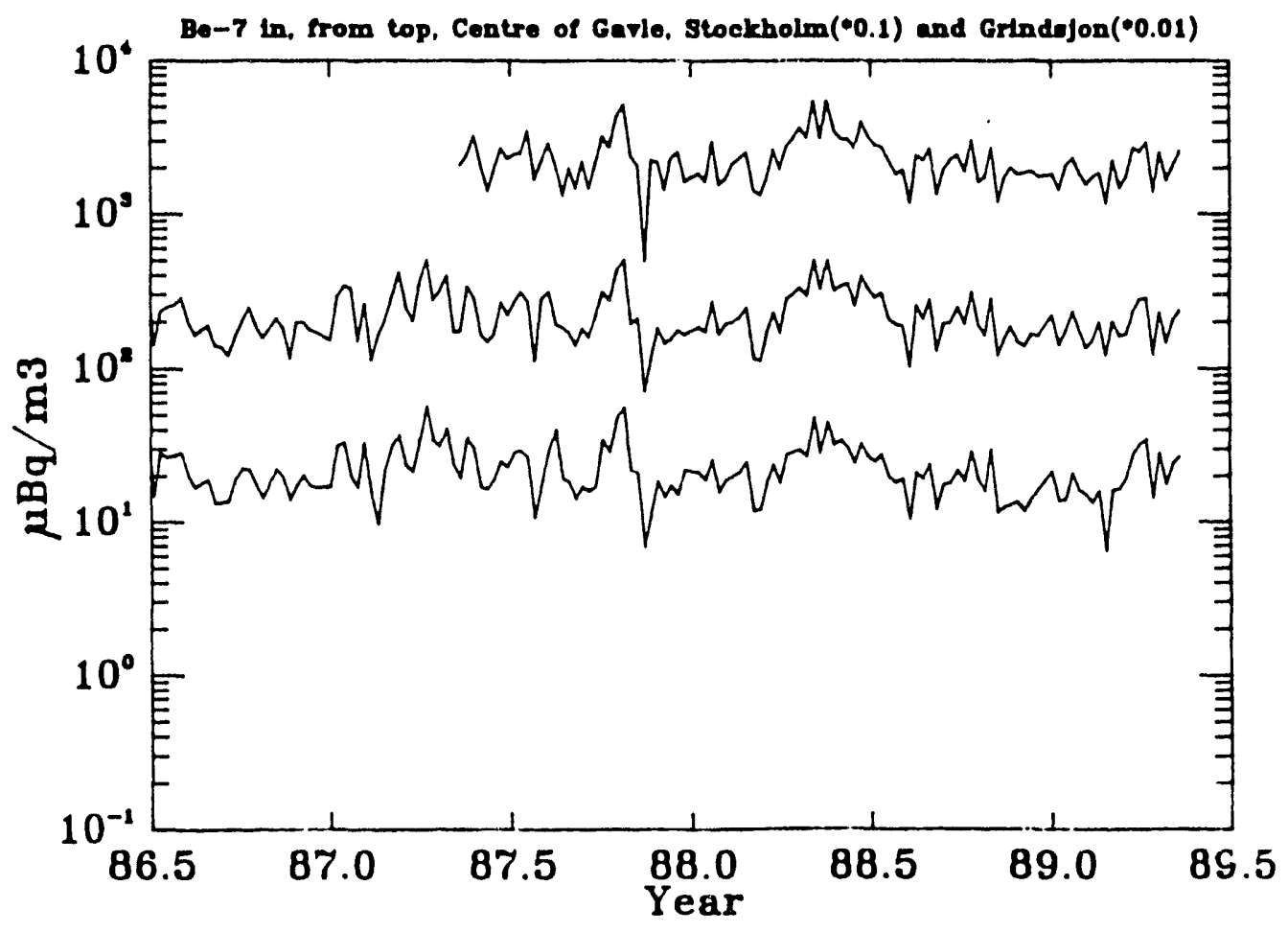

Figure 6.2 Air activity concentrations of Be-7 for sites Center of Gävle, Stockholm and Grindsjün.

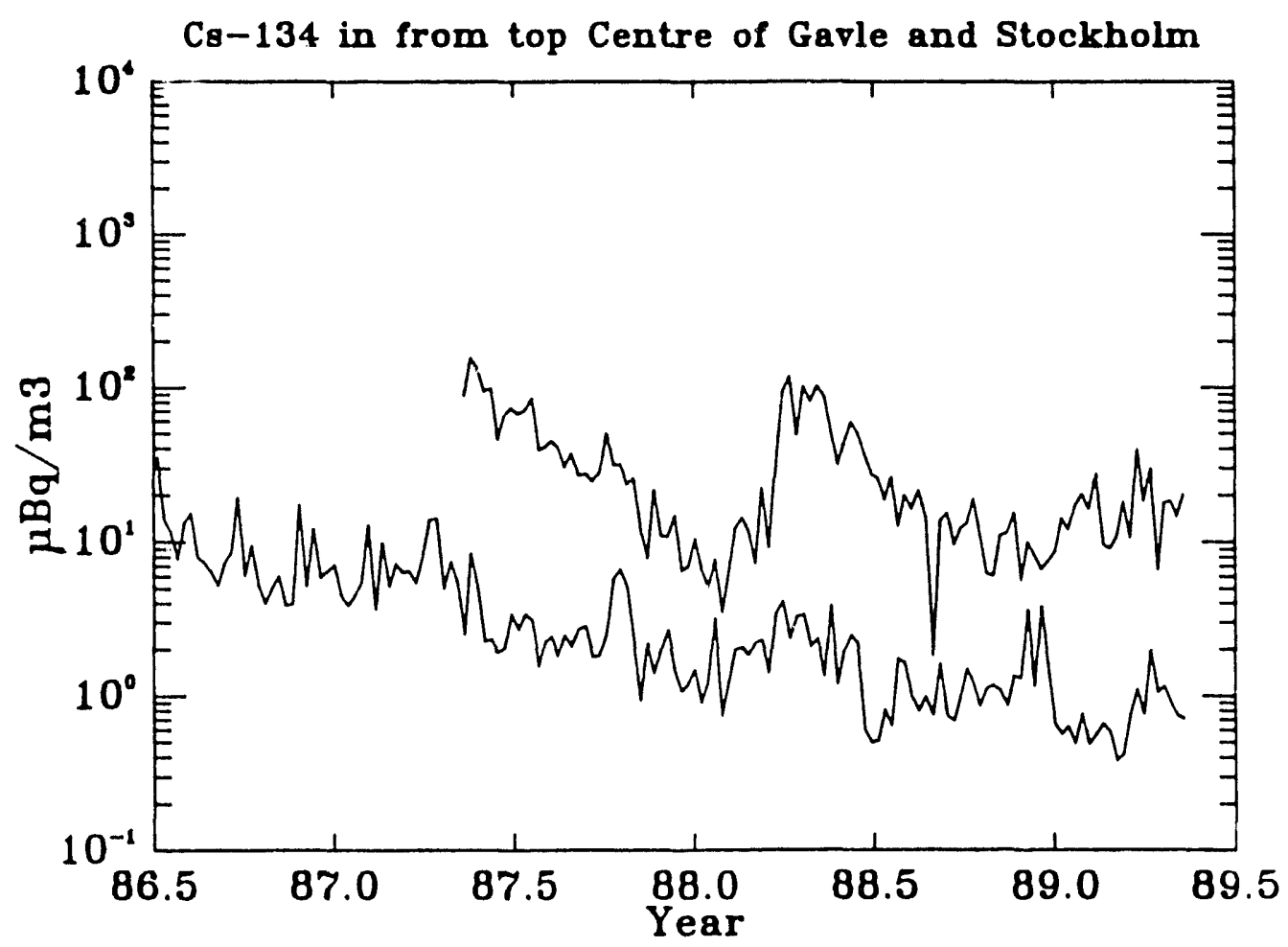

Figure 6.3 Air activity concentrations of Cs-134 for sites Center of Gävle and Stockholm. 
nuclide concentration has been increased significantly during periods with strong South-Easterly wind, coming from the Chernobyl area. Most of the time, however, the air concentration of the cesium nuclides at all sites is due to local resuspension.

The resuspension factors for all sites are given in Table 6.1 as function of time. The highest resuspension factor detertined occured in Stockholm during the third quarter of 1986 ( 2 to 5 months after the Chernobyl accident). This resuspension factur $4.1 \cdot 10^{-8}$, al though the highest measured, is still about a factor 1000 lower than previous investigations have indicated.

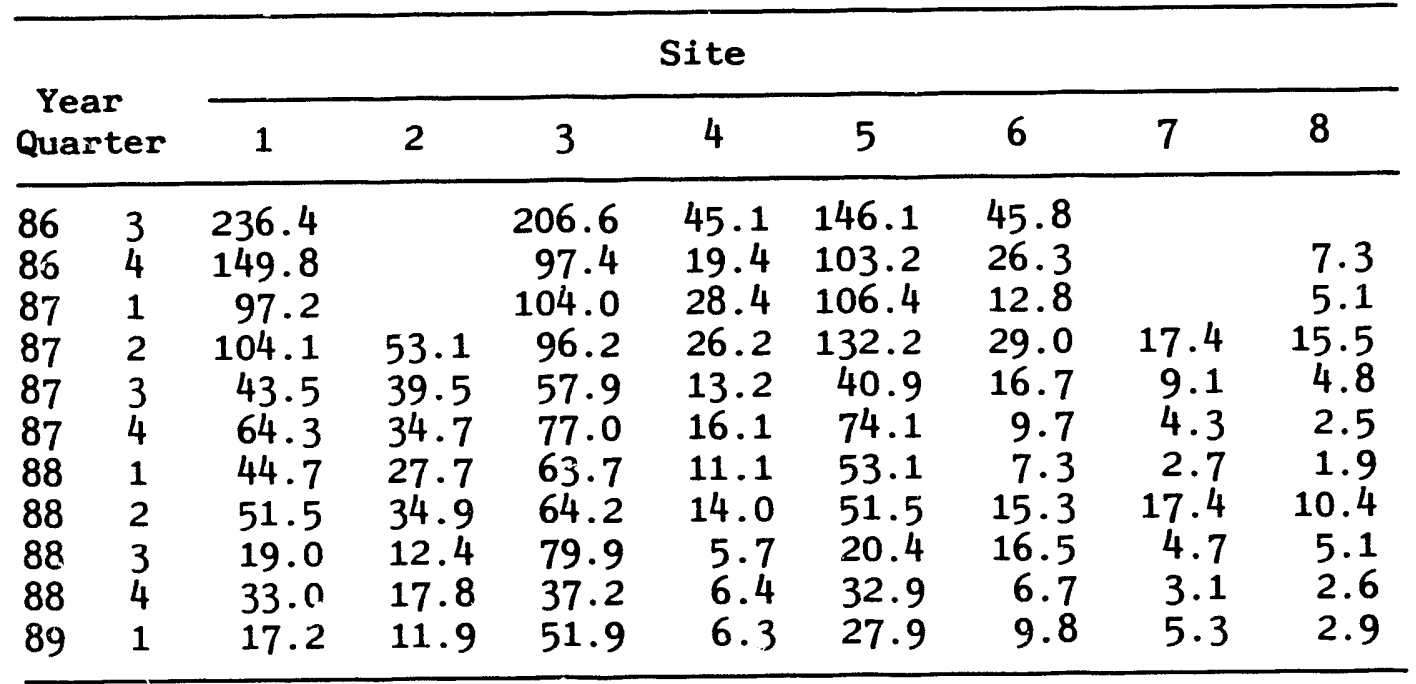

\begin{tabular}{|c|c|c|c|c|c|c|}
\hline \multirow{2}{*}{\multicolumn{2}{|c|}{$\begin{array}{c}\text { Year } \\
\text { Quarter }\end{array}$}} & \multicolumn{5}{|c|}{ Site } \\
\hline & & $\frac{9}{109.3}$ & $\begin{array}{c}10 \\
406.0 \\
271.6\end{array}$ & 11 & 12 & $\begin{array}{c}\text { Average } \\
170.8\end{array}$ \\
\hline $\begin{array}{l}86 \\
86 \\
87 \\
87 \\
87 \\
87 \\
88 \\
88 \\
88 \\
88 \\
89\end{array}$ & $\begin{array}{l}3 \\
4 \\
1 \\
2 \\
3 \\
4 \\
1 \\
2 \\
3 \\
4 \\
1\end{array}$ & $\begin{array}{r}109.3 \\
85.1 \\
77.9 \\
44.9 \\
29.7 \\
24.1 \\
28.6 \\
23.7 \\
29.0 \\
22.9 \\
25.9\end{array}$ & $\begin{array}{r}406.0 \\
271.6 \\
235.7 \\
243.7 \\
110.1 \\
126.9 \\
99.5 \\
128.0 \\
58.6 \\
103.3 \\
45.1\end{array}$ & $\begin{array}{l}5.1 \\
5.4 \\
2.2 \\
1.7 \\
9.5 \\
5.3 \\
2.2 \\
3.0\end{array}$ & $\begin{array}{r}19.0 \\
13.7 \\
6.4 \\
4.8 \\
13.5 \\
11.7 \\
7.7 \\
6.7\end{array}$ & $\begin{array}{r}170.8 \\
95.0 \\
83.4 \\
65.5 \\
32.0 \\
36.9 \\
28.9 \\
36.2 \\
22.4 \\
23.0 \\
17.8\end{array}$ \\
\hline
\end{tabular}

Table 6.1 Resuspension fictors $\left(x 10^{10}\right)$. 
Un sites where the deposition occured as dry deposition significantly higher resuspension factors have been measured than on sites where the dominating activity came down with rain. The measurements performed to determine the relaxation length gave corresponding results; namely that in wet deposition areas, the relaxation length is higher than in dry deposition areas. The deeper the activity is positioned in soil, the less available will it be for resuspension. The resuspension factor is almost exactly inversely proportional to the relaxation length. This information is quite useful, as the relaxation length is much more easily determined than the resuspension factor.

Due to the great seasonal variation in resuspension, a good and useful half-life to be used for resuspension is very difficult to obtain. The seasonal variation is much greater than the decline in resuspension with "aging". At present the best rough estimate is a half-life of about 0.9 years.

The seasonal variations with peaks in spring and autumn, can be explained by less vegetation binding the top soil during these periods. Higher windspeeds, especially at ground surface, is also a factor that will influence the resuspension factor positively during spring and autumn. At times with dry weather and high windspeeds much higher resuspension factors than average can be expected.

Using a simple exponential model the resuspension factor can be given by :

$$
\operatorname{Sf}=\operatorname{Sf}(0) \exp (\ln 2 \cdot t / T 1 / 2)
$$

where $\operatorname{Sf}(0)=2 \cdot 10^{-8}$ and $\mathrm{T} 1 / 2=0.9$ years. Comparing these results wit's models from literature, it is found that this resuspension factor is significantly lower, and has a slower decline.

The size distribution of resuspended activity, will influence how far a resuspended particle will travel before re-deposition. The inhalation doses will also be influenced by the size distribution. Some measurements were therefore performed in the Gävle area during 1988. The cascade impactor was not calibrated, but by comparing with $\mathrm{Be}-7$ it can be seen that $\mathrm{Cs}-134$ is present in the air as significantly larger particles than Be-7 (Figure 6.4). A rough estimate of the cut-off sizes during our sampling, indicates that about $50 \%$ of the activity of cesium nuclides are resuspended as particles greater than $2 \mu \mathrm{m}$. This means that during normal weather conditions resuspension of cesium will only influence the air activity concentration significantly up to some kilometers away.

The conclusion about resuspension in urban areas is, however, uncertain. Interim reporting from the project indicated that there was indeed higher resuspension in urban areas. The effect was perhaps less clear later on. The design of the experiment is such that larger particles ( $>$ ca. $10 \mu \mathrm{m}$ ) will not reach the air filters. The reason is that the air pumps are under roofs. It seems reasonable to expect that resuspended particles in urban areas are on the average larger than in rural areas. Accordingly this experiment, although appropriate for in- 
vestigating inhalation doses due to resuspension, is not well suited for determining total resuspension, particularly in urban areas.

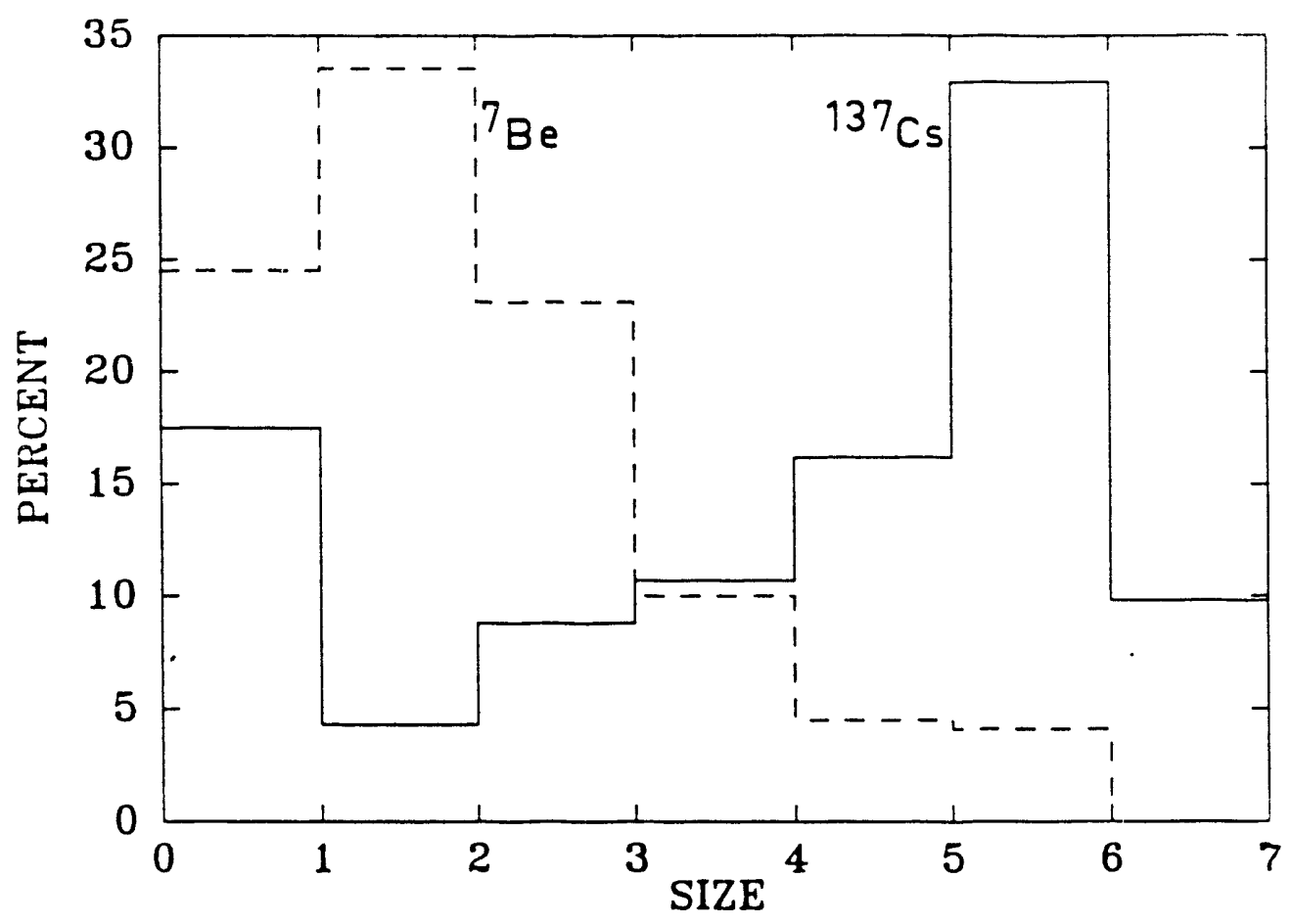

Figure 6.4 Size distribution of resuspended activity.

7 TRANSFER FROM SOIL TO PASTURE, PASTURE TO MILK AND TO MEAT

\subsection{CONCLUSIONS}

There are problems with the quantity called Concentration Ratio (CR), describing transfer via root uptake from soil to grass. The value used for cesium for this parameter is 0.01 (Bq/ $\mathrm{kg} \mathrm{plant}) /(\mathrm{Bq} / \mathrm{kg}$ soil). (In the course of discussions with Sandia, it was found that there has indeed been an error here. The value for $C R$ should have been 0.1 ). There are, however, additional difficulties with utilizing values found in literature for this quantity, since the information needed for applying it to field conditions is of ten missing. Older values of transfer factors from soil to grass were of ten determined from pot experiments, and in these pot experiments it is usually only the concentration of cesium in the soil in the pot that is given, and in some cases the amount of soil in the pots, but almost never the actual dimensions of the pots. The cesium was presumably homogenously distributed in the soil in the pots. For this reason it became customary to use the old units ( $\mathrm{Bq} / \mathbf{k g} \mathrm{plant}) /(\mathrm{Bq} / \mathrm{kg}$ soil). Field conditions, however, are quite different, and especially for unplowed pasture, where all cesium acti- 
vity will be in the upper few centimeters of soil. For that reason, it has become customary post-Chernobyl to describe the transfer using the units $(\mathrm{Bq} / \mathrm{kg} \mathrm{plant}) /\left(\mathrm{Bq} / \mathrm{m}^{2}\right.$ soil surface), and these are also the units in which post-Chernobyl observations generally are given.

The main difference between pot experiments and field conditions is the placement of the cesium relative to the root zone, and in the pot experiments where the pot dimensions are not given, the placement of the cesium relative to the root zone is not even known. Accordingly, measured transfer factors in pot experiments may not correctly represent conditions on actual pasture, and direct application of these transfer factors may give misleading results.

The CR-value used to describe root uptake from soil to grass in MACCS at present ( 0.1 in the corrected version), evidently refers back to such pot experiments. In MACCS this value is implicitly transferred, by assuming homogenous distribution of cesium in a $15 \mathrm{~cm}$ thick layer of soil, into 0.00042 ( $\mathrm{Bq} / \mathrm{kg} \mathrm{plant}) /\left(\mathrm{Bq} / \mathrm{m}^{2}\right.$ soil surface). The weight of the soil compartment has been set to $240 \mathrm{~kg} /\left(\mathrm{m}^{2}\right.$ soil surface). Comparing this value to the post-Chernobyl observations on mountain pasture in Norway, it turns out to be two orders of magnitude lower. The actual errors in predicted total doses via the soil-grass-milk and soil-grass-meat exposure pathways in MACCS will in most cases be relatively insignificant, because the doses via these exposure pathways will be dominated by first-year doses, when the dose from direct deposition upon the grass is dominant.

The Norwegian values for mountain pasture have been chosen for comparison because environmental sampling has been concentrated on these areas, where the potential problems are largest. Because of soil type, uptake to grass in these areas is quite high. Available data from the home farms in the valleys, where uptake is lower, are, however, also higher than the MACCS value.

Also other sources of information, like IAEA Safety Series No. 57 (where $0.1(\mathrm{~Bq} / \mathrm{kg}$ grass)/(Bq/kg soil) is given as default value for the concentration ratio $(\mathrm{CR})$ ) and $\mathrm{GRECA}^{\prime} \mathrm{s}$ parameter study (values as high as $0.1\left(\mathrm{~Bq} / \mathrm{kg}\right.$ grass $/\left(\mathrm{Bq} / \mathrm{m}^{2}\right)$ are given for 1986 , but a Swedish value of 0.004 from 1387 is probably more representative for root uptake), indicate that the CR-value previously used in MACCS was too low, and perhaps that even the revised value of 0.1 is somewhat low.

MACCS input data describing transfer from grass to milk and beef are in excellent agreement with observations.

Measurements of bioavailability show that the manner in which soil ingestion (the fact that the animals take in a certain amount of soil together with pasture) is treated in MACCS, will overpredict the amount of cesium that can be transferred to man via this exposure pathway. The cesium content in plant material and in soil are in MACCS treated the same way; given the same bioavailability, while the Norwegian post-Chernobyl measurements show that cesium in soil or the litter layer are hardly available for uptake to animals at all, while cesium incorporated in the plants by root uptake is almost $100 \%$ avail- 
able. The same argument applies to the direct-deposition-upon-plant exposure pathway. Cesium on the plant surfaces will be less bioavailable than cesium incorporated in the plant via root uptake (see chapter 7.3.4.3). In MACCS these two forms of cesium are at present given the same bioavailability.

\subsection{CONDITIONS UTILIZED IN MACCS}

Comparison between the post-Chernobyl measurements in this context and numerical values utilized in MACCS is not straightforeward, as MACCS input (as given in input data to the computer program) is time-integrated transfer rather than transfer factors. The underlying values are given in an informal note*.

There are two important aspects to the manner in which uptake via roots is calculated in MACCS:

- the concentration ratio via root uptake

- rate of decrease in cesium available for root uptake

The concentration ratio via root uptake is described by the following expression:

$$
\mathrm{CR}=\frac{\text { Radionuclide activity per unit mass of plant }(\mathrm{Bq} / \mathrm{kg})}{\text { Radionuclide activity per unit mass of soil }(\mathrm{Bq} / \mathrm{kg})}
$$

$\mathrm{CR}$ is a basic quantity, since it is usually the activity per unit mass plant that is measured, and of ten the activity per unit mass soil, though it is perhaps more of ten the activity in soil per unit area, like in the majority of post-Chernobyl measurements.

The following equation gives the root uptake fraction as function of the concentration ratio, plant areal mass over a year, and soil areal mass. The root uptake fraction is a quite artificial entity, that describes root uptake as if it is a process taking place at a uniform rate all through the year.

$$
\lambda_{\mathrm{RU}}=\mathrm{CR} \cdot \mathrm{CM} / \mathrm{SM}
$$

Meaning of the quantities above:

CR concentration ratio (dimensionless)

$\lambda_{\mathrm{RU}} \quad$ root uptake rate (per year)

Judy Rollstin: Terrestrial food pathway parameters. Informal report. Albuquerque, New Mexico. September 1988. 
SM is determined by the following two quantities:

DPT depth of soil compartment (m)

@

density of soil $\left(\mathrm{kg} / \mathrm{m}^{3}\right)$

The rate of decrease of cesium in the soil available for roct uptake is described in the following equation, taking radioactive decay, percolation out of the root zone, irreversible binding to soil and reduction due to root uptake into consideration:

$$
S C(t)=S C_{0} \exp \left(-\left(\lambda_{R}+\lambda_{L}+\lambda_{R U}\right) t\right)
$$

where

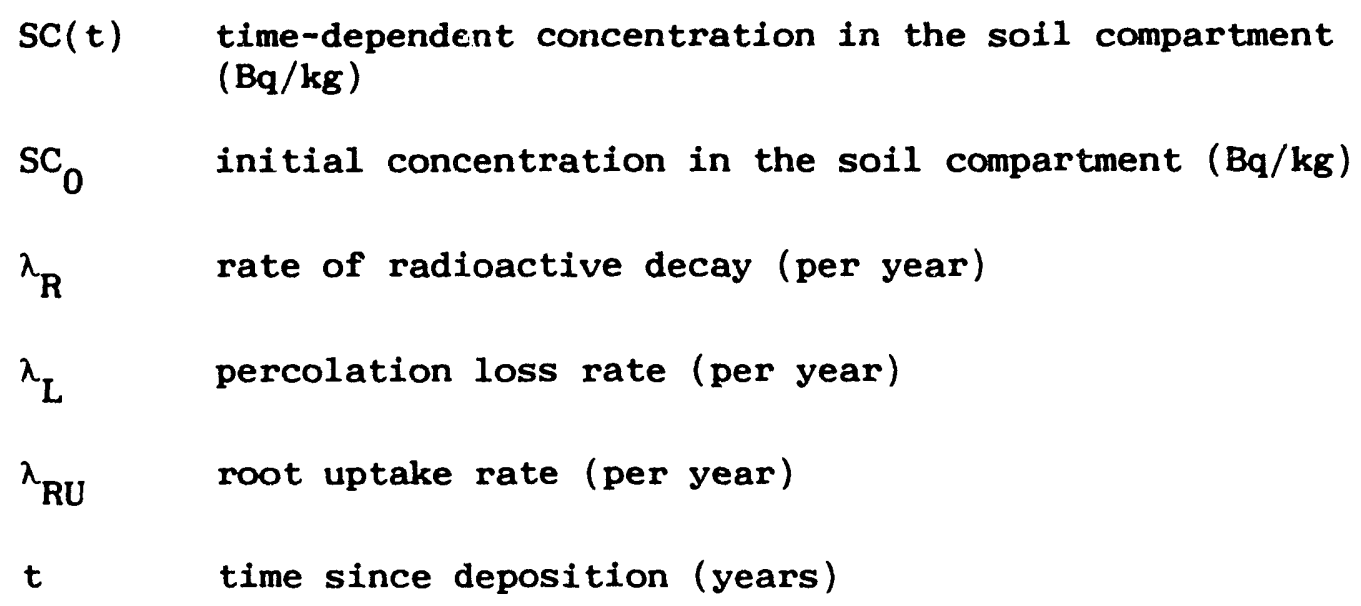

Numerícal valulues_from_informal_report

Relevant to the root uptake exposure pathway:

$$
\begin{array}{ccc}
\lambda_{R} & \lambda_{L} & \lambda_{R U} \\
\text { (per year) } & \text { (per year) } & \text { (per year) }
\end{array}
$$

$\begin{array}{llll}\text { Cs-134 } & 0.3362 & 0.2021 & 0.000074 \\ \text { Cs-137 } & 0.0230 & 0.2021 & 0.000074\end{array}$

$\mathrm{SM}=240 \mathrm{~kg} / \mathrm{m}^{2}$

$\mathrm{CR}($ cesium $)=0.01$

- Judy Rollstin: Terrestrial food pathway parameters. Informal report. Albuquerque, New Mexico. September 1988. 
CR (strontium) $=2.0$

$\mathrm{CM}=0.175 \mathrm{~kg} / \mathrm{m}^{2}$

\subsubsection{The concentration ratio}

There are doubts about the validity of the numerical values of the concentration ratios used in MACCS. This subchapter contains a trace of the bases for these values and related discussions.

(Ref. R088) gives Table 5.17 in (ref. TI83) as source of information for these values, and an abbreviated version of this table is given on the next page (the original table also contains values for a number of other elements, and for some special soil conditions concerning calcium and potassium content and $\mathrm{pH}$, as well as a soil referred to as Florida soil.) The values given below are what appear to be the default values. They are believed to be the basis for the values in MACCS, though they do not agree on all points. The table in (ref. TI83) contains a large number of references. By the way they are grouped, the pertinent references appear to be ROM 54 , ROM57, ROM60 and FRE58. The grouping may, however, be without deeper significance. If so, one will have to go back and examine the other references.

The MACCS values are given in paretheses in the table. They agree well, except for cesium and grass. It is difficult to imagine why, unless it is simply a mistake. The value 0.01 appears in the original Table 5.17 (in Table 5.17 it is the value for ruthenium and wheat), not far from the proper value.

References to the table on the next page:

ROM54 E.M. Romney, W.A. Rhoads, K. Larson: Plant uptake of Sr-90, Ru-106, Cs -137 and Ce-144 from three different types of soil. USAEC Rep. UCLA-294. 1954.

ROM57 E.M. Romney, J.W. Nee1, H. Nishita, J.H. Olafson and K. Larson: Plant uptake of Sr-90, Y-91, Ru-106, Cs-137 and Ce-144 from soils. Soil Science 83 (5), pp. 369-376. 1957.

ROM60 E.M. Romney, W.L. Ehler, A.H. Lange and K. Larson: Some experimental factors influencing radiostrontium uptake by plants. Plant and Soil, XII (1), pp. 41-48, 1960.

FRE58 Lars Fredriksson, Bengt Eriksson, Bertil Rasmuson, Bo Gahne, Kay Edvardson and Kerstin LOW: Studies on soil-plant-animal interrelationships with respect to fission products. Proceedings of the Second United Nations International Conference on the Peaceful Uses of Atomic Energy. Volume 18. pp. 449-470. 1958.

The first and second of the references above appear to report the same experiments. The second reference has been traced, and it reports examination of three types of soil, like stated in the title of the first 
reference. Moreover, the results given in the second reference are given on a form quite different from the data used in MACCS. It is concluded that MACCS data do not origin from these two references.

\begin{tabular}{|c|c|c|c|}
\hline & \multirow[b]{2}{*}{ Strontium-90 } & \multirow{2}{*}{ Cesium-137 } \\
\hline & & & \\
\hline \multirow[t]{2}{*}{ Forage } & $\begin{array}{l}\text { Legumes: } \\
\text { Alfalfa, } \\
\text { Clover, } \\
\text { Sorghum }\end{array}$ & $\frac{3.1}{(3.0) * 1}$ & $\begin{array}{l}0.093 \\
(0.2)^{1}\end{array}$ \\
\hline & Grasses & $\begin{array}{r}1.25 \\
(2.0)\end{array}$ & $\begin{array}{r}0.048 \\
(0.01)\end{array}$ \\
\hline \multirow{2}{*}{$\begin{array}{l}\text { Grains } \\
\text { (kernels) }\end{array}$} & $\begin{array}{l}\text { Wheat, } \\
\text { Oat, } \\
\text { Barley }\end{array}$ & $\begin{array}{c}0.22 \\
(0.2)^{2}\end{array}$ & $\begin{array}{c}0.019 \\
(0.02)^{2}\end{array}$ \\
\hline & $\begin{array}{l}\text { Corn, } \\
\text { Rice (dry) }\end{array}$ & 0.027 & 0.0078 \\
\hline Leafy & $\begin{array}{l}\text { Cabbage, } \\
\text { Lettuce, } \\
\text { Spinach }\end{array}$ & $\begin{array}{c}2.2 \\
(2.0)\end{array}$ & $\begin{array}{r}0.022 \\
(0.02)\end{array}$ \\
\hline \multirow{2}{*}{ Root } & $\begin{array}{l}\text { Radish, } \\
\text { Carrot, } \\
\text { Turnip, } \\
\text { Beet }\end{array}$ & 1.8 & 0.037 \\
\hline & $\begin{array}{l}\text { Potato, } \\
\text { Sweet } \\
\text { potato }\end{array}$ & $\begin{array}{c}0.47 \\
(0.5)^{3}\end{array}$ & $\begin{array}{c}0.032 \\
(0.03)^{3}\end{array}$ \\
\hline Legumes & $\begin{array}{l}\text { Bean, Pea } \\
\text { Soybean } \\
\text { (bean) }\end{array}$ & $\begin{array}{c}1.8 \\
(2.0)\end{array}$ & $\begin{array}{r}0.061 \\
(0.06)\end{array}$ \\
\hline Fruits & $\begin{array}{l}\text { Tomato, } \\
\text { Cucumber, } \\
\text { Apples } \\
\text { etc. }\end{array}$ & $\begin{array}{c}0.24 \\
(0.2)^{4}\end{array}$ & $\begin{array}{c}0.026 \\
(0.03)^{4}\end{array}$ \\
\hline
\end{tabular}

From table 5.17 in (ref. TI83). Some representative plant to soil concentration ratios (pCi/kg dry edible part) $/(\mathrm{pCi} / \mathrm{kg}$ dry soil).

\footnotetext{
* The numbers in parentheses are the values from (ref. R088).

1 This is "stored forage" in MACCS.

2 This is "grains" in MACCS.

3 This is "root vegetables" in MACCS.

4 This is "other foods" in MACCS.
} 
The third reference addresses strontium only. The last of the references is the probable source of MACCS data. This is a paper, from 1958, on some Swedish pot experiments. Although it is possible to derive concentration ratios from the information given in this paper, the experiments were actually not performed in order to determine concentration ratios, but to examine the effects of liming, potassium, strontium and cesium carriers upon uptake.

\subsubsection{Transfer from animal food products to man in MACCS}

The model is based entirely upon equilibrium conditions; that is, the daily intake is constant over a time period that is long compared to the biological half-life. The basic equation for content in milk is the following, which gives the fraction of the deposited radionuclide $i$ that is transferred to milk products:

$\operatorname{MT}_{i}\left(t_{d}\right)=M_{i} * \sum_{k=1}^{n} \operatorname{CFT}_{i k}\left(t_{d}\right) * f_{M k} * f_{k}$

The following is the expression for the crop transfer fraction in the above equation:

$C F T_{i k}\left(t_{d}\right)=\left(D T F_{i k}\left(t_{d}\right)+S T F_{i k}\right) * D F_{i k}$

The following is the equation for transfer to milk under equilibrium conditions :

$\mathbf{M}_{i}=\mathbf{f}_{\mathrm{Mi}}^{*} * \mathbf{M P}$

where

$\operatorname{MT}_{i}\left(t_{d}\right)$ fraction of radionuclide $i$ deposited to farmland at time $t_{d}$ in the year that is transferred to milk products

( $\mathrm{Bq}$ transf./Bq dep.)

$M_{i} \quad$ fraction of daily intake by a cow of radionuclide $i$ that is transferred to average daily amount of milk produced by the cow under equilibrium conditions (dimensionless)

$f_{M i}^{*} \quad$ equilibrium transfer coefficient for milk (Bq/1iter)/(Bq/day)

MP average daily production of milk per dairy animal (1iter)

$\mathrm{CFT}_{i k}\left(t_{d}\right) \quad$ crop transfer function for radionuclide $i$ deposited to crop $k$ at time $t_{d}$ during the year (includes both direct deposition and root uptake). Is (Bq transf.)/(Bq dep.) and corrected for consumption delay 


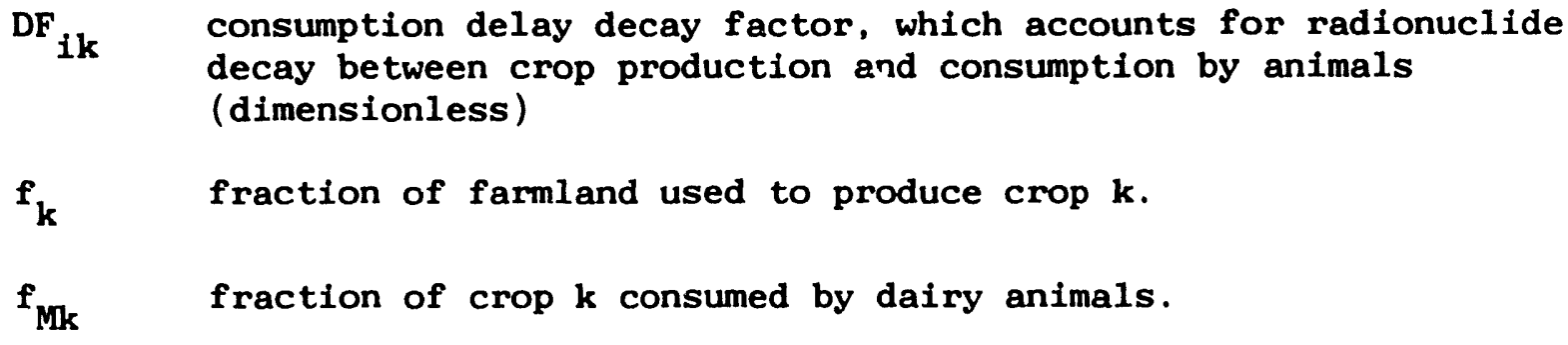

Very similar equations are used to calculate content in beef.

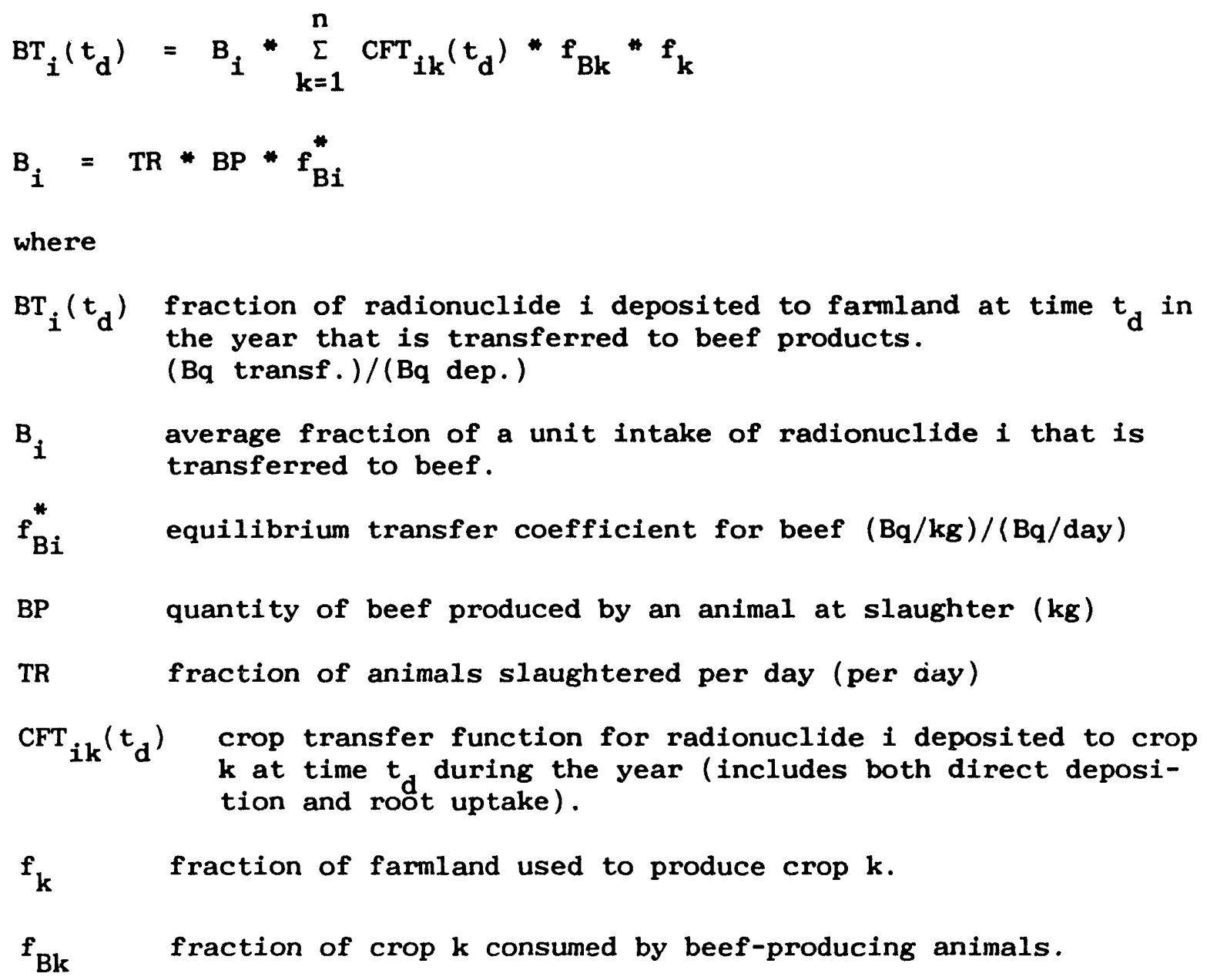


Numerical values of some quantities:

$\begin{array}{lcccc}\text { Isotope } & \mathbf{f}_{\mathbf{M i}}^{*} & \mathbf{f}_{\mathrm{Bi}}^{*} & \mathbf{M}_{\mathbf{i}} & \mathrm{B}_{\mathbf{i}} \\ \mathrm{Sr}-89 & 1.4 \mathrm{E}-3 & 3.0 \mathrm{E}-4 & 0.021 & - \\ \mathrm{Sr}-90 & \mathbf{1 . 4 E}-3 & 3.0 \mathrm{E}-4 & 0.021 & - \\ \mathrm{Cs}-134 & 7.1 \mathrm{E}-3 & 2.0 \mathrm{E}-2 & 0.11 & 0.005 \\ \mathrm{Cs}-137 & 7.1 \mathrm{E}-3 & 2.0 \mathrm{E}-2 & 0.11 & 0.005 \\ \mathrm{I}-131 & 9.9 \mathrm{E}-3 & 7.2 \mathrm{E}-3 & 0.12 & - \\ \mathrm{I}-133 & 9.9 \mathrm{E}-3 & 7.2 \mathrm{E}-3 & 0.059 & -\end{array}$

Radioactive decay losses within the animal are included in the iodine values.

$$
\begin{aligned}
& \mathrm{TR}=0.00085 \text { per day } \\
& \mathrm{BP}=280 \mathrm{~kg}
\end{aligned}
$$

From the modifications to the Users Guide:

$\begin{array}{lllll}\text { Isotope } & \text { DCYPMH } & \text { DCYPBH } & \text { TFMLK } & \text { TFBF } \\ & & & & \\ \text { Sr-89 } & 0.66 & 0.77 & 0.022 & 0.00022 \\ \text { Sr-90 } & 1.0 & 1.0 & 0.022 & 0.00022 \\ \text { Cs-134 } & 1.0 & 1.0 & 0.11 & 0.023 \\ \text { Cs-137 } & 1.0 & 1.0 & 0.11 & 0.024 \\ \text { I-131 } & 0.28 & 0.18 & 0.13 & 0.0024 \\ \text { I-133 } & 0.002 & 0.0 & 0.062 & 0.0011\end{array}$

DCYPMH and DCYPBH are said to be transfer factors describing the processing losses and radioactive decay which occur between the production and consumption of milk and meat products respectively. For meat and milk products, however, there are no processing losses in MACCS, and the factors above reflect only radioactive decay. They are not relevant in the present context.

TFMLK and TFBK are the quantities $M$ and $B$ in the previous chapter.

\subsubsection{Connection between MACCS parameter values and measured values}

Soil to grass

Post-Chernobyl it is usual to express the transfer from soil to plants as transfer coefficients expressed in ( $\mathrm{Bq} / \mathrm{kg} \mathrm{plant}) /\left(\mathrm{Bq} / \mathrm{m}^{2}\right)$. This is 
also done in chapter 7.3 . However, the concentration ratio expressed in ( $\mathrm{Bq} / \mathrm{kg}$ plant)/(Bq/ kg soil) (or $\mathrm{Cl}$ instead of $\mathrm{Bq}$ ) seems to have been in frequent use pre-Chernobyl, and also in MACCS. The reason may be that the concentration ratios pre-Chernobyl were of ten determined from pot experiments, where the amount of radioactivity added to and mixed with the soil in the pot is given, along with the amount of soil in the pot in $\mathrm{kg}$, but not the dimensions of the pot.

The areal mass of the soil compartment is needed in order to transform a concentration ratio into the correponding transfer coefficient, needed for comparison with post-Chernobyl measurements. The areal mass used in MACCS is given" as $240 \mathrm{~kg} / \mathrm{m}^{2}$. The density of soil is given in other MACCS-documentation as $1600 \mathrm{~kg} / \mathrm{m}^{3}$. so that the areal mass corresponds to a soil layer of $15 \mathrm{~cm}$, which may be a reasonable value for plowed pasture (although not for semi-natural pasture).

After the values for concentration ratios in MACCS have been transformed into the same units as post-Chernobyl measurements, they appear to be very low compared to the measured values, as discussed further in chapter 7.1 .

Grass to milk and beef

The transfer coefficients for milk and beef are the relevant parameters in this context. These are the parameters $f_{M i}^{*}$ and $f_{B i}^{*}$ which give the fraction of daily intake that is transferred to one 1 iter of milk or one $\mathrm{kg}$ of beef. All the equations used in MACCS, and quoted earlier in this chapter, are not really relevant in this context, since their purpose is to make calculation of a total population dose via these exposure pathways possible. The transfer coefficients are input to these equations.

The table in the above called "Numerical values of some quantities" contains values of the transfer coefficients, together with values of the derived quantities $M_{i}$ and $B_{i}$, which are the parameters actually used in the computations. In (ref. R088), where current MACCS input data are specified, the value of $B_{i}$ has been modified. The parameter $f_{B i}^{*}$, however, is unchanged. The reason for the modification of $B i$ is that the original value was for beef only, while human meat consumption is chicken, turkey and pork as well as beef. Accordingly, the transfer coefficients for cattle, upon which MACCS input data are based, are:

$$
f_{M i}^{*}=0.0071 \quad f_{B i}^{*}=0.020
$$

In chapter 7.3 these values will be compared to the measured values. 


\subsection{POST-CHERNOBYL MEASUREMENTS IN NORWAY}

7.3.1 The ratio between cesium levels in soil, grass, beef and milk in semi-natural pastures in Norway

Persons involved in this project:

Per Strand, A.M. Helle, Gerd Kjølás

National Institute of Radiation Hygiene

A preliminary version of this material was kindly made available for use in the GRECA survey in May 1988. Here is an extended version. The investigations will cortinue. The levels have not fallen markedly over these years.

The information is from an area called Valdres in Norway. Measurements have been performed in 1987, 1988 and 1989. Measurements have been performed both in summer and winter. The summer measurements are for semi-natural pastures, and are reported in this chapter. The winter measurements are concemed with plowed pastures, and are reported in the next chapter.

Each of the results presented refers to a specific farm (summer farm or chalet), so that the values for grass, soil, meat and milk can easily be coupled to give site-specific transfer factors. The summer farms are located in the mountain areas and are only used in the summer months.

Table 7.1 below contains the results of the measurements, averaged over a summer season. Table 7.2 contains transfer factors derived from the values in table 7.1 .

Table 7.3 is not quite relevant in the present context, but is included because it shows the interesting aspect, that the variation in the ratios between content in milk and in beef is considerably smaller than the variation in the ratios between content in milk and grass, respectively beef and grass. (Some few cases that may be atypical have been disregarded to arrive at this conclusion, for reasons given underneath the table). Said differently: If the transfer from grass to milk on a farm is high, the transfer on this farm is also high from grass to beef. There are two possible explanations for this effect:

- It may be more difficult to obtain representative grass samples than representative milk and beef samples; resulting in larger uncertainty in the grass values.

- The variation in the $\mathrm{milk} / \mathrm{grass}$ and beef/grass ratios may be caused by real differences in bioavailability of the cesium in grass from one farm to another. 
The variation in $\mathrm{mil} / \mathrm{k} / \mathrm{grass}$ and beef/grass ratios is quite large. Some of the extreme values may be invalid, because the collected grass samples may be unrepresentative. This can easily be the case, as it is difficult to determine correctly what species of grass the cattle graze, and how much of the plants they take. Untypical ratios may also appear if a significant portion of the plant intake of the cattle is other plants than grass.

There are extreme values at farms 20,21, 29 and 30 (high), and at farm 12 (low). (Farm 7 is not considered, since the values are suspect for other reasons.) At farms 20 and 21 only one ratio is available at each, so there is nothing to compare it to. At farms 29 and 30 the $\mathrm{milk} / \mathrm{grass}$ and beef/grass ratios are both high, and the grass/soil ratio is low. This may indicate that the measured content in grass is too low compared to the content in grass actually grazed by the cattle. At farm 12 both the milk/grass and beef/grass ratios are low, but the grass/soil ratio is only a little above the average, and accordingly does not support the argument that the measured content in grass could be too high.

Transfer from soil to grass

The transfer factor from soil to grass $(\mathrm{Bq} / \mathrm{kg}$ d.w. grass $) /\left(\mathrm{Bq} / \mathrm{m}^{2}\right)$ varies over less than one order of magnitude; from 0.012 to 0.093 . There are no clear differences between the years.

Transfer from grass to milk and beef

The transfer coefficients in the end of the previous chapter give the fraction of daily intake by the animal that is transferred to one liter of milk or one $\mathrm{kg}$ of beef, while the transfer factors in this chapter give the fraction of content in one $\mathrm{kg}$ of grass that is transferred to one liter of milk or one $\mathrm{kg}$ of beef. One or the other of these sets of quantities must accordingly be multiplied or divided by the amount of grass intake per day by the animal, in order to make them comparable. The simplest approach is to multiply the transfer coefficients in the previous chapter with the daily grass intake. which in Norway is $10-12 \mathrm{~kg}$ grass dry weight (11 kg/day is used in the following).

The following values, derived from MACCS input data, should be compared to the values in table 7.2:

- Ratio between content in milk and grass: $0.078(\mathrm{~Bq} / \mathrm{kg}) /(\mathrm{Bq} / \mathrm{kg})$

- Ratio between content in beef and grass: $0.22(\mathrm{~Bq} / \mathrm{kg}) /(\mathrm{Bq} / \mathrm{kg})$ 
The values used in MACCS lie about in the middle of the range covered by the measured values, which vary from 0.0037 to 0.78 for milk and from 0.026 to 0.66 for beef. These variations are much larger than for the soil to grass transfer factors. There is no clear difference between the years.

\begin{tabular}{|c|c|c|c|c|c|c|}
\hline $\begin{array}{l}\text { Farm } \\
\text { no. }\end{array}$ & $\begin{array}{c}\text { Grass } \\
(\mathbf{B q} / \mathbf{k g})\end{array}$ & $\begin{array}{c}1987 \\
\text { Milk } \\
\text { (Bq/kg) }\end{array}$ & $\begin{array}{c}\text { Beef } \\
(\mathrm{Bq} / \mathbf{k g})\end{array}$ & $\begin{array}{l}\text { Grass } \\
(\mathrm{Bq} / \mathbf{k g})\end{array}$ & $\begin{array}{c}19881 \\
\text { Milk } \\
(\mathrm{Bq} / \mathbf{k g})\end{array}$ & $\begin{array}{c}\text { Beef } \\
(\mathrm{Bq} / \mathbf{k g})\end{array}$ \\
\hline $\begin{array}{r}1 \\
2 \\
3 \\
4 \\
5 \\
6 \\
7 \\
8 \\
9 \\
10 \\
11 \\
12 \\
13 \\
14 \\
15 \\
16 \\
17 \\
18 \\
19 \\
20 \\
21 \\
22 \\
23 \\
24 \\
25 \\
26 \\
27 \\
28\end{array}$ & $\begin{array}{r}2192 \\
10046 \\
3.31 \\
1326 \\
4161\end{array}$ & $\begin{array}{l}149 \\
552 \\
662 * \\
441 \\
251\end{array}$ & $\begin{array}{r}340 \\
1792 \\
\\
622^{*}\end{array}$ & $\begin{array}{r}89 \\
798 \\
4780 \\
1060 \\
131 \\
221 \\
2980 \\
2540 \\
8380 \\
\\
2820 \\
2820 \\
1697\end{array}$ & $\begin{array}{r}12 \\
218 \\
388 \\
151 \\
18 \\
23 \\
133 \\
139 \\
529 \\
29 \\
171 \\
133 \\
268 \\
240 \\
429 \\
\\
441 \\
\\
178 \\
\\
58 \\
239 \\
197 \\
227 \\
565 \\
642\end{array}$ & $\begin{array}{r}372 \\
1005 \\
\\
51 \\
144 \\
133 \\
\\
82 \\
388 \\
67 \\
1091\end{array}$ \\
\hline
\end{tabular}

1 The 1988 data for milk and beef may include data from the month of August, when a significant portion of the cesium intake may be via mushrooms rather than grass.

- There is reason to doubt the validity of these values.

Table 7.1 Summer season. The numbers in the table are averages over the season. 


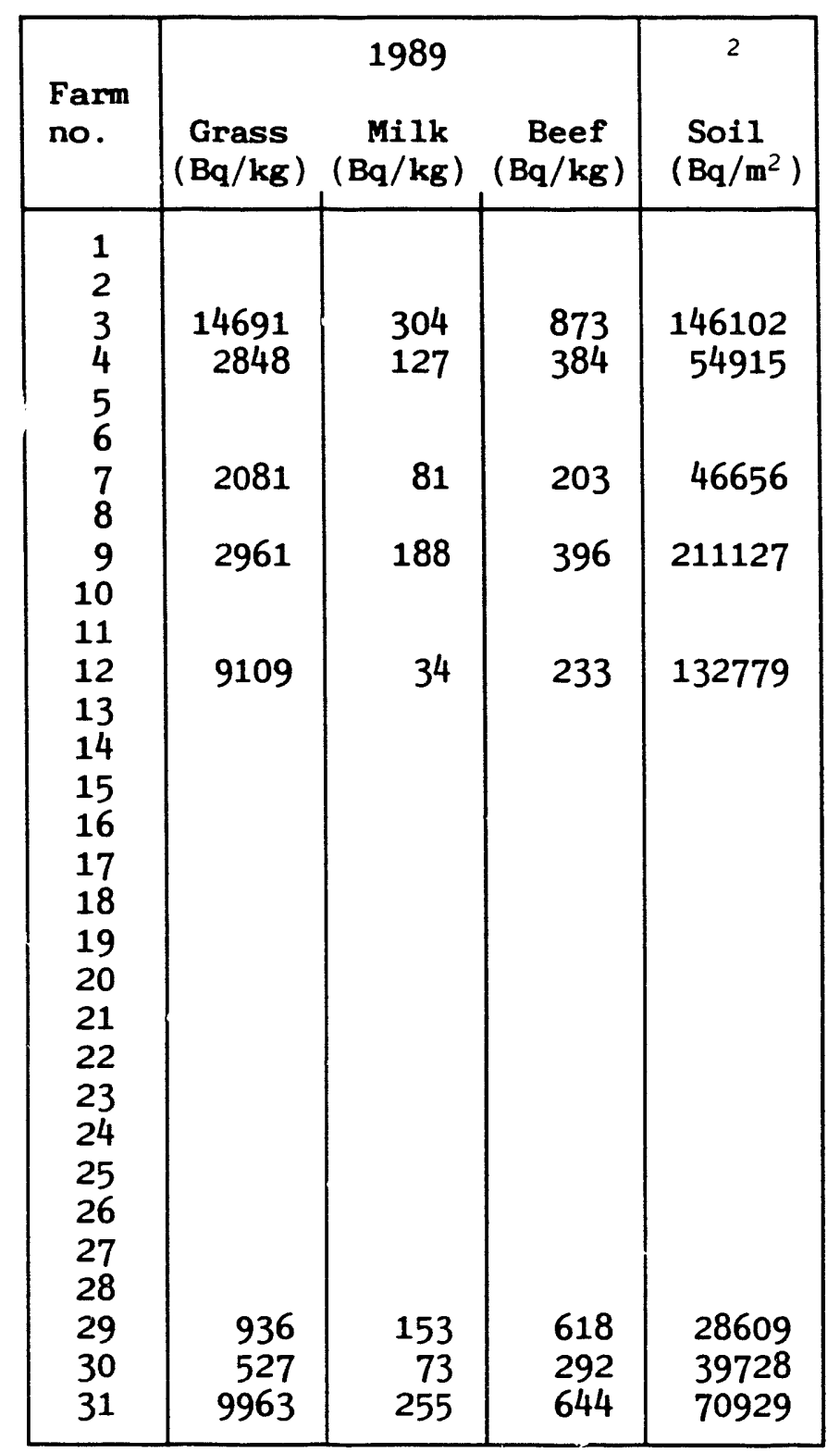

2 The soil values are corrected for decay back to 27 April 1986. Continuation of Table 7.1. 


\begin{tabular}{|c|c|c|c|c|c|c|}
\hline $\begin{array}{l}\text { Farm } \\
\text { no. }\end{array}$ & $\begin{array}{l}\frac{\text { Grass }^{2}}{\text { Soil }} \\
\frac{(\mathrm{Bq} / \mathbf{k g})}{\left(\mathrm{Bq} / \mathrm{m}^{2}\right)}\end{array}$ & $\begin{array}{r}1987 \\
\text { Milk } \\
\begin{array}{r}\text { Grass } \\
\frac{(\mathrm{Bq} /}{(\mathrm{Bq} /}\end{array}\end{array}$ & $\begin{array}{l}\frac{\text { Beef }}{\text { Grass }} \\
\frac{\mathrm{sg})}{\mathrm{kg})}\end{array}$ & $\begin{array}{l}\frac{\text { Grass }^{2}}{\text { Soil }} \\
\frac{(\mathrm{Bg} / \mathrm{kg})}{\left(\mathrm{Bq} / \mathrm{m}^{2}\right)}\end{array}$ & $\begin{array}{c}1988^{1} \\
\text { Milk } \\
\text { Grass } \\
\frac{(\mathrm{Bq} / 1}{(\mathrm{Bq} / 1}\end{array}$ & $\begin{array}{l}\frac{\text { Beef }}{\text { Grass }} \\
\frac{\mathrm{sg})}{\mathrm{sg})}\end{array}$ \\
\hline $\begin{array}{r}1 \\
2 \\
3 \\
4 \\
5 \\
6 \\
7 \\
8 \\
9 \\
10 \\
11 \\
12 \\
13 \\
14 \\
15 \\
16 \\
17 \\
18 \\
19 \\
20 \\
21 \\
22 \\
23 \\
24 \\
25 \\
26 \\
27 \\
28\end{array}$ & $\begin{array}{l}0.067 \\
0.028 \\
0.019\end{array}$ & $\begin{array}{l}0.068 \\
0.055 \\
0.50^{*} \\
0.106\end{array}$ & $\begin{array}{l}0.155 \\
0.178 \\
\\
0.47^{*}\end{array}$ & $\begin{array}{l}0.031 \\
0.018 \\
0.061 \\
0.038 \\
0.020\end{array}$ & $\begin{array}{l}0.135 \\
0.273 \\
0.081 \\
0.142 \\
0.137 \\
0.104 \\
0.045 \\
0.055 \\
0.063 \\
\\
0.095 \\
0.141 \\
\\
0.156 \\
0.78\end{array}$ & $\begin{array}{l}0.194 \\
0.23 \\
\\
0.146 \\
0.120\end{array}$ \\
\hline
\end{tabular}

1 The 1988 data for milk and beef may include data from the month of August, when a significant portion of the cesium intake may be via mushrooms rather than grass.

2 The soil values in Table 7.1 are corrected for decay back to 27 April 1986. When the transfer factors above are calculated, however, radioactive decay is taken into account to obtain the value for 31 July of the respective year.

* There is reason to doubt the validity of these values.

Table 7.2 Transfer factors (ratios grass/soil, milk/grass and beef/grass) summer season. The numbers in the table are averages over the season. 


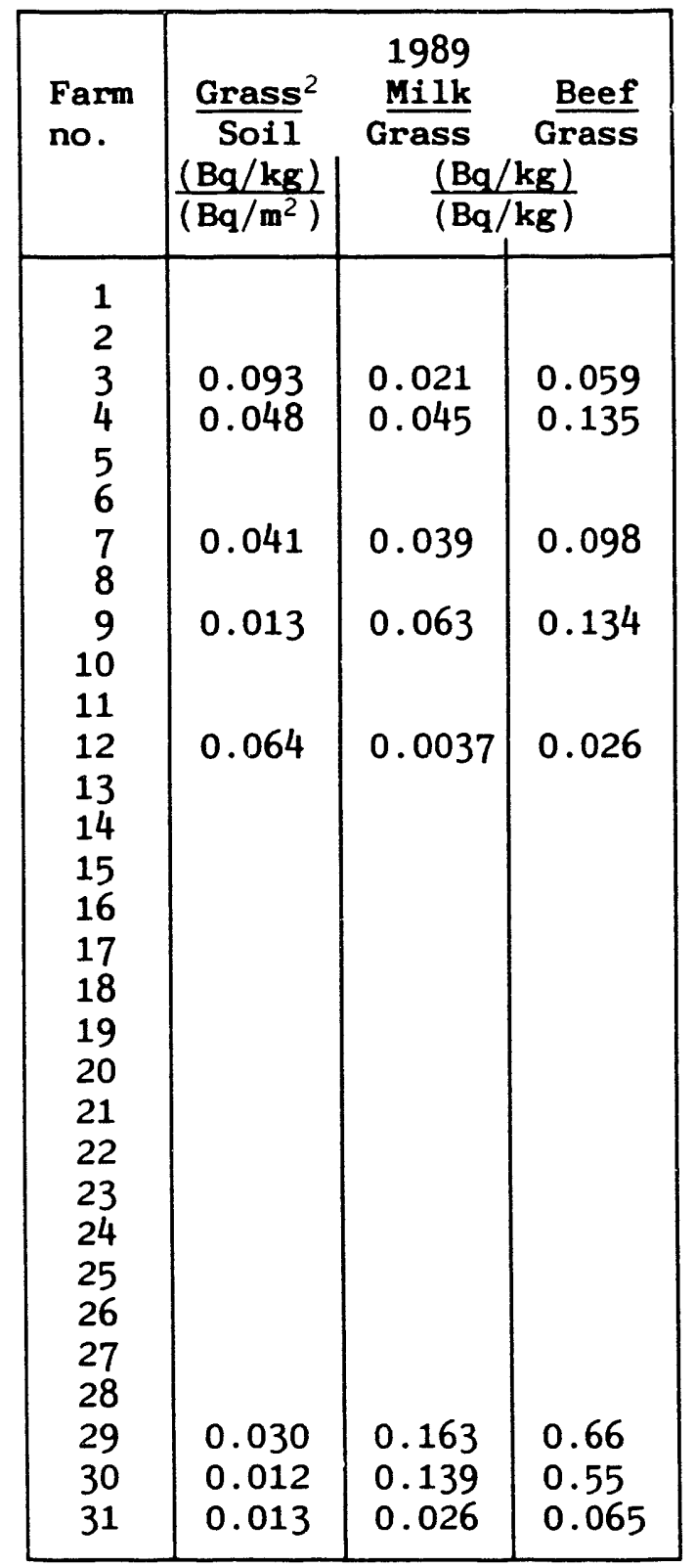

2 The soil values in Table 7.1 are corrected for decay back to 27 April 1986. When the transfer factors above are calculated, however, radioactive decay is taken into account to obtain the value for 31 July of the respective year.

Continuation of Table 7.2. 


\begin{tabular}{|c|c|c|c|}
\hline $\begin{array}{l}\text { Farm } \\
\text { no. }\end{array}$ & $\begin{array}{l}1987 \\
\frac{\text { Beef }}{\text { Milk }}\end{array}$ & $\begin{array}{l}1988 \\
\frac{\text { Beef }}{\text { Milk }}\end{array}$ & $\begin{array}{l}1989 \\
\frac{\text { Beef }}{\text { Milk }}\end{array}$ \\
\hline $\begin{array}{r}1 \\
2 \\
3 \\
4 \\
5 \\
6 \\
7 \\
8 \\
9 \\
10 \\
11 \\
12 \\
13 \\
14 \\
15 \\
16 \\
17 \\
18 \\
19 \\
20 \\
21 \\
22 \\
23 \\
24 \\
25 \\
26 \\
27 \\
28 \\
29 \\
30 \\
31\end{array}$ & $\begin{array}{l}2.2 \\
3.2 \\
0.94^{*}\end{array}$ & $\begin{array}{l} \\
2.7 \\
1.9 \\
0.3^{* *} \\
1.1 \\
0.5^{* *} \\
0.9 \\
2.5\end{array}$ & $\begin{array}{l}2.9 \\
3.0 \\
2.8 \\
2.1\end{array}$ \\
\hline
\end{tabular}

- There is reason to doubt the validity of this value.

* Only measurements quite early in the season are available at these farms. Milk rapidly builds up to equilibrium, while it takes longer for beef to reach equilibrium.

Table 7.3 Ratio of milk content to beef content. Summer season. 
7.3.2 The ratio between cesium levels in soil, grass, beef and milk in plowed pastures in Norway

Persons involved in this project:

Per Strand, A.M. Helle, Gerd Kjølás

National Institute of Radiation $\mathrm{H}$ 'rgiene

A preliminary version of this material was kindly made available for use in the GRECA survey in May 1988. Here is an extended version.

The information is from an area called Valdres in Norway.

Each of the results presented refers to a specific farm (home farm), so that the values for grass, soil, meat and milk can easily be coupled to give site-specific transfer factors. The home farms are located in the valleys. The grass fed to the cattle during winter is harvested on the home farm. The values are averages over the winter months (December to March).

Table 7.4 below contains the results of the measurements, averaged over a winter season. Table 7.5 contains transfer factors derived from the values in table 7.4 .

Table 7.6, like Table 7.3 for summer conditions (chapter 7.3 .1 ), shows that the variation in the ratios between content in milk and in beef is considerably smaller than the variation in the ratios between content in milk and grass, respectively beef and grass.

Discussion of the variation in ratios

See discussion underneath the table itself. The extreme values will be disregarded in the discussions.

Transfer from soil to grass

The transfer factor from soil to grass $(\mathrm{Bq} / \mathrm{kg}$ d.w. grass $) /\left(\mathrm{Bq} / \mathrm{m}^{2}\right)$ varies over almost two orders of magnitude; from 0.00098 to 0.028 . Overall the transfer factors for plowed pastures are significantly lower than for semi-natural pastures, but the average values differ only by less than a factor 5 .

Transfer from grass to milk and beef

The transfer coefficients in the end of chapter 7.2.2 give the fraction of daily intake by the animal that is transferred to one 1iter of milk or one $\mathrm{kg}$ of beef, while the transfer factors in this chapter give the fraction of content in one $\mathrm{kg}$ of grass that is transferred to 
one liter of milk or one $\mathrm{kg}$ of beef. One or the other of these sets of quantities must accordingly be multiplied or divided by the amount of grass intake per day by the animal, in order to make them comparable. The simplest approach is to multiply the transfer coefficients in chapter 7.2.2 with the daily intake of hay from the plowed pasture at the home farm as silage, which in Norway in winter is equivalent to 7 - $8 \mathrm{~kg}$ grass dry weight $(7.5 \mathrm{~kg} /$ day is used in the following).

The following values, derived from MACCS input data, are equivalent to the values in Table 7.5:

- Ratio between content in milk and grass: $0.053(\mathrm{~Bq} / \mathrm{kg}) /(\mathrm{Bq} / \mathrm{kg})$

- Ratio between content in beef and grass: $0.15(\mathrm{~Bq} / \mathrm{kg}) /(\mathrm{Bq} / \mathrm{kg})$

The value used in MACCS for milk lie about in the middle of the range covered by the measured values, which vary from 0.020 to 0.096 , while the value used in MACCS for beef lie in the upper range, but still well within the range, covered by the measured values, which vary from 0.042 to 0.32 . There is no clear difference between the years.

\begin{tabular}{|c|rrr|c|}
\hline $\begin{array}{l}\text { Farm } \\
\text { no. }\end{array}$ & \multicolumn{3}{|c|}{1987} & 1 \\
& $\begin{array}{c}\text { Grass } \\
(\mathrm{Bq} / \mathbf{k g})\end{array}$ & $\begin{array}{r}\text { Milk } \\
(\mathrm{Bq} / \mathbf{k g})\end{array}$ & $\begin{array}{c}\text { Beef } \\
(\mathrm{Bq} / \mathbf{k g})\end{array}$ & $\begin{array}{c}\text { Soi1 } \\
\left(\mathrm{Bq} / \mathrm{m}^{2}\right)\end{array}$ \\
\hline 1 & 139 & 17 & 44 & 59505 \\
2 & 288 & 6 & 23 & \\
4 & 474 & 16 & 62 & 22270 \\
5 & 244 & 5 & 25 & 18790 \\
6 & 150 & 14 & 19 & \\
7 & 259 & 15 & 47 & \\
8 & 177 & 17 & 145 & 66250 \\
9 & 57 & 19 & 67 & 77600 \\
20 & 381 & 12 & 16 & \\
25 & 345 & 19 & 109 & \\
32 & 82 & 5 & 58 & \\
\hline
\end{tabular}

1 The soil values are corrected for decay back to 27 April 1986.

Table 7.4 Winter season. The numbers in the table are averages over the season. 


\begin{tabular}{|c|c|c|c|}
\hline $\begin{array}{l}\text { Farm } \\
\text { no. }\end{array}$ & $\begin{array}{l}\frac{\text { Grass }^{1}}{\text { Soil }} \\
\frac{(\mathrm{Bq} / \mathbf{k g})}{\left(\mathrm{Bq} / \mathrm{m}^{2}\right)}\end{array}$ & $\begin{array}{c}1987 \\
\text { Milk } \\
\begin{array}{c}\text { Grass } \\
(\mathrm{Bq} /\end{array}\end{array}$ & $\begin{array}{l}\frac{\text { Beef }}{\text { Grass }} \\
\frac{\mathrm{kg})}{\mathrm{kg})}\end{array}$ \\
\hline $\begin{array}{r}1 \\
2 \\
4 \\
5 \\
6 \\
7 \\
8 \\
9 \\
20 \\
25 \\
32\end{array}$ & $\begin{array}{c}0.0031 \\
0.028 \\
0.017 \\
0.0035 \\
0.00098\end{array}$ & $\begin{array}{l}0.12^{*} \\
0.021 \\
0.034 \\
0.020 \\
0.093 \\
0.058 \\
0.096 \\
0.33^{*} \\
0.031 \\
0.055 \\
0.061\end{array}$ & $\begin{array}{l}0.32^{*} \\
0.080 \\
0.13 \\
0.10 \\
0.13 \\
0.18 \\
0.82^{*} \\
1.18^{*} \\
0.042 \\
0.32 \\
0.71^{*}\end{array}$ \\
\hline
\end{tabular}

1 The soil values in Table 7.4 are corrected for decay back to 27 April 1986. When the transfer factors above are calculated, however, radioactive decay is taken into account to obtain the va'.ue for the 28 February of the respective year.

- These values are obviously too high. The reason is simply that significant amounts of the activity from summer pasture is still present in these animals (biological half-life around 30 days in beef). In milk the activity from summer pasture falls off much more rapidly, and is only noticeable on two farms. The abnormal ratios are at the farms where the activity levels in home pasture are particularly low.

Table 7.5 Transfer factors (ratios grass/soil, milk/grass and beef/grass), winter season. The numbers in the table are averages over the season.

\begin{tabular}{|c|c|}
\hline $\begin{array}{l}\text { Farm } \\
\text { no. }\end{array}$ & $\begin{array}{c}1987 \\
\text { Beef }\end{array}$ \\
\hline Milk \\
\hline 1 & 2.6 \\
2 & 3.8 \\
4 & 3.8 \\
5 & 5.0 \\
6 & 1.4 \\
\hline
\end{tabular}

\begin{tabular}{|c|c|}
\hline $\begin{array}{l}\text { Farm } \\
\text { no. }\end{array}$ & $\begin{array}{c}1987 \\
\text { Beef }\end{array}$ \\
\hline $\begin{array}{c}\text { Milk } \\
7\end{array}$ & 3.1 \\
8 & 8.5 \\
9 & 3.6 \\
20 & 1.4 \\
25 & 5.8 \\
32 & 11.6 \\
\hline
\end{tabular}

Table 7.6 Ratio of milk content to beef content, winter season. 


\subsubsection{Semi-natural vs plowed pastures. Soil type. Fertilizer}

An additional set of measurements has been performed by:

Per Strand, National Institute for Radiation Hygiene

Lars Haugen, Agricultural University of Norway

This work is not yet published.

About 370 samples have been collected from 11 different counties. Of these were 35 from semi-natural pastures, the rest from plowed pasture. They have been sorted according to type of pasture, then according to type of soil, and finally according to whether or not fertilizer has been used on the field. The results, in the form of transfer coefficients ((Bq/ kg d.w. grass)/( $\mathrm{Bq} / \mathrm{m}^{2}$ deposited activity on ground)) are given in the following tables, where the spread of the results are indicated by the standard deviations given.

From the tables it is clear that the standard deviation is very large, and for this reason it is easy to argue against any conclusions drawn from the results. The large variation in these measurements is a fact. But it must not be regarded merely as "uncertainty" in the results. There are physical realities hidden behind these variations; realities that are partly understood at the moment, and that will be better understood in the future. Part of the spread among the measurements is connected to uncertainties in the sampling procedures, and a very small part due to uncertainties in the measurements of raaioactivity. Most of the spread, however, reflects real differences in the conditions in the different sampling positions. Conditions like the ones high-lighted in Tables 7.7, 7.8 and 7.9; some of them understood and explained, and others less well understood.

\begin{tabular}{|c|l|c|c|c|}
\hline $\begin{array}{c}\text { Sample } \\
\text { type }\end{array}$ & $\begin{array}{c}\text { Fertilized } \\
\text { or not }\end{array}$ & $\begin{array}{c}\text { Number } \\
\text { of } \\
\text { samples }\end{array}$ & $\begin{array}{c}\text { Transfer } \\
\text { factor } \\
\frac{(\mathrm{Bg} / \mathrm{kg})}{\left(\mathrm{Bq} / \mathrm{m}^{2}\right)}\end{array}$ & $\begin{array}{l}\text { Standard } \\
\text { deviation }\end{array}$ \\
\hline All samples & $\begin{array}{l}\text { Not fertil. } \\
\text { Fertilized }\end{array}$ & $\begin{array}{r}37 \\
224\end{array}$ & $\begin{array}{l}0.220 \\
0.060\end{array}$ & $\begin{array}{l} \pm 0.0551 \\
\pm 0.202\end{array}$ \\
\hline Plowed & Not fertil. & 16 & 0.286 & \pm 0.0801 \\
pasture & Fertilized & 213 & 0.062 & \pm 0.207 \\
\hline
\end{tabular}

Table 7.7 Correlation between transfer factor from soil to grass and use of fertilizer. 


\begin{tabular}{|c|c|c|c|c|}
\hline $\begin{array}{c}\text { Sample } \\
\text { type }\end{array}$ & $\begin{array}{c}\text { Soil } \\
\text { type }\end{array}$ & $\begin{array}{c}\text { Number } \\
\text { of } \\
\text { samples }\end{array}$ & $\begin{array}{c}\text { Transfer } \\
\text { factor } \\
(\mathrm{Bg} / \mathrm{kg})\end{array}$ & $\begin{array}{c}\text { Standard } \\
\text { deviation }\end{array}$ \\
\hline Al1 samples & Mineral & 149 & 0.031 & \pm 0.058 \\
& Min.+Org. mix & 63 & 0.088 & \pm 0.088 \\
& Organic & 53 & 0.216 & \pm 0.518 \\
\hline Plowed & Mineral & 135 & 0.026 & \pm 0.037 \\
pasture & Min.+Org. mix & 53 & 0.081 & \pm 0.299 \\
& Organic & 48 & 0.211 & \pm 0.535 \\
\hline Semi-natural & Mineral & 10 & 0.101 & \pm 0.174 \\
pasture & Min.+Org. mix & 5 & 0.246 & \pm 0.261 \\
& Organic & 5 & 0.266 & \pm 0.344 \\
\hline Plowed past. & Mineral & 126 & 0.023 & \pm 0.029 \\
Fertilized & Min.+Org. mix & 50 & 0.084 & \pm 0.308 \\
& Organic & 43 & 0.144 & \pm 0.303 \\
\hline
\end{tabular}

Table 7.8 Correlation between transfer factor from soil to grass and soil type.

\begin{tabular}{|c|c|c|c|c|}
\hline $\begin{array}{c}\text { Sample } \\
\text { type }\end{array}$ & $\begin{array}{c}\text { Type of } \\
\text { pasture }\end{array}$ & $\begin{array}{c}\text { Number } \\
\text { of } \\
\text { samples }\end{array}$ & $\begin{array}{c}\text { Transfer } \\
\text { factor } \\
\frac{(\mathrm{Bg} / \mathrm{kg})}{\left(\mathrm{Bq} / \mathrm{m}^{2}\right)}\end{array}$ & $\begin{array}{c}\text { Standard } \\
\text { deviation }\end{array}$ \\
\hline All samples & Seminatural & 20 & 0.178 & \pm 0.245 \\
Plowed & 236 & 0.076 & \pm 0.288 \\
\hline
\end{tabular}

Table 7.9 Correlation between transfer factor from soil to grass and type of pasture.

\subsubsection{Measurements of bioavailability}

\subsubsection{Measurements of increase in bioavailability from 1986}

At the Agricultural University of Norway animal experiments on bioavailability have been performed. Although this work is not yet published, the conclusions have been made available for the present re- 
port. In this project it has been found, in short, that the bioavailability of cesium in grass has increased over the years from 1986. This effect is explained by the difference in proportion between the fraction of cesium that is present in the form of external contamination on plant surfaces and the fraction that is incorporated in the plants via root uptake. This is the same effect observed in the experiments on sequential extraction and "in vivo" and "in vitro" experiments described in the following subchapters, but the experiments referred to in this subchapter are actual animal experiments under controlled conditions.

\subsubsection{Sequential extraction for measuring bioavailability}

Persons involved in this project:

G. Riise, H.E. Bjørnstad, H.N. Lien and B. Salbu

Agricultural University of Norway

D. Oughton, University of Manchester, United Kingdom

After the Chernobyl fall-out, it was found in Norway that transfer coefficients from vegetation to soil showed large variations. The reason for these variations are probably connected to differences in the physico-chemical forms of the radionuclides concerned. It is possible to obtain information on the binding mechanisms of radionuclides, i.e. primary ad/ab-sorption processes, from desorption experiments. A certain procedure for sequential extraction has been used in order to identify how much of the radiocesium is easily available for uptake, how much is associated with the organic fraction of the soil, and how much is unavailable for biological uptake.

Displacement processes, i.e. reversible processes without binding rupture can be distinguished by the use of

1) inert electrolytes, e.g. $\mathrm{NH}_{4} \mathrm{Ac}$

Dissolution processes, i.e. the change of the physico-chemical forms of sorbed species, can be distinguished by the use of:

2) slightly reducing agents, i.e. $\mathrm{NH}_{2} \mathrm{OH}$ in $\mathrm{HAC}$

3) oxidizing agents, e.g. $\mathrm{H}_{2} \mathrm{O}_{2}$ in dilute $\mathrm{HNO}_{3}$

4 ) strong acidic oxidizing agents, e.g. $7 \mathrm{M} \mathrm{HNO}_{3}$

5) chelating or complexing agents, and

6) micro-organisms

Sequential extraction experiments

In the project the association of radioactive $\mathrm{Cs}$-nuclides and Sr-90 with components in soil has been investigated. Soil cores, including litter, with a diameter of $10 \mathrm{~cm}$ were collected at different sites in Central Norway. The soil samples (including litter) were subjected to a sequential extraction procedure. 
The collected soil samples were sectioned in $2 \mathrm{~cm}$ layers, dried at $60^{\circ} \mathrm{C}$ and homogenized prior to gamma-spectrometry. Dry weight was determined at $105^{\circ} \mathrm{C}$ and loss of ignition (a procedure to determine the organic content of the sample) at $450^{\circ} \mathrm{C}$.

Dried, homogenized samples were weighed (ca $2 \mathrm{~g}$ ), and sequentially extracted with the reagents 1 to 4 in the scheme above. The extractants were separated from the solids by centrifugation (10 $000 \mathrm{rpm}$ ), and the residue was then washed with Milli-Q-water and centrifuged. Soil samples, liquids and solid fractions were subjected to gamma spectrometry (Cs-137 and Cs-134) or liquid scintillation counting (Sr-90), while stable cesium content was determined by instrumental neutron activation analysis.

The following extraction procedure was utilized:

F1 - Exchangeable fraction

$20 \mathrm{ml}$ of $1 \mathrm{M} \mathrm{NH}_{4} \mathrm{Ac}(\mathrm{pH} 7)$ was added to the soil (ca $2 \mathrm{~g}$ ). The suspension was shaken for two hours prior to separation.

F2 - S1ightly reducible fraction

$20 \mathrm{ml} \mathrm{NH} \mathrm{NH}_{2} \mathrm{OH} 25 \%(\mathrm{v} / \mathrm{v}) \mathrm{HAc}$ was added to the residue. The suspension was shaken for six hours at $80^{\circ} \mathrm{C}$ prior to separation.

F3 - Oxidized fraction

$20 \mathrm{ml}$ of $30 \% \mathrm{H}_{2} \mathrm{O}_{2}$ and $\mathrm{HNO}_{3}$ was added to residue. The suspension was shaken for six hours at $80^{\circ} \mathrm{C}$ prior to separation.

F4 - Acidic oxidized fraction

$20 \mathrm{ml}$ of $7 \mathrm{M} \mathrm{HNO}$ was added to residue. The suspension was shaken for six hours at $80^{\circ} \mathrm{C}$ prior to separation.

F5 - Residue

Contains the remaining activity $(F 5=$ total activity $-(F 1+F 2+$ F3 + F4)).

Results from the extraction experiments

Figures 7.1 and 7.2 illustrate the enrichment of Cs-137 and Cs-134 in the upper $2 \mathrm{~cm}$ layer of the soil (including litter), indicating that migration into deeper layers has been rather slow.

Table 7.10 is included, even though it is not relevant to bioavailability. The vertical distribution of cesium in soil, as well as the ratio between the two cesium-nuclides has been determined as part of this research program, and the results are summarized in this table.

In Table 7.11 are summarized some results from the sequential extraction experiments. There are large variations in the content of radiocesium between the different fractions. Fraction F1 represents Cs -137 and $\mathrm{Cs}-134$ in simple ionic form, easily exchangable with competing ions. This fraction is important in connection with root uptake to 
Peat Soil Hoysjoen, 1988

sumple no.1

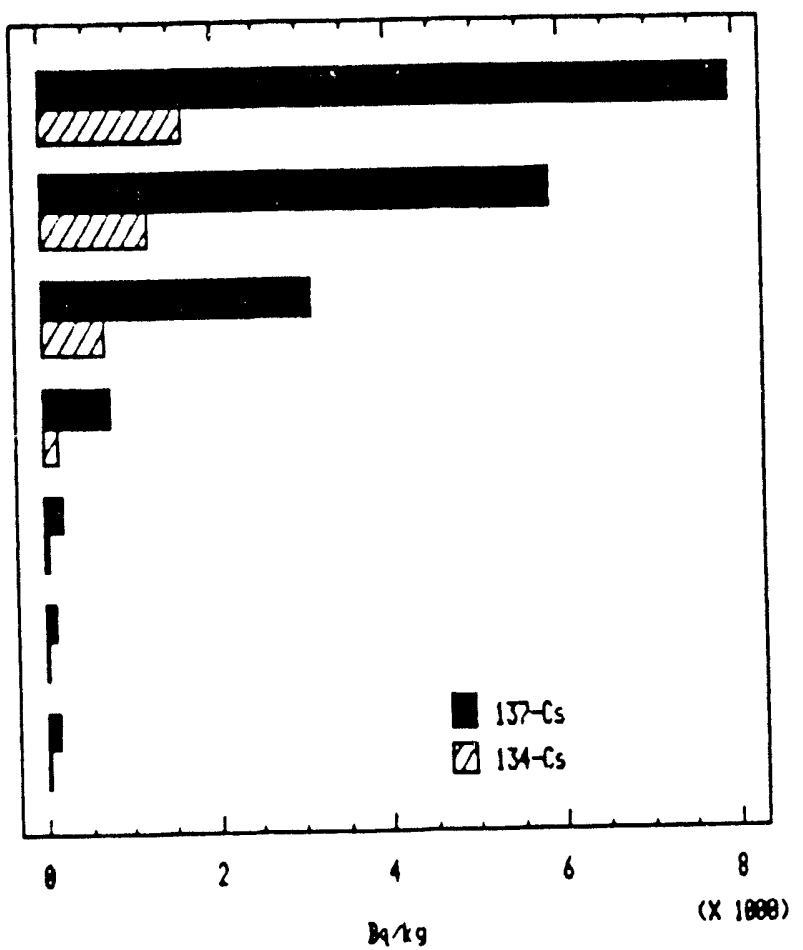

Pert Soil Hoysjoen, 1988

Sarple no.2

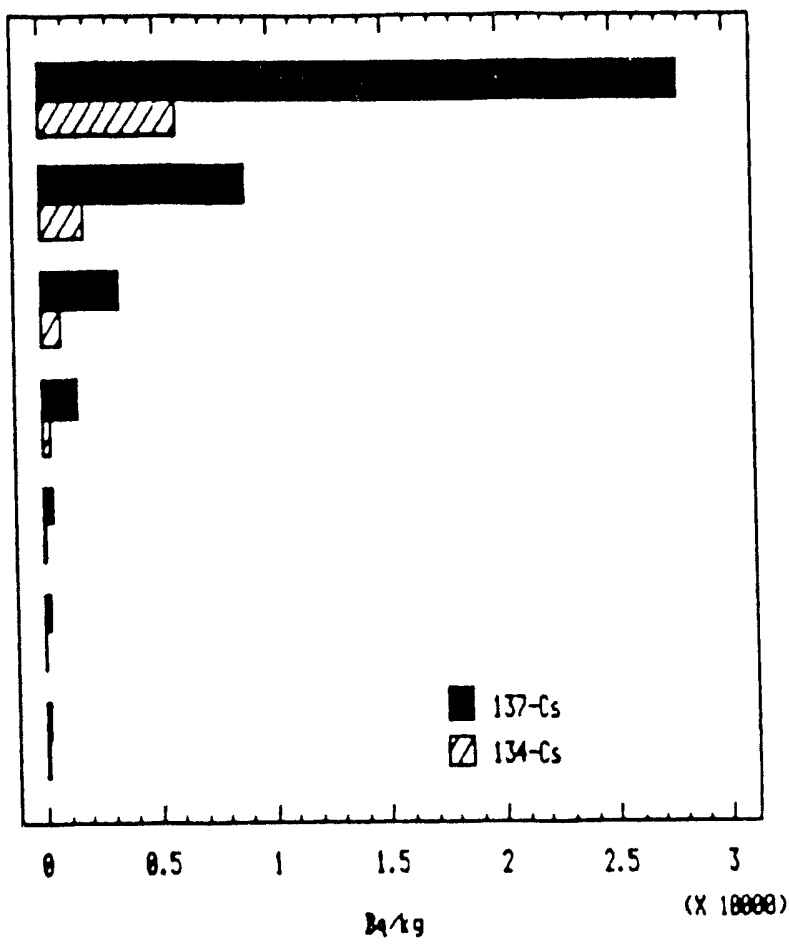

Figure 7.1 Vertical distribution of radioactive cesium nuclides $(\mathrm{Bq} / \mathrm{kg})$ in peat soil, Central Norway, September 1988.

Mirera! Soll Hojesjoen, 1988

suple no.l

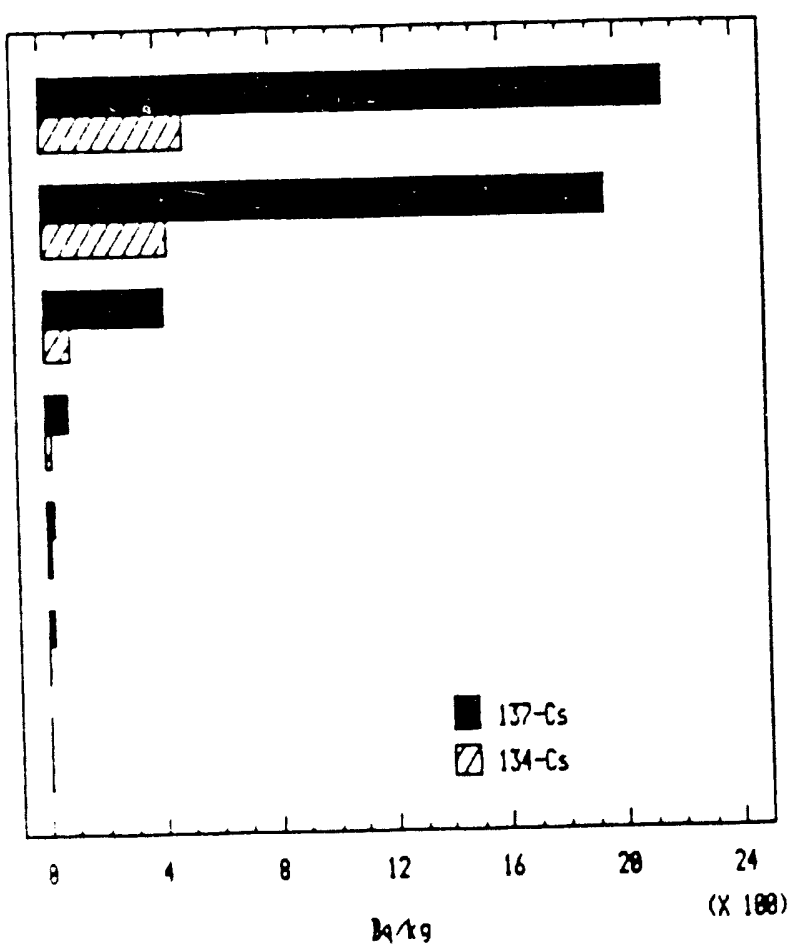

Mineral Soil thasjoen, 1988

sam le no.2

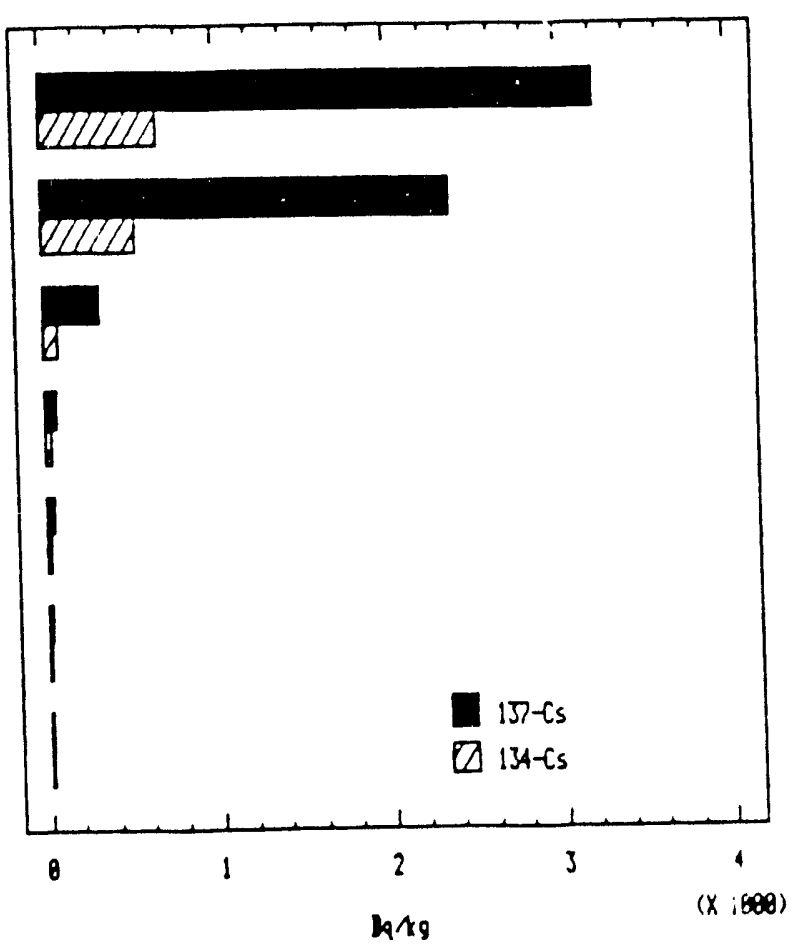

Figure 7.2 Vertical distribution of radioactive cesium nuclides (Bq/kg) in mineral soil, Central Norway, September 1988. 
plants. In fraction $\mathrm{F} 2$ is used a reagent that is effective dissolving the amorphous phases of $\mathrm{Mn}$ and $\mathrm{Fe}$ oxidues/hydroxides and associated microcomponents. Fraction F3 represents primarily oxidized organic material; while in fraction $\mathrm{F} 4$ mineral phases are stripped to a certain extent in $7 \mathrm{M} \mathrm{HNO}_{3}$. It should be stressed that the fractions obtained are operationally defined. However, the reproducibility is remarkably good.

\begin{tabular}{lcccc}
\hline $\begin{array}{l}\text { Sample } \\
\text { (site) }\end{array}$ & Year & $\begin{array}{c}\text { Whole soil } \\
\text { (Bq/kg Cs-134+Cs-137) }\end{array}$ & $\begin{array}{c}\% \text { in } \\
0-2 \mathrm{~cm}\end{array}$ & $\begin{array}{c}\text { Cs-134/Cs-137 } \\
\text { (ratio) }\end{array}$ \\
\hline Heimdalen & 1987 & 37700 & 97.9 & 0.68 \\
Heimdalen & 1989 & 38400 & ND 1 & 0.66 \\
Vestre Slidre & 1987 & 31800 & ND & 0.49 \\
Vestre Slidre & 1988 & 265000 & ND & 0.53 \\
Kjølastøl & 1987 & 16300 & 95.7 & 0.64 \\
Beitostølen & 1987 & 12800 & 86.7 & 0.47 \\
Vinstern & 1987 & 34200 & 93.9 & 0.45 \\
\hline
\end{tabular}

Table 7.10 Vertical distribution in soil, and ratio Cs-134/Cs-137.

\begin{tabular}{|c|c|c|c|c|c|c|}
\hline $\begin{array}{l}\text { Sample } \\
\text { (site) }\end{array}$ & Year & F1 & $\begin{array}{c}\text { tions } \\
\text { F2 }\end{array}$ & $\begin{array}{c}(\mathrm{Bq} / \mathrm{kg} \mathrm{Cs} \\
\mathrm{F} 3\end{array}$ & $\begin{array}{c}34+C s-137) \\
\text { F4 }\end{array}$ & F5 \\
\hline Heimdalen & 1987 & 1200 & 600 & 4800 & 21000 & 10100 \\
\hline Heimdalen & 1989 & 4700 & 2600 & 4800 & 20200 & 15000 \\
\hline Vestre Slidre & 1987 & 1500 & 800 & 2800 & 15600 & 7600 \\
\hline Vestre Slidre & 1988 & 4800 & 3800 & 7800 & 129000 & 119000 \\
\hline Kjølast $\varnothing 1$ & 1987 & 1800 & 800 & 700 & 6100 & 6900 \\
\hline Beitostolen & 1987 & 600 & 400 & 700 & 8600 & 2500 \\
\hline Vinstern & 1987 & 1100 & 800 & 4300 & 19200 & 8800 \\
\hline
\end{tabular}

$1 \mathrm{ND}=$ Not Determined

Table 7.11 Radioactive cesium in different fractions of sequential extraction of soil samples.

It is found that, for all samples investigated, radiocesium is strongly associated with components in the soil (fractions F3, F4 and F5), and particularly mineral matter, and less than $10 \%$ is readily mobile (fractions F1 and F2). Accordingly, one should expect a rather low transfer factor from soil to vegetation.

In Figure 7.3 the results of the neutron activation measurements are shown. The figure gives the ratio between Cs-137 and Cs-133 (stable cesium), and this ratio is remarkably constant for all fractions. This indicates that, to a large extent, isotopic exchange with naturally occurring stable cesium appears to have taken place during the three year period since deposition took place. In fraction F4 the Cs-137 
content seems to be somewhat higher relative to stable cesium than for the other fractions. From Table 7.11 it is seen that, for most of the soil samples, fraction F4 (strong acidic oxidizing agent) is effective in desorbing the radiocesium. As the diffusion through double layers into mineral lattices is a slow process, the Cs-fixation may not yet have reached equilibrium, as indicated by this fraction.

For some of the samples, association of radiocesium with oxidisable material present in the soil, indicated by fraction F3, is significant.

Figure 7.4 summarizes the results concerning Sr-90. The easily mobile fractions (F1 and F2) are significantly higher than the strongly bound fractions (F3, F4 and F5). Compared to radiocesium, a substantially higher fraction of $\mathrm{Sr}-90$ is mobile and available for plant uptake.

The present experiments indicate that the main part of the deposited radiocesium can be represented as a relatively inert pool or reser-

$157-$ - Cs and Stable Caesium in

Heimalen Litter 1989

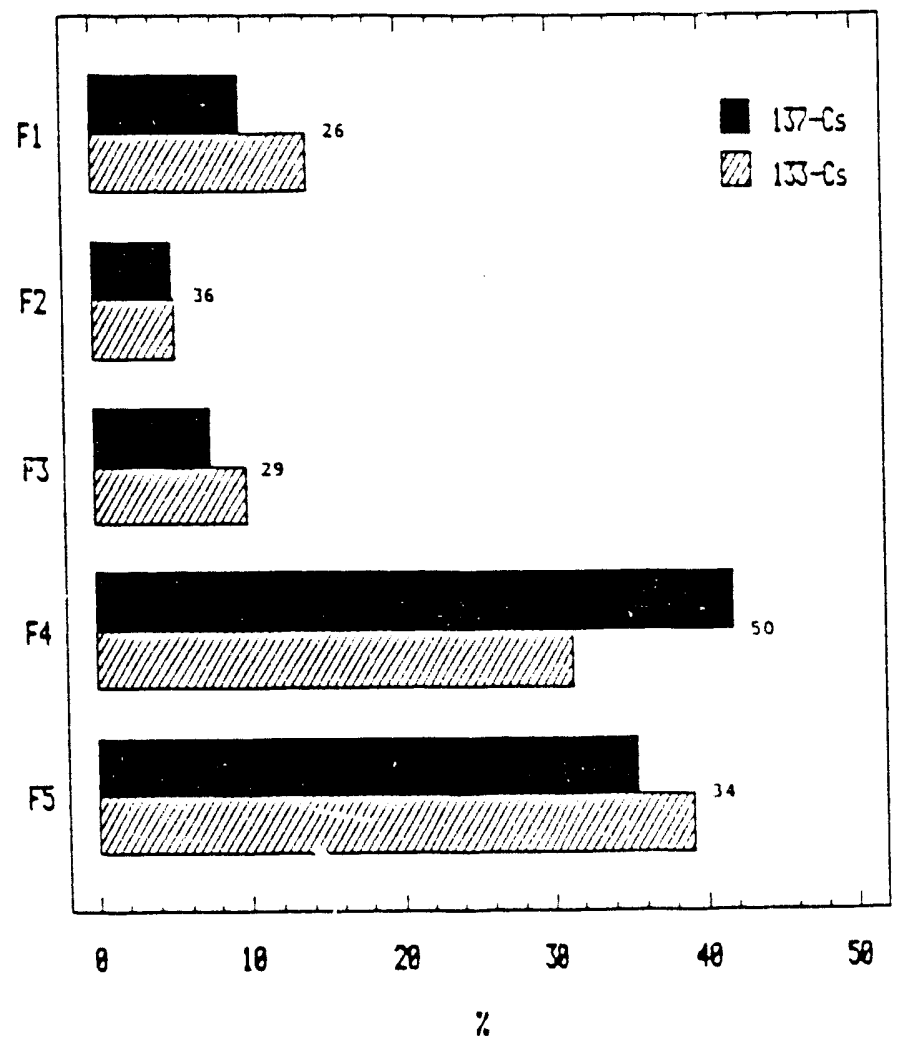

Figure 7.3 Distribution of Cs-137 and stable cesium in soil sample $(0-2 \mathrm{~cm}) .137 / 133$ ratio is given after the bars $(\mathrm{Bq} / \mathrm{\mu g})$. Central Norway. 1989. 
voir. However, transformation processes taking place in the environment (e.g. weathering) may influence the mobility both of the radiocesium nuclides and of other radionuclides (i.e. Sr-90). It is therefore important to have available well established techniques for measuring mobility. These experiments indicate that the sequential extraction technique is useful for obtaining such information. However, proper standardization of the technique is needed in order to obtain more chemically defined fractions.

$137-\operatorname{cs}$ and $90-5 r$ in

Heintalen Litter 1989

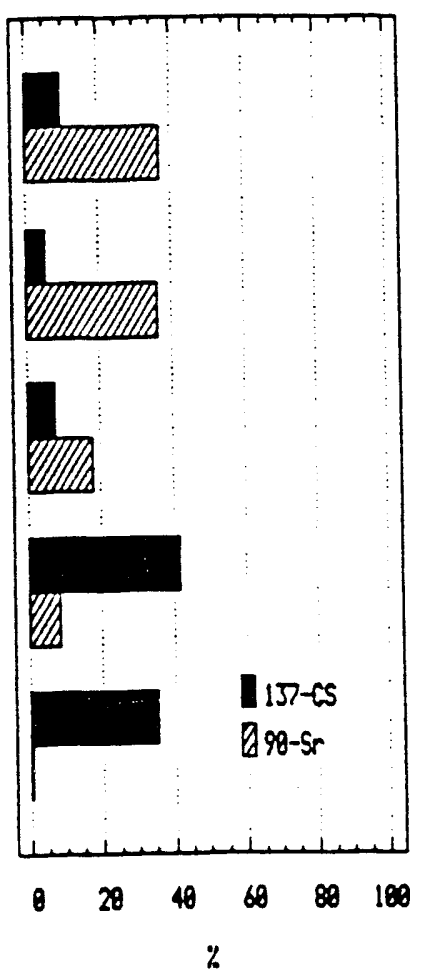

$157-c_{s}$ and $98-5 r$ in Vestre Slidre Litter 1988

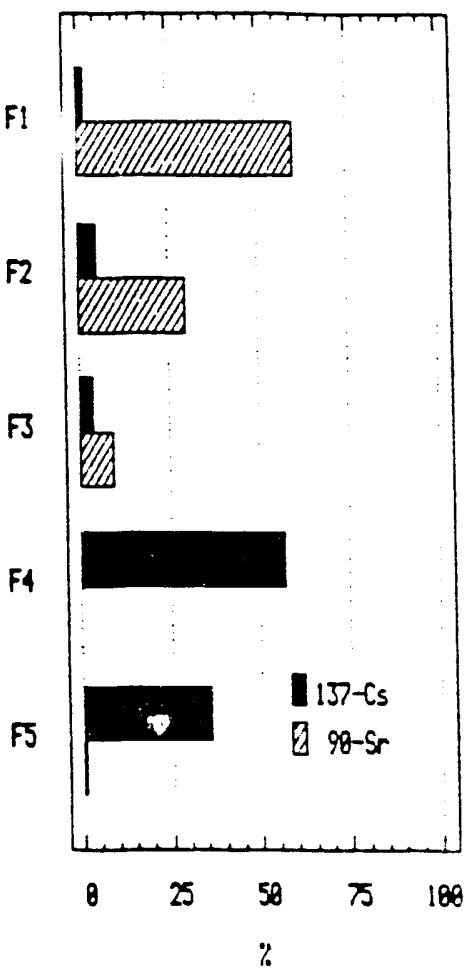

Figure 7.4 Relative distribution of radioactive cesium nuclides and Sr-90 in the different fractions $(0-2 \mathrm{~cm}$ sample) Heimdalen 1989 and Vestre Slidre 1988.

\subsubsection{Transfer from vegetation to sheep, in vivo and in vitro}

Persons involved in this project:

G. Ostby, G. Riise, B. Salbu, T.H. Garmo and K. Hove Norwegian Agricultural University

The transfer from vegetation to sheep depends on degradation processes in the GI tract as well as on the physico-chemical forms of radiocesium. Experiments have been performed in which the bioavailability of radiocesium has been investigated by measuring the release of 
radiocesium from plant material directly to the rumen liquid (stomach juice) of sheep, both in sacco (in vivo) and in vitro.

Information on the transfer of radiocesium from fodder to animals is usually obtained from feeding experiments. However, this technique is extremely time consuming and expensive. Furthermore, transformation processes taking place in the litter layer may change the physicochemical forms of radiocesium with time, and make it necessary to determine "transfer factors" or similar quantities repeatedly. Therefore, a more rapid and inexpensive technique for estimating the relevant available fraction of cesium-nuclides in the vegetation is urgently needed.

Accurately weighted fresh or dried $\left(40^{\circ}\right)$ samples of grass, herbage, mushrooms, lichens and litter collected in Central Norway were used in the experiments, both the in sacco and in vitro experiments (Table 7.12).

\begin{tabular}{|c|c|c|c|c|}
\hline Sample type & Year & $\mathbf{k B q} / \mathbf{k g}$ & $\begin{array}{c}\text { In sacco } \\
(\% \text { released })\end{array}$ & $\begin{array}{c}\text { In vitro } \\
(\% \text { released })\end{array}$ \\
\hline $\begin{array}{l}\text { Grass } \\
\text { Grass } \\
\text { Grass } \\
\text { Grass }\end{array}$ & $\begin{array}{l}1986 \\
1987 \\
1988 \\
1989\end{array}$ & $\begin{array}{r}10 \\
10 \\
5 \\
20\end{array}$ & $\begin{array}{l}78 \\
98\end{array}$ & $\begin{array}{l}15 \\
65 \\
65 \\
90\end{array}$ \\
\hline $\begin{array}{l}\text { Herbage } \\
\text { Rumex acetosa } \\
\text { Rumex acetosa } \\
\text { Deschampsia flexnosa } \\
\text { Deschampsia caespitosa }\end{array}$ & $\begin{array}{l}1986 \\
1987 \\
1989 \\
1989\end{array}$ & $\begin{array}{r}12 \\
7 \\
7 \\
10\end{array}$ & $\begin{array}{l}98 \\
98 \\
85\end{array}$ & $\begin{array}{l}60 \\
85\end{array}$ \\
\hline $\begin{array}{l}\text { Mushroom } \\
\text { Tricoloma album } \\
\text { Rozites caperata }\end{array}$ & $\begin{array}{l}1988 \\
1988\end{array}$ & $\begin{array}{l}150 \\
259\end{array}$ & $\begin{array}{l}100 \\
100\end{array}$ & $\begin{array}{l}75 \\
75\end{array}$ \\
\hline $\begin{array}{l}\text { Lichen } \\
\quad \text { Cladonia stellaris }\end{array}$ & 1988 & 25 & 71 & 32 \\
\hline $\begin{array}{l}\text { Litter } \\
\text { Litter }\end{array}$ & $\begin{array}{l}1988 \\
1989\end{array}$ & $\begin{array}{l}40 \\
48\end{array}$ & & $\begin{array}{r}1 \\
10\end{array}$ \\
\hline
\end{tabular}

Table 7.12 Characteristics of the contaminated vegetation, and release of radiocesium $(\%)$ from vegetation after 48 hours incubation in rumen liquid. 
24 nylon bags (porediameter of $35-40 \mathrm{~mm}$ ) containing $1 \mathrm{~g}$ samples of contaminated vegetation each were placed in the rumen of a fistulated sheep. Fistulation makes it possible to place the samples directly into the stomachs of the sheep. Four bags were withdrawn after incubation times of $1 \mathrm{~h}, 2 \mathrm{~h}, 4 \mathrm{~h}, 8 \mathrm{~h}, 24 \mathrm{~h}$, and 48 hours, respectively. The activities of $\mathrm{Cs}-134$ and $\mathrm{Cs}-137$ in each sample bag were measured prior to experiments. After withdrawal of the bags the activity of the Cs-nuclides, as well as dry weight of the sample material were determined.

The "in vitro" experiments

Six aliquots of $2 \mathrm{~g}$ plant material each were added to $50 \mathrm{ml}$ rumen liquid withdrawn from fistulated sheep. After incubation at $30^{\circ} \mathrm{C}$ at different time intervals $(1 \mathrm{~h}, 2 \mathrm{~h}, 4 \mathrm{~h}, 8 \mathrm{~h}, 24 \mathrm{~h}, 48 \mathrm{~h})$ the aliquots were ultracentrifuged $(40000 \mathrm{rpm})$ in order to remove high molecular weight components ( $>50 \mathrm{~nm}$ ). The activities of Cs-134 and Cs-136 were determined prior to the experiment and after the centrifugation.

Results from the "in sacco and vitro" experiments

The in sacco measurements show, as in Figure 7.5 , that the radioactive Cs-nuclides are released very rapidly from the nylon bags containing the contaminated plant material. For all samples except lichens about 90-100\% of the Cs-nuclides are released within 1-2 hours even though significant amounts of plant material were retained in the bag after 48 hours of incubation (20-90\% on dry weight basis). The cumulative releases are also shown in Table 7.12 .

No significant differences are seen between the release of Cs-nuclides from mushrooms, grass and herbage. The pore diameter of the nylon bags is, however, rather large $(35-40 \mathrm{~mm})$ and radiocesium released may be associated with high molecular weight components in the rumen liquid suspension, which will be relatively unavailable for subsequent uptake from the digestive tract of the animal.

From the in vitro experiments (Figure 7.6), it is seen that about 60 $70 \%$ of the radiocesium released from plant material during $1-2$ hours incubation is present as low molecular weight species $(<50 \mathrm{~nm})$. The results indicate that the low molecular weight fraction of Cs-nuclides depends on type of vegetation and is not significantly influenced by the drying prodedure. The release from litter is extremely low, which indicates that contamination of vegetation due to resuspension from the litter layer should not be considered important for uptake in sheep. Nor should soil ingestion be considered important.

Figure 7.7 shows a comparison between experiments on samples from different years. It was found that in grass collected in 1986 about 15\% of the total activity of the Cs-nuclides was present as low molecular 
weight forms after incubation. For grass collected in 1987 and 1988 this fraction was about $65 \%$, while $90 \%$ is obtained for grass collected in 1989. The probable explanation for these differences is connected to surface contamination of vegetation by resuspension. From Table 7.12 it is seen that most of the cesium in litter is in inert forms (high molecular weight forms). Resuspension of cesium from Chernobyl would be expected to be most pronounced in 1986, and decrease over the following years. Thus, the results from these experiments indicate that the major portion of cesium nuclides in grass collected in 1986 was associated with resuspended litter/soil, while this portion was much smaller in 1987 and 1988. In grass collected in 1989 almost all cesium in the grass was due to root uptake.

The difference in bioavailability found in these experiments, and described in the preceding paragraph, is also found in another set of experiments conducted at the Agricultural University of Norway (these are the experiments also referred to in chapter 5.3.4.1), where the transfer from grass contaminated with $\mathrm{Cs}-134$ to milk is measured from feeding experiments. For grass collected in 1986 the transfer was low $(3-4 \%)$, but increased in 1987 (8.8\%) and in 1988 (10\%). For Cs-134 plus tracer ( $\mathrm{CsCl}$ ) the transfer was $12 \%$.

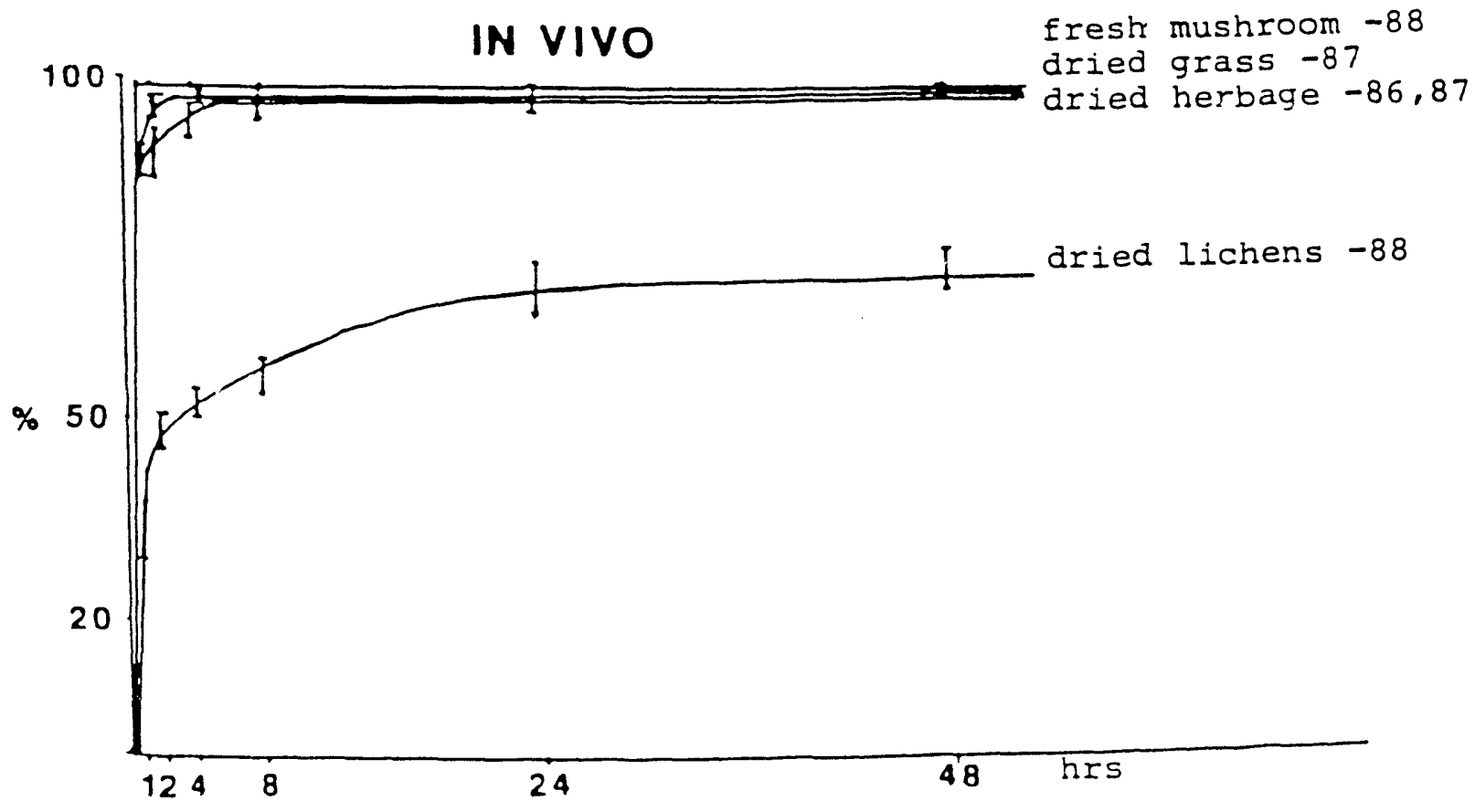

Figure 7.5 Release of radiocesium (\%) from contaminated vegetation during 48 hours incubation in sacco. 
Compared with results obtained for the in vitro incubation experiments remarkable good agreement between these and the feeding experiments is seen for $1987(60-65 \%)$. For grass collected in 1986 and 1988 the in vitro incubation seems to underestimate the transfer to some extent. However, the differences may also be attributed to variation in the surface contamination (e.g. resuspension) of the grass investigated.

The results from these experiments imply that, even though the total activities of the cesium nuclides in vegetation may decrease with time, the relative fraction of easily available Cs-nuclides may increase with time.

From the in vitro experiments it appears, in contrast to the in sacco experiments, that the low molecular weight fraction varies considerably between the different types of vegetation. This diffierence is not yet properly explained, but a probable explanation has been given earlier in this chapter.

The in vitro incubation technique described here seems therefore to be a promising technique for obtaining information on the potential availability of radiocesium in vegetation. Compared to feeding experiments, in vitro incubation with rumen liquid is a fast technique, giving results in $4-8$ hours, and reproducible results are obtained at low expenses.

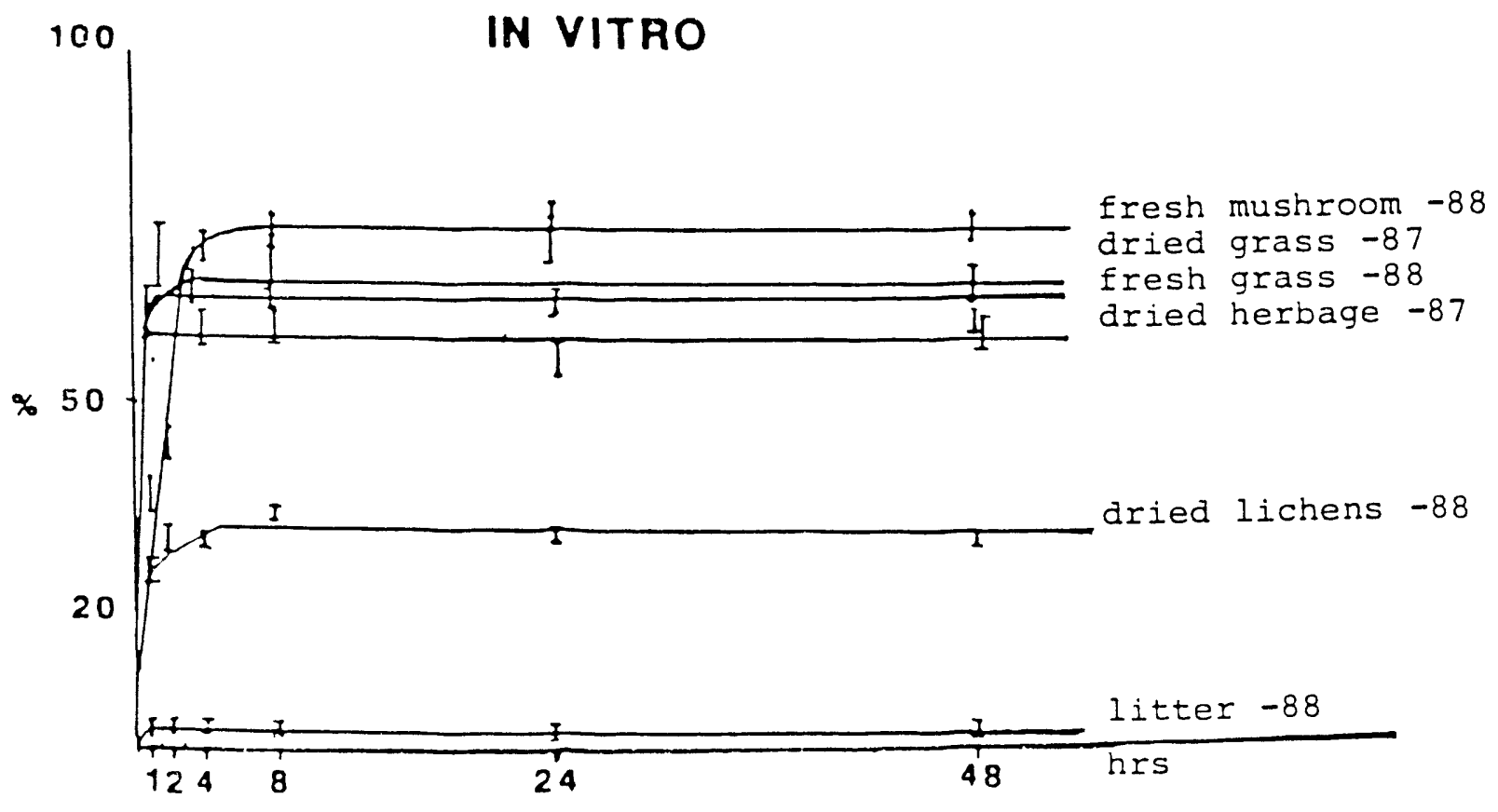

Figure 7.6 Release of low molecular weight radiocesium (\%) from contaminated vegetation during 48 hours in vitro incubation with rumen liquid. 


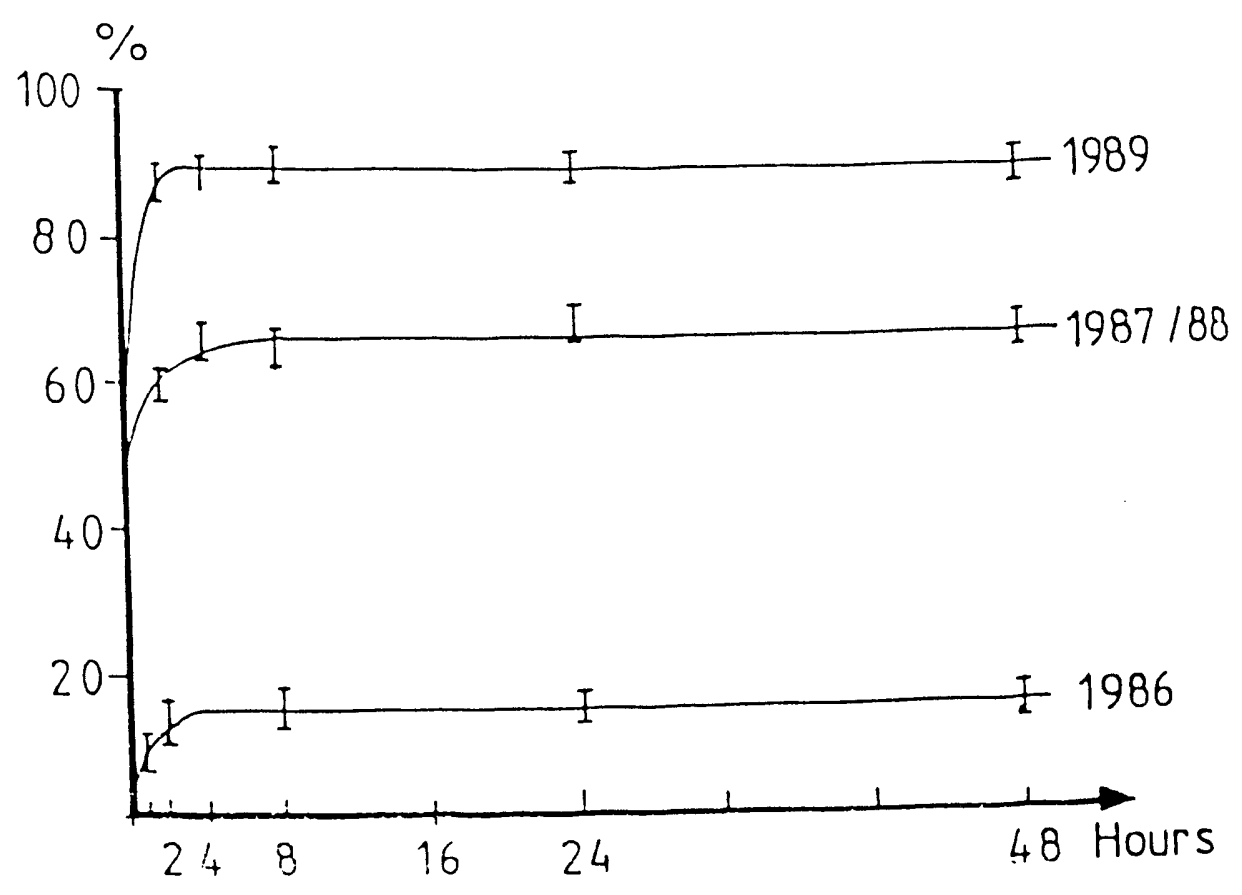

Figure 7.7 Release of low molecular weight radiocesium (\%) from contaminated grass collected in 1986, 1987, 1988 and 1989. Central Norway.

\section{WATER PATHWAYS}

\subsection{CONCLUSIONS}

Although it is impossible to actually measure wash-off from land surfaces to lakes post-Chernobyl, the MACCS assumption concerning initial wash-off agrees well with expert judgement, based upon various postChernobyl observations (distribution of cesium in lake delta, distribution in sediment).

The concentration factor from lake water to fish is given in the Ostmeyer and Helton report listed in the introduction to the present report, and is in quite good agreement with Norwegian post-Chernobyl observations of concentrations of cesium in water and fish from the same lakes. Fish, however, is not included as a pathway in the actual MACCS code at present. Discussions with Sandia during preparation of this report indicate that fish may nevertheless be an exposure pathway of some importance, and future inclusion of this pathway in MACCS is being considered. Discussions of aquatic food are included in the present chapter, although they do not refer directly to the present ver- sion of MACCS. 
The manner in which the concentration in water is calculated from a certain "deposit" (includes wash-off from surrounding areas) to a lake is, however, quite inappropriate. Rather than being evenly distributed in the water, followed by a gradual removal with a half-life of some years, as assumed in the model utilized in MACCS, the cesium is from post-Chernobyl measurements found to be quickly attached to particles and accumulated in the bottom sediment. MACCS calculations of concentrations in drinking water, using the approach described, will overestimate these concentrations by many orders of magnitude.

\subsection{CONDITIONS UTILIZED IN MACCS}

It is assumed that the strontium and cesium isotopes are likely to dominate exposure via the water pathways, and only these isotopes are included in the model. MACCS always assumes that release is to the atmosphere. Direct liquid releases to water bodies are not considered.

In the model used in MACCS radioactive materials can be introduced into water bodies by direct deposition or by wash-off from surrounding land areas. Only fresh-water bodies are considered.

Human exposure is via drinking water. In this model each watershed is treated separately, and each watershed must belong to a "watershed class". For each watershed class the parameters needed in the calculations are defined in the Site Data File. Each interval in the spatial grid must be assigned to one of the watershed classes. For each of these intervals is also given the "fraction of land", which is used in the wash-off calculations (but also in the nutrition pathway calculations). One minus the "fraction of land" is used in the direct deposition upon waterbodies calculations. There are potential problems here when the part of a grid element that is not land, is ocean and there should be no exposure via the water pathways. However, it can be managed by assigning artificial values to the watershed class parameters.

The water pathways model is quite simple, and described (for a specific nuclide and watershed class) by the equations (taken from the Ostmeyer and Helton report):

$$
\begin{aligned}
& \mathrm{LPPD}=\mathrm{ST} * \mathrm{TF} \\
& \mathrm{ST}=\mathrm{GC}(\mathrm{x}, \mathrm{y}) * \mathrm{~A}(\mathrm{x}, \mathrm{y}) *(\mathrm{LF}(\mathrm{x}, \mathrm{y}) * \mathrm{WF}+(1-\mathrm{LF}(\mathrm{x}, \mathrm{y}))) \\
& \mathrm{TF}=\mathrm{IGDF} *\left(\mathrm{PE}_{\mathrm{d} w}+\mathrm{PE}_{\mathrm{af}}\right)
\end{aligned}
$$

where

LPPD liquid pathway population dose (Sv) 

transfer factor $(\mathrm{Sv} / \mathrm{Bq})$

GC ground concentration $\left(\mathrm{Bq} / \mathrm{m}^{2}\right) .(\mathrm{x}, \mathrm{y})$ refer to the spatial grid element

A

area of the grid element $\left(\mathrm{m}^{2}\right)$

LF

land fraction (dimensionless)

WF

wash-off fraction (dimensionless) (see chapter 8.1.2)

IGDF

ingestion dose conversion factor ( $\mathrm{Sv} / \mathrm{Bq})$

$\mathrm{PE}_{\mathrm{dw}}$

drinking water exposure per "unit deposition into the water body" ( $\mathrm{Bq}$ ingested/Bq deposited)

$P E_{\text {af }}$

aquatic food exposure per "unit deposition into the water body" ( $\mathrm{Bq}$ ingested/Bq deposited)

"Per unit deposition into the water body" refers to the sum of the direct deposition and the integrated wash-off from the drainage area.

These equations also basically describe the manner in which MACCS treats the problem, with the difference that aquatic food is not included.

\subsubsection{Direct deposition}

The part of the source term to the watershed that is direct deposition upon the water surfaces, is simply the ground concentration times the size of the grid element times the fraction of this area that is water. Here is the inherent assumption that deposition upon water and land surfaces are identical. This is true for wet deposition, but not for dry deposition. A significant overestimation of this part of the source term may result.

The only input parameters needed are the area of each spatial grid element and the fraction of each element that is water.

\subsubsection{Wash-off}

The part of the source term to the watershed that is wash-off is calculated just like the direct deposition component, but in addition the term is multiplied by a wash-of f fraction. The wash-off fraction is given by the following equation:

$w F=\left(\lambda_{a} \lambda_{R}+\lambda_{b}\right) x_{o} /\left(\lambda_{R}+\lambda_{b}\right)$

where 
$\lambda_{\text {a }}$

$\lambda_{\mathbf{b}}$

$\lambda_{\mathbf{R}}$

X

initial wash-off fraction (dimensionless)

long-term wash-off rate (per year)

radionuclide decay rate (per year)

atmospheric deposit to land (Bq)

It is a mistake that the quantity "atmospheric deposit to land" is included in the expression for WF. It must really mean the same as "ground concentration" multiplied by "area of grid element" multiplied by "land fraction", and this is already in the expression for the source term given in the first part of chapter 8.2 .

The expression for the wash-off fraction is derived from two assumptions :

- An initial fraction (described by $\lambda_{a}$ ) is washed off "immediately".

- The remainder is washed off with a constant rate (described by $\lambda_{b}$ ).

One weakness of this approach is that it is assumed to be independent of the deposition conditions. It is certain that at least the initial fraction will differ significantly between dry deposition conditions and heavy rain.

In the MACCS description it is said that the approach is conservative, since only radioactive decay is taken into consideration in addition to the wash-off processes. Chemical binding to the soil is neglected in this connection. Chemical binding may, however, not be so important, as much of the long-term wash-off will be erosion.

In the Users Guide the inital fraction for wash-off of cesium is set equal to 0.02 , and the rate of 1 ong-term wash-off is 0.005 per year. In the final version, which was received after work was completed on this task, these values have been modified to 0.005 and 0.001 respectively.

\subsubsection{Drinking water}

Population exposure via drinking water is in the MACCS description given by the equation:

$\mathrm{PE}_{\mathrm{dW}}=I W C * W T * W C * \mathrm{POP}_{\mathrm{d} W}$

where 
average integrated radionuclide concentration for the waterbody per "unit deposition of radionuslide"

(Bq-year $/ \mathrm{m}^{3}$ per $\mathrm{Bq}$ deposited)

WT

water treatment factor (dimensionless)

WC

water consumption per person and year (11ter/year)

POP $_{\text {wC }}$

size of the population receiving drinking water from the water body

From the Users Guide it is apparent that in designing the program one has chosen a much simpler approach than the one described in the Model Description, draft version. (The descriptions given in the present chapter and chapter 6.2 .4 for aquatic food were written before the final version of the Model Description was received.) The parameter "Ingestion factor" (WINGF) is used to describe the combined impact of drinking water and aquatic food. WINGF is (Bq ingested)/(Bq entering water). Water treatment factors, water consumption, concentration of radionuclides in water, concentration factor to fish, annual production of fresh-water fish etc are not part of input to the computer program, but are presumably used in calculating WINGF. In the problem in the Users Guide, draft version, WINGF $=10^{-6}$. In the final version of the Users Guide WINGF has been modified to $5 \cdot 10^{-6}$.

\subsubsection{Aquatic food}

Population exposure via aquatic food is in the Ostmeyer and Helton description given by the equation:

$P E_{\text {af }}=I W C * C R * F P$

where

IWC average integrated radionuclide concentration for the waterbody per "unit deposition of radionuclide" (Bq-year $/ \mathrm{m}^{3}$ per $\mathrm{Bq}$ deposited)

CR concentration factor for fish relative to water $(\mathrm{Bq} / \mathrm{kg}) /\left(\mathrm{Bq} / \mathrm{m}^{3}\right)$

FP

annual production of fresh-water fish from the waterbody $(\mathrm{kg} /$ year $)$

See chapter 8.2.3 for the approach described in the Users Guide.

\subsubsection{Connection between MACCS parameter values and measured values}

The approach in MACCS is busically quite simple. The fraction of cesium being washed off from land areas to the water body (one initial 
and one long-term component) is integrated over all time. This fraction is then multiplied by WINGF, which determines how much of the cesium will eventually be consumed by humans. The user, hewever, has the possibility of using models of such complexity as he finds suitable for determining these two quantities. The discussion in the present chapter must necessarily be limited to a discussion of the data given in the Users Guide, which have been determined using very simple models.

Some general trends are evident from the post-Chernobyl data:

- Drinking water is of no importance whatever relative to fresh-water fish from the same waterbody, when there is fish present. The measurements in the Norwegian lakes show that the concentration in fish is typically about a factor at least 1000 higher than concentration in water from the same lake. In chapter 8.4.6 it is shown that even with an extremely large water consumption, the fish consumption would have to be as low as 300 - 400 grams per year for water to dominate over fish from the same lake.

- Even though actual measurements of the initial wash-off fraction has not been performed, and hardly ever can be performed properly, the opinion of the experts in this field in Norway is that a typical value would be around $1-2 \%$. This is between the values given in the original and final versions of the MACCS Users Guide.

- The long-term wash-off rate can not be determined until many years from now. The variations that can be seen now between samples collected in different years reflect local variations in the deposition pattern rather than wash-off.

- A comparison between the conditions in the Ostmeyer and Helton report and post-Chernobyl measurements is possible only for the "transfer factors" coupling deposition per $\mathrm{m}^{2}$ in the general area to content in fish (Table 8.5). This aspect is discussed in the following.

"Transfer factors" to fish.

The "transfer factors" given in Table 8.5 are not basic quantities, but nevertheless seem to be useful for describing the transfer, since their values for the different municipalities vary over quite a limited range (about a factor 10), in spite of the relatively large variation in conditions between these municipalities.

As mentioned in the above, the initial wash-off is assumed in the final version of the MACCS Users Guide to be 0.005. Typically about 1 - $10 \%$ of the land area of a watershed is water. This means that the amount of cesium in a lake for quite a number of years after deposition in the area, will in most cases be dominated by the cesium that deposited directly upon the lake surface. (This is provided there was wet deposition. Otherwise deposition on the lake surface would be 
lower than deposition on land surfaces, because of the difference in roughness, and wash-off might dominate.)

An additional reference by Helton, which has been used as basis for some aspects of MACCS, is (HE85). It seems from the title that this publication does not consider contamination by direct deposition to the water body. This, however, is not true. An example is given where the consequences of a release directly to the water of Lake Michigan are calculated. This example assumes a release directly to the water; not via the atmosphere, but for the sake of argument in the present chapter, this does not matter.

i. imoval from the lake water, by unspecified processes (probably outflow from the lake and attachment to sediment), is given by a halflife of 3.5 years. Initial concentration in the lake water is determined by dividing the release by the water volume of the lake.

The post-Chernoby1 measurements in Norway indicates that this approach is quite inappropriate. The cesium concentration in the lake drops very quickly to a very low level. Almost from the very beginning practically all cesium in a lake is in the sediments; not in the water.

(Ref. HE85) also gives the concentration factor from water to fish. Although this transfer is not the physically important transfer, which is from sediment (via various "fish nutrition" pathways) to fish, this quantity is comparable to the rough ratio mentioned above between concentration in water and in fish in the same lake. The value of 2000 given in (ref. HE85) agrees very we11 with the Norwegian observations. The reason for this is that the value given in the reference is based upon actual observations, and the value is correct, although the mode of transfer has been misrepresented.

Finally, it is interesting to note that in the calculations given as examples in (ref. HE85) fish is the dominating pathway, giving population doses of two to six times those from drinking water. An additional exposure pathway considered in this reference, irrigation, is found to be of no importance. Both these findings agree well with post-Chernobyl experience in Norway.

\subsection{POST-CHERNOBYL MEASUREMENTS IN NORWAY}

\subsubsection{Survey of the radioactivity in game and wild freshwater fish}

During 1986 a large number of measurements of game and freshwater fish were performed (ref. The measurements were performed by three local Municipal Food Control Laboratories in cooperation with Institutt for Energi teknikk.

The Chernoby 1 fall-out in the Oppdal municipality ranges from about $5 \mathrm{kBq} / \mathrm{m}^{2}$ to more than $100 \mathrm{kBq} / \mathrm{m}^{2}$. (Ref. SK87) contains results from measurements of 529 samples of game and 870 samples of $\mathrm{fish}$. The game measurements, however, are not relevant in the present context. The fish measurements reported are updated to include all measurements 
before and including 24 February 1987. 26 of the fish samples are preChernobyl. There are also a couple of pre-Chernobyl samples of game.

A survey among fishermen and hunters was also performed. They were asked whether they knew the content of radioactive material in the game/fish in the area and what was their source of information (newspaper, TV, reports from the authorities etc.). They were asked whether they would hunt/fish next year. People who decided not to hunt/fish in 1986 were asked why, etc. This survey is of course of a character quite different from the rest of the report, but it is quite interesting. This part of the report is not referred to further in the present report. The material, however, might be quite useful in other contexts.

\subsubsection{Pre-Chernobyl cesium content}

Pre-Chernobyl content was found to be quite low. Reindeer meat from 1975 and 1985 contained from 60 to $140 \mathrm{~Bq} / \mathrm{kg}$. Content in fish from 1984 and 1985 ranged from less than 10 to about $100 \mathrm{~Bq} / \mathrm{kg}$.

\section{$\underline{8.3 .3 \quad \text { Soil samples }}$}

The measurements of ground concentration were performed by the National Institute of Radiation Hygiene of Norway, and are reported in (ref. BA86)

Eight samples from each municipality in Norway were collected. They were collected in pairs; that is on four locations in each municipality. The locations should be widely spread, geographically and topographically. The samples include all vegetation growing on the soil sample, and soil to a depth of $4 \mathrm{~cm}$. Locations in open, level terrain were chosen, and the locations were distant from roads and forest. There should be as little vegetation as possible and the soil should not have been treated since 25. april 1986. The samples were collected during the summer of 1986 . Four samples from each municipality (one from each location) were mixed, and one kilo of the mixture sent to the Radiation Hygiene Institute, while the remaining four samples were stored locally for later use. Table 8.1 contains the results for the municipalities of the Oppland county, as reported in (ref. SK87), bu't rearranged (by Skurdal et al) in order of descending ground activity. All concentrations in this chapter are the sum of $\mathrm{Cs}-134$ and $\mathrm{Cs}-137$ activity. The fish concentrations are fresh weight.

Table 8.1 also contains concentration values for trout for all municipalities where +rout data are available (also from Skurdal et al, but averaged over each municipality for use in the present report.

\subsubsection{Ground concentrations and concentrations in trout}

In Table 8.1 are listed deposition within each municipality and concentration in the collected fish, averaged over all fish caught in the 
municipality. The fish concentrations are given for two time periods, as explained in the below. There is a certain correlation between ground concentration and concentration in fish within the municipalities, but it is far from clearcut.

\begin{tabular}{|c|c|c|c|c|c|c|}
\hline & Municipality & $\begin{array}{l}\text { Ground conc. } \\
\left(\mathrm{kBq} / \mathrm{m}^{2}\right)\end{array}$ & $\begin{array}{l}\text { Trout } \\
\text { June } 15 \\
\text { (kBq/kg }\end{array}$ & & $\begin{array}{l}\text { Trout } \\
\text { Sept } 1 \\
(\mathbf{k B g} / \mathbf{k g})\end{array}$ & \\
\hline 1 & Øystre Slidre & 155.810 & 5.643 & (1) & 6.077 & (1) \\
\hline 2 & Vágá & 132.500 & 2.990 & (6) & 3.847 & (5) \\
\hline 3 & Sel & 102.370 & 4.677 & (2) & 5.698 & $(2)$ \\
\hline 4 & Dovre & 93.920 & 1.763 & (9) & 2.131 & (10) \\
\hline 5 & Vang & 48.540 & 1.988 & $(8)$ & 0.489 & (18) \\
\hline 6 & Nord-Aurdal & 46.460 & 3.426 & (5) & 3.998 & (4) \\
\hline 7 & Lom & 44.380 & 0.514 & (18) & 0.654 & $(16)$ \\
\hline 8 & Etnedal & 38.350 & 0.861 & $(17)$ & - & \\
\hline 9 & Vestre Slidre & 36.600 & 3.551 & (4) & 3.187 & (7) \\
\hline 10 & Nord-Fron & 32.180 & 3.816 & $(3)$ & 5.175 & $(3)$ \\
\hline 11 & Nordre Land & 31.610 & 1.428 & (12) & 3.354 & (6) \\
\hline 12 & Sør-Fron & 31.200 & 0.892 & (15) & 1.034 & (15) \\
\hline 13 & Sor-Aurdal & 24.730 & 1.659 & $(10)$ & 1.561 & (12) \\
\hline 14 & Oyer & 22.580 & 0.870 & $(16)$ & 1.666 & (11) \\
\hline 15 & Gausdal & 21.340 & 1.151 & (14) & 1.519 & (13) \\
\hline 16 & Ringebu & 20.840 & 2.172 & $(7)$ & 2.343 & (8) \\
\hline 17 & Skjjakk & 18.960 & 0.176 & $(22)$ & 0.507 & (17) \\
\hline 18 & Søndre Land & 13.610 & - & & - & \\
\hline 19 & Lillehammer & $13 \cdot 520$ & 1.450 & (11) & 2.309 & (9) \\
\hline 20 & Gjøvik & 8.740 & 0.232 & (21) & 0.238 & (19) \\
\hline 21 & Lesja & 7.770 & 1.392 & (13) & 1.454 & (14) \\
\hline 22 & Lunner & 6.420 & 0.360 & (19) & - & \\
\hline 23 & Gran & 5.580 & 0.264 & (20) & - & \\
\hline 24 & Jevnaker & 4.650 & - & & - & \\
\hline 25 & Ostre Toten & 2.660 & - & & - & \\
\hline 26 & Vestre Toten & 2.520 & - & & - & \\
\hline
\end{tabular}

Table 8.1 Ground concentrations and concentrations in trout (all concentrations are sum of $\mathrm{Cs}-134$ and $\mathrm{Cs}-137$, and the fish concentrations are fresh weight). The numbers in parenthesis represent ranking on concentration in trout.

Th.ere are two obvious sources for anomalies:

- variation of concentration in fish with time after deposition.

- variation of concentration in fish with type of lake and surrounding area, including size of drainage area.

The concentrations in fish measured as early as May 1986 are quite low, as are the concentrations measured in June in most cases. For this reason data earlier than 15 June are not included in the averages 
in the table. But throughout summer and fall there seems to have been continued increase, as illustrated by data in Tables 8.2 and 8.3 . which contain data for two lakes (these concentrations are individual measurements). Because this continued rise had been observed, the righthand column in Table 8.1 was included, where only data later than 1 September are included. However, this did not have a large impact upon the ranking.

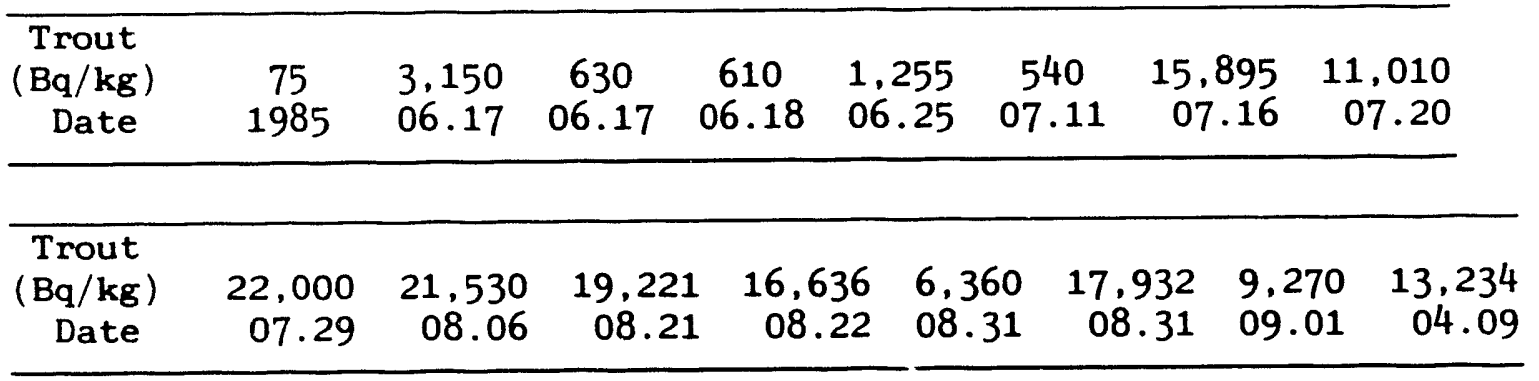

\begin{tabular}{crrr}
\hline Trout & & & \\
$(\mathrm{Bq} / \mathrm{kg})$ & 13,819 & 22,351 & 19,205 \\
Date & 09.20 & 10.06 & 10.21 \\
\hline
\end{tabular}

Table 8.2 Trout data from municipality no 1, Lake Vinsteren.

\begin{tabular}{crlllrrr}
\hline Trout & & & & & & & \\
(Bq/kg) & 2,930 & 4,210 & 4,033 & 7,551 & 16,554 & 16,461 & 3.814 \\
Date & 06.23 & 07.24 & 08.23 & 08.30 & 10.02 & 10.21 & 11.27 \\
\hline
\end{tabular}

Table 8.3 Trout data from municipality no 10, Lake Furusjøen.

The other obvious variation, with type of lake and landscape, is also linked to height above sea level. Roughly one can say that lakes below some 500 meters above sea level are lakes in forest, lakes above ca. 900 meters above sea level are typical lakes of the mountain plateau, while lakes above ca. 1100 meters above sea levels are typical of the bare mountains, with lakes low in nutrition and accordingly with high cesium uptake in fish.

Table 8.1 also contains ranking of the municipalities, after concentration in fish. In the following some municipalities with unexpected rankings are examined in more detail.

The most anomalous municipalities are no. $7,8,9,10$ and 16. 
Municipality 7: The values here are quite low compared to the ground concentration. The reason may be that there are no or few mountain lakes in the region. One third of the samples in this municipality is from a lake at 815 meters above sea level, which is not really quite high enough to be a proper mountain lake.

Municipality 8: The concentration values in fish are low relative to the ground concentration. Even in this municipality the reason may be that there are no or few proper mountain lakes. There are also only 8 samples in this municipality. The lakes where the height above sea level can be read from the map are at 698, 791 and 893 meters above sea level. The trout from the latter lake has concentration significantly higher than the two trouts from the other two lakes.

Municipality 9: In this municipality the concentrations in trout are high compared to the ground concentration. Some of the lakes in this region have particularly high concentrations in trout. The lakes are at altitudes around 900 meters above sea level, with one exception which is at 364 meters above sea level and which does not have any of the high-concentration samples. The altitude of the lakes does not seem to give sufficient explanation of the high values. It may be that the drainage area is particularly large.

Municipality 10: Here the trout concentrations are also high compared to the ground concentrations. In this area there is one particular lake that pulls the average up, but this lake is at 840 meters above sea level, which is not really all that high. Like for municipality 9 there may be other reasons for the high values.

Municipality 16: In this municipality also the fish conntions are high compared to the ground concentrations. In this case most of the explanation lies in the many high samples from one particular lake at 908 meters above sea level.

It can not be expected that all samples shall follow the trends of being high in areas with high ground deposition, rising with time after deposition took place, and high in mountain lakes. Although most of the material actually show these trends, there are exceptions. Data from one lake is given as an example in Table 8.4.

\begin{tabular}{ccccc}
\hline Trout & & & & \\
(Bq/kg) & 2,220 & $4 ., 28$ & 495 & 652 \\
Date & 07.15 & 08.14 & 08.31 & 10.10 \\
\hline
\end{tabular}

Table 8.4 Trout data from municipality no 13 , Lake Busuvatn. 
There are about 300 - 400 lakes from which samples have been collected, and 6 fish species in addition to trout, although the number of samples for the other species is much lower, and only from some of the lakes. They are not considered in the present report.

\subsubsection{Soil to fish "transfer factor"}

Even if the ranking of municipalities according to ground concentrations and by concentrations in fish did not give quite the same ranking, and there are indications that transfer of cesium is more pronounced for fish in lakes in the high mountain regions, it is felt that use of generalized "transfer factors", linking ground concentrations directly to concentrations in fish, could be useful.

Such "transfer factors" are given in Table 8.5. The "transfer factors" for the different municipalities are within the range from 0.009 to 0.187 (a factor of 21) when all measurements from June 15 are considered, and from 0.010 to 0.187 (a factor of 19) when only the autumn is considered. This range of variation is sufficiently narrow to indicate that the concept may be useful for predicting concentrations in fish in lakes with conditions not too different from the Norwegian ones.

It must be remembered, when these "transfer factors" are used, that they represent a simple relation between ground concentration and concentration in fish. The variation in magnitude represents real variations in the conditions, like magnitude of drainage area, type of soil in the surrounding area, whether the lake is rich or poor in nutrients or potassium etc. It would be much more appropriate (but also much more costly) to determine a series of transfer factors for different types of lakes, classified according to these characteristics.

\subsubsection{Concentrations in water in the lakes}

The concentrations of cesium (also sum Cs-134 and 137) in lake water were also measured in a large number of lakes in this area. Results are actually available from all over the country, but in connection with the present Task, the area from which fish results have been presented in the preceding chapters, is obviously the most interesting. The results are presented in Table 8.6. The samples were collected in the last half of June 1986. Only the municipalities from which water concentrations are available are included in the table.

It is evident that the concentrations in lake water are very small, mostly below the detection limit. And the water concentrations are at least a factor of 1000 below the concentrations in fish from the same lake. Obviously, water consumption may be considerably larger than consumption of fish, but a person will hardly drink more than one liter per day. Only when fish consumption would be lower than 300 to 400 grams per year could water dominate as scurce of cesium intake in this situation. 


\begin{tabular}{|c|c|c|c|}
\hline & Municipality & $\begin{array}{l}\text { "Transfer fac } \\
(\mathrm{Bq} / \mathrm{kg} \text { fish }) /\left(\mathrm{Bq} / \mathrm{m}^{2}\right. \\
\text { June } 15 \rightarrow\end{array}$ & $\begin{array}{l}\text { tor" } \\
\text { deposited Cs-137) } \\
\text { Sept } 1 \rightarrow\end{array}$ \\
\hline 1 & Øystre Slidre & 0.036 & 0.039 \\
\hline 2 & Vágá & 0.026 & 0.029 \\
\hline 3 & Sel & 0.046 & 0.056 \\
\hline 4 & Dovre & 0.019 & 0.023 \\
\hline 5 & Vang & 0.041 & 0.010 \\
\hline 6 & Nord-Aurdal & 0.074 & 0.086 \\
\hline 7 & Lom & 0.012 & 0.015 \\
\hline 8 & Etnedal & 0.022 & - \\
\hline 9 & Vestre Slidre & 0.097 & 0.087 \\
\hline 10 & Nord-Fron & 0.119 & 0.161 \\
\hline 11 & Nordre Land & 0.045 & 0.106 \\
\hline 12 & Sør-Fron & 0.029 & 0.033 \\
\hline 13 & Sør-Aurdal & 0.067 & 0.063 \\
\hline 14 & Øyer & 0.039 & 0.074 \\
\hline 15 & Gausáal & 0.054 & 0.071 \\
\hline 16 & Ringebu & 0.104 & 0.112 \\
\hline 17 & Skjăk & 0.009 & 0.027 \\
\hline 19 & Lillehammer & 0.107 & 0.171 \\
\hline 20 & Gjøvik & 0.027 & 0.027 \\
\hline 21 & Lesja & 0.179 & 0.187 \\
\hline 22 & Lunner & 0.056 & - \\
\hline 23 & Gran & 0.047 & - \\
\hline
\end{tabular}

Table 8.5 The ratios between concentration in fish (fresh weight) and concentration on ground in the different municipalities.

\begin{tabular}{rlrc}
\hline Municipality & $\begin{array}{c}\text { Ground conc. } \\
\left(\mathbf{k B q} / \mathrm{m}^{2}\right)\end{array}$ & $\begin{array}{c}\text { Concentration in } \\
\text { water } \\
(\mathrm{Bq} / \mathbf{k g})\end{array}$ \\
\hline 1 & Øystre Slidre & 155.810 & 24 \\
4 & Dovre & 93.920 & 1 \\
6 & Nord-Aurdal & 46.460 & $<1$ \\
9 & Vestre S1idre & 36.600 & 6 \\
10 & Nord-Fron & 32.180 & 8 \\
12 & Sør-Fron & 31.200 & $<1$ \\
14 & Øyer & 22.580 & $<1$ \\
17 & Skjakk & 18.960 & 5 \\
21 & Lesja & 7.770 & $<1$ \\
\hline
\end{tabular}

Table 8.6 Concentrations in lake water Mid-Summer 1986. 
BA86 Steinar Backe, Hans Bjerke, Anne Liv Rudjord and Finn Ugletveit: Cesium fall-out in Norway after the Chernobyl accident. (In Norwegian). National Institute of Radiation Hygiene. Report no. 1986:5 (ISSN 0800-4137). Norway. 1986.

BJ87 B. Bjurman, R. Finck, R. Arntsing, L.-E. de Geer, S. Jakobsson and I. Vintersved: Resuspension measurements second half of 1986 (In Swedish). FOA Rapport C 20678-9. Stockholm, Sweden. November 1987 .

BJ88 Bjørn Bjurman: The resuspension of radioactive particles in Sweden after the Chernobyl accident. 5:e Nordic Radioecologyseminar. Răttvik, Sweden, August 1988.

HE85 J.C. Helton, A.B. Muller and A. Bayer: Contamination of surface water bodies after reactor accidents by the erosion of atmospherically deposited radionuclides. Health Physics, Vol. 48, No. 6 , June 1985 .

SE76 G.A. Sehmel: Particle resuspension from an asphalt road caused by car and truck traffic. In: Atmosphere-surface exchange of particulate and gaseous pollutants (G.A. Sehmel, Ed.), pp. 990. Technical Information Service, US Department of Commerce. Springfield, Virginia. 1976.

SK87 Jostein Skurdal, Geir Vagstein and Irene Tjørve: Radioactivity in the municipality Oppland after Chernobyl - consequences for game and fish (In Norwegian). County Governor in Oppland, Environmental Protection Department, Report no. 6, 1987.

TI83 John E. Till and H. Robert Meyer (editors): Radiological assessment. A textbook on environmental dose analysis. NUREG/CR-3332 (ORNL-5968). Washington D.C. 1983.

TV90a U1f Tveten: Review of the chronic exposure pathway models in MACCS and several other well-known probabilistic risk assessment models. NUREG/CR-5377. Washington D.C. June 1990.

TV90b U1f Tveten (editor): Environmental Consequences of Releases from Nuclear Accidents - A Nordic Perspective. NORD 1990:46. Nordic Liaison Committee for Atomic Energy. Norway. March 1990.

WA75 Reactor Safety Study: An assessment of accident risks in U.S. commercial nuclear power plants. Main report (WASH-1400. NUREG 75/ 014), and Appendix VI (PB-248 206). Washington D.C. 1975 . 
Oak Ridge National Laboratory (4)

Attn: Mr. Keith Eckerman

Mr. David Kocher

Mr. David Cook

P.0. Box X

Oak Ridge, TN 37831

Argonne National Laboratory (5)

Attn: Mr. S. Y. Chen

Mr. Kou-John Hong

Mr. Larry Eyberger

Mr. Brad Micklich

Mr. Yuchien Yuan

9700 South Cass Ave.

Argonne, IL 60439

Brookhaven National Laboratory (6)

Attn: Mr. Arthur Tingle

Mr. Vinod Mubayi

Mr. Eric Cazzoli

Mr. Trevor Pratt

Ms. Carrie Grimshaw

$\mathrm{Mr}$. Bob Youngblood

Building 130

Upton, NY 11973

EG\&G Idaho, Inc. (10)

Attn: Mr. Jack Dallman

Mr. Darrel Knudson

$\mathrm{Mr}$. Bob Lyon/Mr. Chuck Dobbe

$\mathrm{Mr}$. Al Bowman $/ \mathrm{Mr}$. Ken Jones

Mr. John Tolli

Mr. Mike Abbott

Mr. Steve Maheras

Mr. Neldon Marshall

P.O. Box 1625

Idaho Falls, ID 83415

Knolls Atomic Power Laboratory (2)

Attn: Mr. Ken McDonough

Mr. Dominic Sciaudone

P.O. Box 1072

Schenectady, NY 12301-1072
Pacific Northwest Laboratory

P.O. Box 999

Attn: Mr. Vo Truoung

Mr. Dennis Strenge

Mr. Bruce Napier

Ms. Kathy Rhoads

Mr. Iral Nelson

Ms. Pamela Doctor

Richland, WA 99352

Westinghouse Hanford Co. (2)

Attn: Mr. Fred Mann

Mr. Milt Schultz

P.O. Box 1970

Richland, WA 99352

Savannah River Laboratory

Attn: Mr. Dave Sharp

Mr. Wade Bickford

Mr. Kevin O'Kula

Mr. Charles Murphy, Jr.

Mr. H. E. Hootman

$\mathrm{Mr}$. C. E. Leach

Aiken, SC 29808

U. S. Department of Energy

Attn: Mr. Richard Moore

785 DOE Place

Idaho Falls, ID 83402

Westinghouse Idaho Nuclear

Company, Inc. (2)

Attn: Mr. Doug Wentzel

Box 4000

Mr. Roger Henry

Idaho Falls, ID 83403

Los Alamos National Laboratory

(4)

Attn: Ms. Mary Meyer

Mr. Doug Muir

Mr. Desmond Stack

Ms. Jane Booker

Los Alamos, NM 87845

Lawrence Livermore National

Laboratory (3)

Attn: Mr. George Greenly

Mr. Marvin Dickerson

Mr. Rolf Lange

Livermore, CA 94550

Dist-1 
Rocky Flats Plant

Attn: Mr. Terry Foppe

P.O. Box 464

Golden, CO 80401

U.S. Environmental Protection Agency (2)

Office of Radiation Programs

Environmental Analysis Division

Attn: Mr. Allen Richardson

Mr. Joe Logsdon

Washington, DC 20460

U. S. Department of Energy (3)

Attn: Mr. Ken Murphy (EH-332)

Mr. Ed Branagan (EH-332)

Mr. Sarbes Acharya (NS-20)

Washington, DC 20545

U. S. Nuclear Regulatory Commission (22)

Attn: Mr. Mark Cunningham

Mr. Jim Glynn

Ms. Christiana Lui (20)

5650 Nicholson Lane

Rockville, MD 20852

U. S. Department of Health and Human

Services

Food and Drug Administration

Attn: Mr. Bruce Burnett CDRH (HFZ-60)

5600 Fishers Lane

Rockville, MD 20857

TVA (2)

Attn: Mr. Ken Keith

Mr. William Mimms

W 10 D 201

400 West Summit Hill

Knoxville, TN 37902

Illinois Dept. of Nuclear Society

Attn: Mr. Mike Momeni

1035 Outer Park Drive

Springfield, IL 62707

Inhalation Toxicology Research Institute

Attn: Mr. Bobby Scott

P.O. Box 5890

Albuquerque, NM 87185
Battelle Columbus Laboratories

(2)

Attn: Mr. R. S. Denning

Mr. Jim Gieseke

505 King Avenue

Columbus, $\mathrm{OH} 43201$

Mr. Kamal Araj

BDM Corporation

7915 Johns Branch Dr.

McLean, VA 22102

Mr. Harold Careway

General Electric Co., M/C 754

175 Curtner Ave.

San Jose, CA 95125

Mr. Robert Gobel

Center for Technology,

Environment, and

Development

Clark University

950 Main Street

Worcester, MA 01610-1477

Mr. Shengdar Lee

Yankee Atomic Co.

1671 Worcester Road

Framingham, MA 01701

Mr. Mike Cheok

NUS

910 Clopper Road

Gaithersburg, MD 20878

Mr. Bill Eakin

Northeast Utilities

Box 270

Hartford, CT 06141-0270

Mr. Jim Mayberry

Ebasco Services

160 Chubb Ave.

Lyndhurst, NJ 07071

SAIC

Ms. Zen Mendoza

5150 El Camino Real

Suite C 31

Los Altos, CA 94022

Dist-2 
Mr. Ken O'Brien

University of Wisconsin Nuclear Engineering Dept. 153 Engineering Research Bldg. Madison, WI 53706

\section{S - CUBED}

Attn: Mr. Scott Bigelow 2501 Yale SE, Suite 300

Albuquerque, NM 87106

American Electric Power (2)

Attn: Mr. David Black

Mr. Ray Dremel

1 Riverside Plaza

Columbus, $\mathrm{OH} \quad 43215$

Fauske and Associates, Inc. Attn: Mr. Gerald Davidson 16 W 070 West 83 rd Street Burr Ridge, IL 60521

Pickard, Lowe and Garrick (2)

Attn: Ms. Jackie Lewis Mr. Keith Woodard

Suite 730

1615 M. Street

Washington, DC 20036

SAIC (2)

Attn: Mr. Chris Amos Mr. J . J . Wiengardt

2109 Air Park Road SE

Albuquerque, NM 87106

SAIC (3)

Attn: Mr. Roger Blond Mr. Dave Aldrich Mr. Geoff Kaiser

Mail Stop 2-5-1

1710 Goodridge Drive

McLean, VA 22102

Florida Power \& Light Attn: Mr. John Luke P.O. Box 14000

Juno Beach, FL 33408
Duke Power Co. (2)

Design Engineering

Attn: Mr. Duncan Brewer

Mr. Steve Deskevich

422 South Church Street

Charlotte, NC 28242

Energy Research, Inc.

Attn: Mr. Mohsen Khatib-Rahbar P.O. Box 2034

Rockville, MD 20852

Westinghouse Electric Co. (2)

Attn: Mr. Griff Holmes

Mr. John Iacovino

Energy Center East

Bldg. 371

P.O. Box 355

Pittsburgh, PA 15230

Stone \& Webster Engineering Corp.

(2)

Attn: Mr. Edward Warman

Mr. Dick Gardner

P.O. Box 2325

Boston, MA 02107

Bechtel Power Corporation

Attn: Mr. William Hopkins

15740 Shady Grove Road

Gaithersburg, MD 20877-1454

Physical Research, Inc.

Attn: Mr. R. Toossi

25500 Hawthorne Blvd.

Torrance, CA 90505-6828

Technadyne Engineering

Consultants, Inc. (3)

Attn: Mr. Burt Newmark

Ms. Tere Love

Mr. Steve Lebien

P.O. Box 13928

Albuquerque, NM 87192

Electric Power Research Institute Attn: Mr. Ian Wall

3412 Hillview Avenue

Palo Alto, CA 94304 
Scientech

Attn: Mr. Jim Meyer

11821 Parklawn Drive

Suite 100

Rockville, MD 20852

NUMARC

Attn: Mr. Ray Ng

1776 Eye St. NW

Suite 300

Washington, DC 20006-2496

Mechanics and Sirructures Dept.

Attn: George Apostolakis

Bill Kastenberg

UCLA

Los Angeles, CA 90024

Dept. of Chemical and Nuclear Engineering

Attn: D. G. Cacuci

University of California

Santa Barbara, CA 93106

Harvard School of Public Health

Attn: John Evans

665 Huntington Avenue

Boston, MA 02115

Division of Business and Economics

Attn: Stephen C. Hora

University of Hawaii at Hilo

1400 Kapiolani Street

Hilo, HI 96720

Pickard, Lowe and Garrick, Tac.

Attn: Alfred Torri

2260 University Drive

Newport Beach, CA 92660

Prof. Agustin Alonso

E.T.S. Ingenieros Industriales

Jose Gutierres Abascal N 2

28006 Madrid

SPAIN
Dr. Der-Yu Hsia

Nuclear Regulatory Division

Atomic Energy Council

Executive Yuan

67, Lane 144

Keelung Road, Section 4

Taipei 10772

TAIWAN

Mr. Schobo Chakraborty

Swiss Federal Nuclear Safety

Inspectorate

Federal Office of Energy

Ch-5303, Wurlingen

SWITZERLAND

Dr. Malcolm Crick

NRPB

Chilton Didcot

Oxfordshire

OX11 ORQ

UNITED KINGDOM

Dr. William Nixon

UK AEA/SRD

Wigshaw Lane

Culcheth, Warrington

WA3 4NE

UNITED KINGDOM

Environment Canada

Attn: Mr. M. Daggupaty

4905 Dufferin Street

Downsview

Ontario, M3H 5T4

CANADA

Riso National Laboratory

Attn: Mr. Soren Thykier-Nielsen

Postbox 49

DK-4000 Roskilde

DENMARK

Technical Research Centre of

Finland (VTT)

Nuclear Engineering Laboratory

(YDI)

Attn: Mr. Seppo Vuori

Lonnrotinkatu 37

P.O. Box 169

SF-00181 Helsinki 18

FINLAND 
Institute of Nuclear Technology and

Radiation

Protection

Attn: Mr. John G. Kollas

N.R.C.P.S. "Demokritos"

P.O. Box 60228

GR-153 10 Aghia Paraskevi

Attiki

GREECE

ENFA/DISP (3)

Attn: Mr. Alvaro Valeri

Mr. G. Saponaro

Mr. Alfredo Bottino

Via Vitaliano Brancati, 48

00144 Rom EUR

ITALY

Tokai Research Establishment

Attn: Mr. Hideo Matsuzuru

Tokai-mura

Maka-gun

Ibaraki-ken, 319-11

JAPAN

KEMA Laboratories

Attn: Mr. Jan Van Der Steen

Utrechtseweg, 310

Postbus 9035

NL-6800 ET Arnhem

NETHERLANDS

Consejo de Seguridad Nuclear

Attn: Mr. D. Eugenio Gil Lopez

Calle Justo Dorado, 11

E-28040 Madrid

SPAIN

Studsvik Nuclear

Attn: Mr. Lennart Devell

Studsvik Energiteknik $A B$

S-611 82 Nykoping

SWEDEN

Abteilund Strahlenschutz

Attn: Mr. Hanspeter Isaak

Hauptabteilung fur die Sicherheit der

Kernanlagen (HSK)

$\mathrm{CH}-5303$ Wurenlingen

SWITZERLAND
National Radiological Protection

Board

Attn: Ms. Marion Hill

Chilton

Didcot

Oxon. OX11 ORQ

UNITED KINGDOM

Nuclear Safety Research

Attn: Mr. G. Neale Kelly

Commission of the European

Communities

Rue del la Loi, 200

B-1049 Bruxelles

BELGIUM

Division of Nuclear Safety

Wagramestrasse, 5

Attn: Mr. Ephraim Asculai

P.O. Box 100

A-1400 Wien

AUSTRIA

University of Hong Kong

Mechanical Engineering Dept.

Attn: Mr. M. K. Yeung

Pokfulam

HONG KONG

New University of Lisbon

Attn: Mr. Leonel Canelas

Quinta de Torre

2825 Monte de Caparica

PORTUGAL

Electrowatt Engineering Services (UK) Ltd.

Attn: Mr. Stephen Boult

Grandford House

16 Carfax, Horsham

Vest. Sussex RH12 1UP

UNITED KINGDOM

Comissao Nacional de Energia

Nuclear

Attn: Ms. Nadia Soido Falcao

Martins

R General Severiano $90 \mathrm{~S} / 408-\mathrm{A}$

Rio de Janeiro

BRAZIL 
Division de la Radioprotection

Attn: Mr. Paul Kayser

1. Avenue des Archiducs

L-1:35 Luxembourg-Belair

LUXEMBOURG

Greek Atomic Energy Commission

Attn: Ioannis G. Bartizis

Nuclear Research Center Demokritos

Aghia Paraskevi

Attikis

GREECE

BGA/ISH/ZDB

Attn: Anton Bayer

P.0. Box 1108

D. 8042 Neuherberg

GERMANY

Comitato Nazionale per l'Energia Nucleare Attn: Carla Brofferio

Viale Regina Margherita, 125

Casella Postale N. 2358

I-00100 Roma A. D.

ITALY

Kernforschungszentrum Karlsruhe/INR

Attn: Klaus Burkart

Postfach 3640

D.7500 Karlsruhe 1

GERMANY

Deputy Director, Air Quality and Inter-

Environmental Research Branch

Attn: Alistair D. Christie

Environment Canada

Atmospheric Environment Service

4905 Dufferin Street

City of North York, Downsview

Ontario, M3H 5T4

CANADA

Studsvik Energiteknik $A B$

Attn: Lenmart Devell

Studsvik

Fack

S-611 82 Nykoping 1

SWEDEN
Biblioteca CSN

Attn: Jacobo Diaz Diaz

Consejo de Sequridad Nuclear

c/Sor Angela de la Cruz, 3

28020 Madrid

SPAIN

KEMA Laboratories

Attn: Berend Th. Eendebak

Utrechtseweg, 310

Postbus 9035

NL-6800 ET Arnhem

NETHERLANDS

Kernforschnungszentrum

Karlsruhe/INR

Attn: Joachim Ehrhardt

Postfach 3640

D-7500 Karlsruhe 1

GERIANY

Nethertown

Attn: Ernest Gilby

Glebelands Road

Knutsford Chesire, WA16 9 DZ

UNITED KINGDOM

Health Physics Department

Attn: Paul Govaerts

SCK/CEN

Boeretang 200

B- 2400

Mol

BELGIUM

United Kingdom Atomic Energy Authority

Attn: Michael Haynes

Safety \& Reliability Directorate

Wigshaw Lane

Culcheth

Warrington WA3 $4 \mathrm{NE}$

UNITED KINGDOM

Gesellschaft fur

Reaktorsicherheit

Attn: Edward Hofer

D-8046 Carching

GERMANY 
Dept. of Nuclear Safety Evaluation

Attn: Toshimitsu Homma

Japan Atomic Energy Research Institute

Toka1-mura

Obarak1-ken 319-11

JAPAN

Division of Reactor Safety Evaluation

Attn: Toshinori Iifima

Reactor Safety Research Center

Japan Atomic Energy Research Institute

Tokai Research Establishment

Tokai - mura

Naka-gun

Ibaraki-ken 319-11

JAPAN

Abteilung fur die Sicherheit der

Kernanlagen

Attn: H. P. Isaak

Bundesamt fur Energiewirtschaft

$\mathrm{Ch}-5303$ Wurenlingen

SWITZERLAND

NRPB

Attn: J. A. Jones

Chilton, Didcot

OXOn OXI1 ORQ

UNITED KINGDOM

Health and Safety Directorate

Attn: Felix Luykx

CEC Batiment Jean Monet (C4-122)

Boite Postale 1907

L02920 Luxembourg

LUXEMBOURG

Institut de Protection et de Surete Nucleaire (IPSN)

Attn: Daniel Manesse

Commissariat a l'Energie Atomique

Centre de'Etudes Nucleaires de Fontenay-

aux-Roses

Bojte Postale 6

F-92260 Fontenay-aux-Roses

FRANCE
Central Electricity Generting Board

Attn: Shan Nair

Berkeley Nuclear Laboratories

Berkeley

Gloucestershire GL13 9PB

UNITED KINGDOM

Technical Research Centre of

Finland

Attn: Ilkka Savolainen

Nuclear Engineering Laboratory

P.O. Box 169

SF-00181 Helsinki 18

FINLAND

ENEL-DCO

Attn: Sebastiano Serro

Ente Naxionale per 1'Energia

Elettrica

Via G. B. Martini, 3

Casella Postale N. 386

I-00186 Roma

ITALY

Radiation Protection Program CEC Attn: Jaak Sinnaeve

Rue de la Loi, 200

B-1049 Bruxelles

BELGIUM

Junta Bagues Somonte

Attn: Juan Bagues Somonte

Ciudad Universitaria

Avenida Complutense, 22

Madrid-3

SPAIN

Israel Atomic Energy Commission

Attn: Eli Stern

P.0. Box 7061

Tel Aviv 61070

ISRAEL

Institue for Energy Technology

Attn: Ulf Tveten

Postbox 40

N-2007 Kjeller

NORWAY 
F. E. Haskin

Dept. of Chemical \& Nuclear Engineering

University of New Mexico

Albuquerque, NM 87131

Dist-8 
3141 S. A. Landenberger (5)

3141-1 C. Ward (3) for DOE/OSTI

3151 W. I. Klein

3200 N. R. Ortiz

3202 G. J. Smith

3212 H. N. Jow

6216 D. J. Alpert

6321 R. E. Luna

6342 M. G. Marieta

6400 D. J. McCloskey

6410 D. A. Dahlgren

6411 R. J. Breedirig

6411 D. M. Kunsman

6412 A. L. Camp

6412 A. C. Payne

6413 T. D. Brown

6413 D. I. Chanin

6413 F. T. Harper (20)

6413 J. C. Helton

6413 L. A. Miller

6413 J. L. Sprung

6416 J. A. Rollstin

6453 L. F. Restrepo

7254 L. T. Ritchie

8524 J. A. Wackerly 


\section{BIBLIOGRAPHIC DATA SHEET}

ISee instructions on the reverse,

2. TITLE AND SUBTITLE

Radionuclide Behavior in the Environmert
5. AUTHOR(S)

U. Tveten
U.S. NUCLEAR REGULATORY COMMISSION

(Aeloped by NRC. Add Vol., Supp., Aov.

NUREG/CR-5304

SAND90-7116

3. DATE REPORT PUBLISHED

MONTH

September 1991

4. FIN OR GRANT NUMBER

A1 843

6. TYPE OF REPORT

Technical

7. PERIOD COVERED (Inc/usive Dates/

8. PERFORMING ORGANIZATION - NAME AND ADDRESS IIf NRC. provide Division. Office or Region, U.S. Nuclear Augulatory Commizsion, and mailing address. if contractor, provide name and mauling address.

Institutt for Energiteknikk

Under Contract to:

Postboks 40

Sandia National Laboratories

$\mathrm{N}-2007$ Kjeller

Albuquerque, NM 87185

Norway

9. SPONSORING ORGANIZATION - NAME AND ADDRESS IIt NRC, type "Same as doove", it contractor, provide NAC Oivision, Office or Region, U.S. Nuclear Regulatory Commission, and mailing adaress.

Division of Systems Research

Office of Nuclear Regulatory Research

U. S. Nuclear Regulatory Commission

Washington, DC 20555

10. SUPPLEMENTARY NOTES

11. ABSTRACT 1200 words or less)

Available data on radionuclide behavior are reviewed for quality and consistency in the measurement of (1) initial ground concentration in Norway of radionuclides from chernobyl, and (2) subsequent concentrations of these radionuclides in various environmental media as a function of time. The data were then used to verify and indicate improvements in consequence models of radionuclide behavior in the MACCS code. The models were of environmental processes such as migration into soil, weathering, resuspension, food chain contamination, and loss or reconcentration by runoff. In most areas of the MACCs code that were examined, the models and the data were in agreement. A few models were found to be faulty or inarlequate.

12. KEY WORDS/DESCR! PYORS L List words or phrases that will assist researchers in locating the reoort 1

Chernobyl

MACCS

radionuclide

exposure

consequence models

Norway

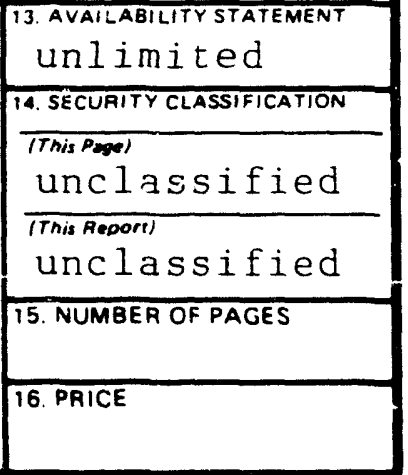



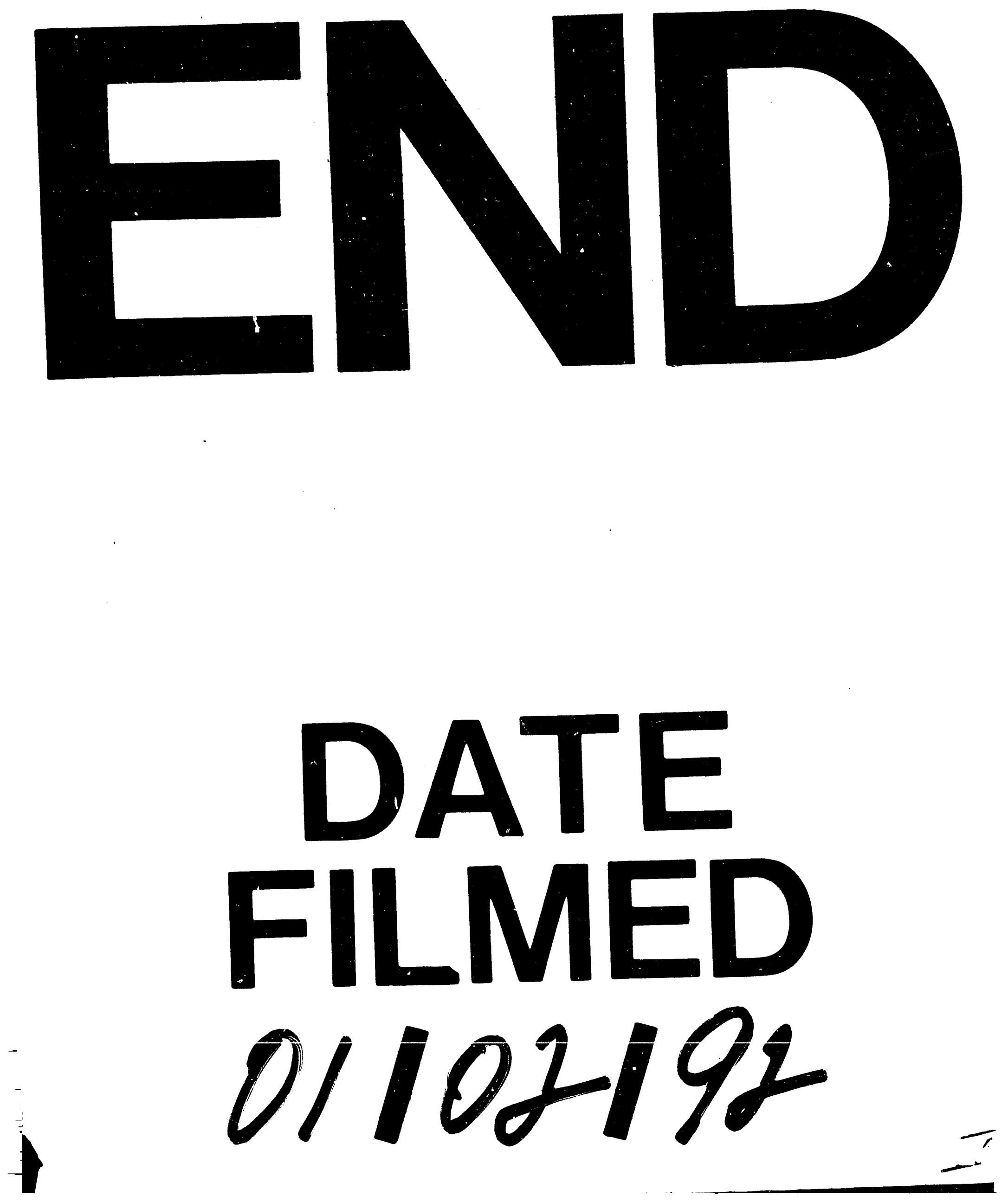
